Supporting Information

\title{
Use of Green Solvents in Metallaphotoredox Cross-Electrophile Coupling Reactions Utilizing Lipophilic Modified Dual Ir/Ni Catalyst System
}

Pete Delgado*, Raoul J. Glass", Gina Geraci, Rohit Duvadie, Dyuti Majumdar, Richard I. Robinson, Imran Elmaarouf, Malte Mikus and Kian L. Tan*

Global Discovery Chemistry - SynTech Group, Novartis Institutes for Biomedical Research, 250 Massachusetts Avenue, Cambridge, MA 02139, United States

*Corresponding authors emails:

$\square$ Pete.delgado@novartis.com and $\square$ kian.tan@novartis.com 


\section{TABLE OF CONTENTS}

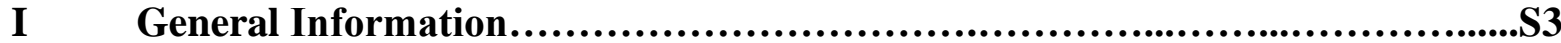

II Table S1 and Table S2. Solvent Screen data of the two Dual Catalyst system...S5

III Table S3. Solvent Comparison of Tree (6/7) Vs T-Bu (1/2) Dual Catalyst

System for Br-Br Cross Coupling...............................................8

IV Typical solution of reaction mixture prior and after exposure to blue LED ......S9

V Figure S1 and S2. Typical examples of the reaction mixture LC-MS results.....S10

VI Solubility Experiments of the Ir and Ni Tree (6/7) catalyst....................S11

VII Determination of CV redox potential.................................................. S13

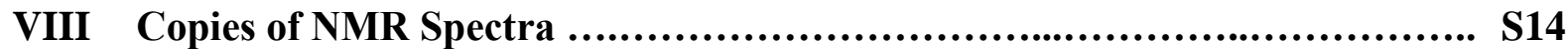

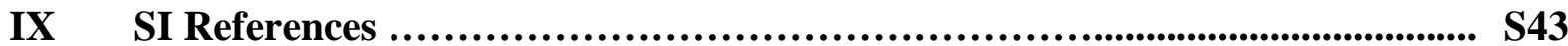




\section{General Information}

The following photoreactors were utilized in these studies.

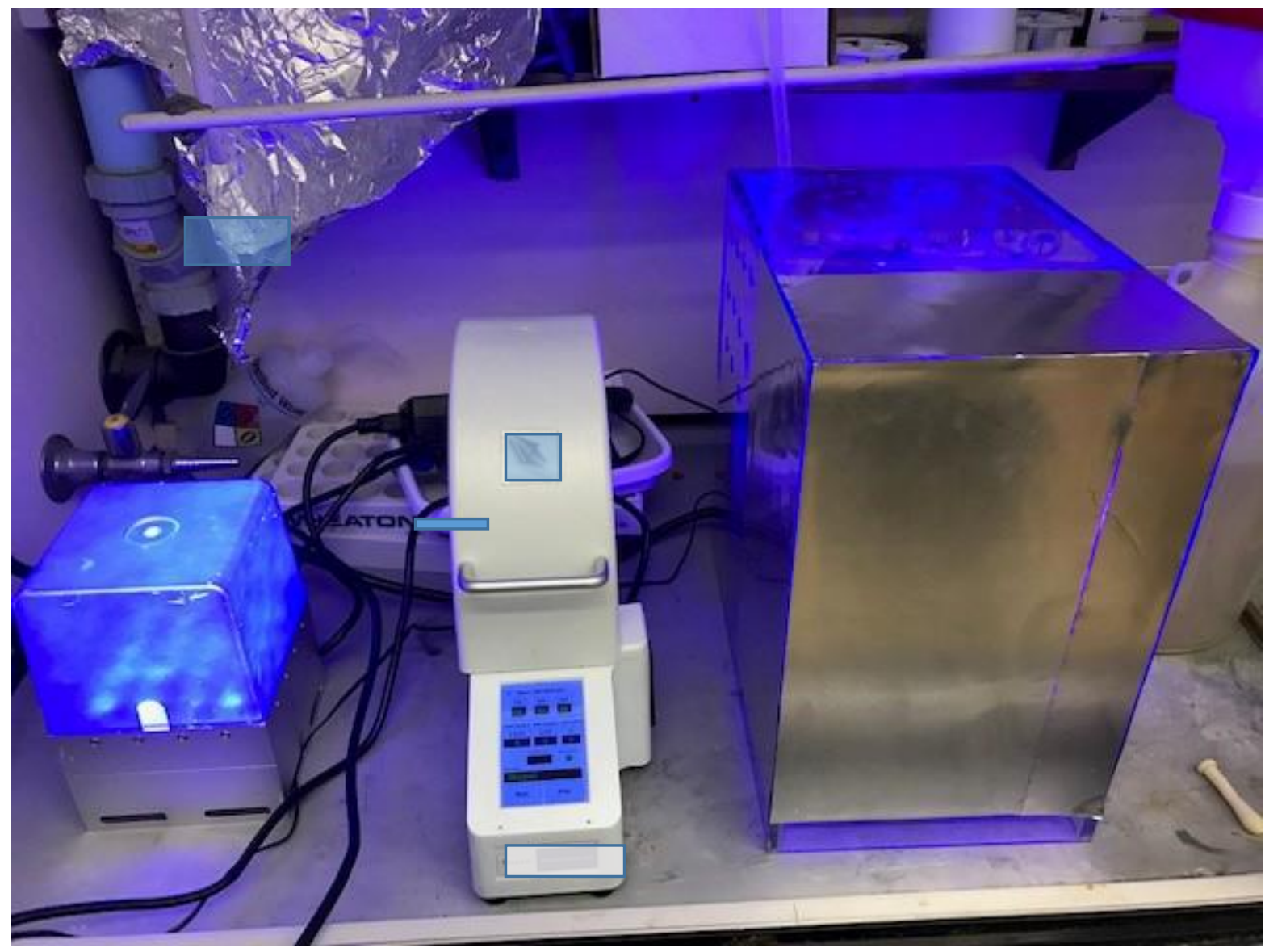

From left to right: SynLED Parallel Photoreactor, PhotoreactorM2 and Heptochem reactor. The Heptochem reactor is inside the protective shielding box. See side view below. 


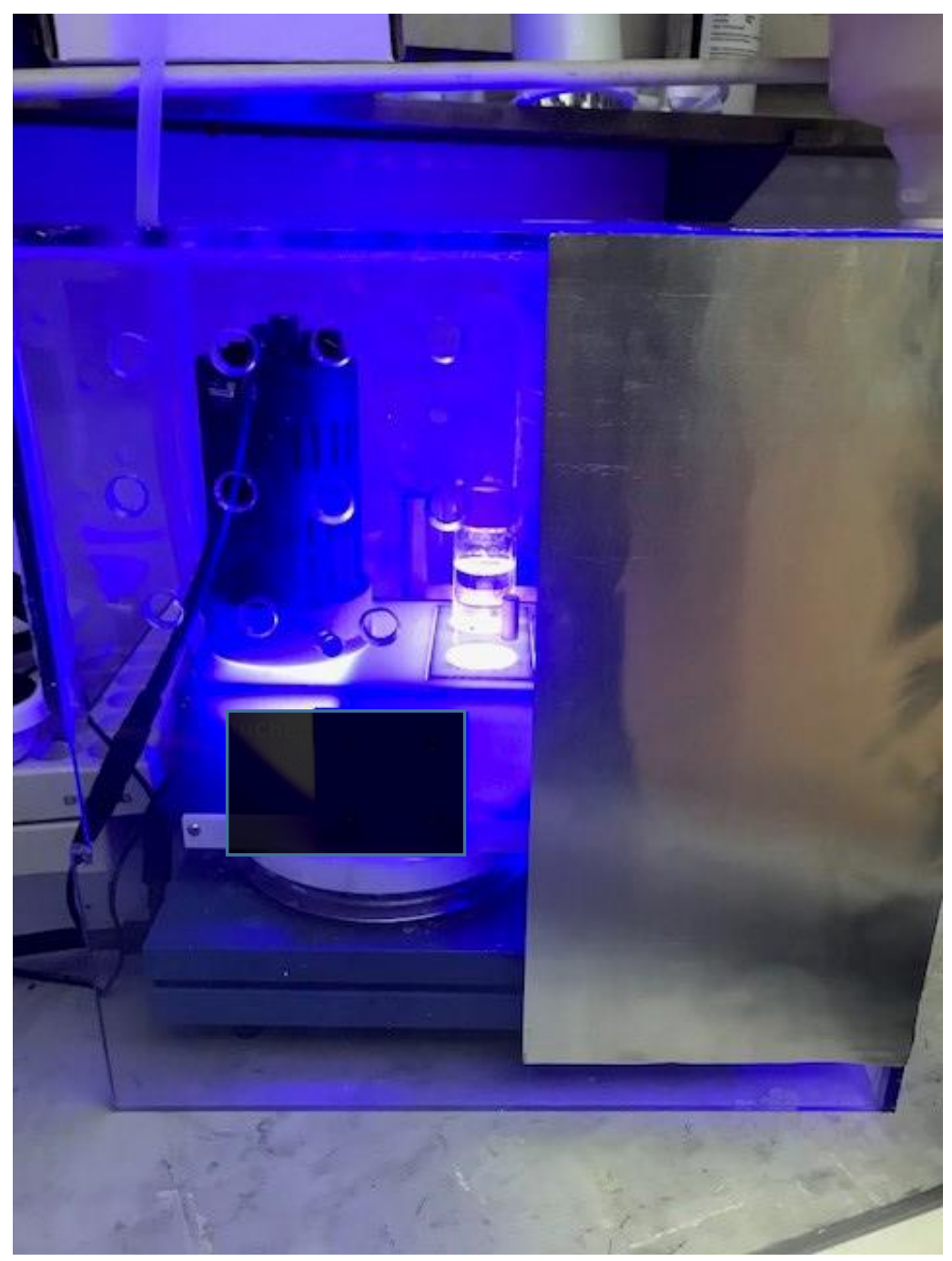

The branched alkylate bipyridine ligand (figure $\mathbf{5}$ in the manuscript) has been referred as the "Tree" ligand and the dual catalyst system $\mathbf{6} / \mathbf{7}$ called the Tree, or TREE, catalyst system throughout our internal studies. This Tree term is utilized throughout our studies in this SI section. 


\section{Table S1: Solvent screening (HPLC yield)}
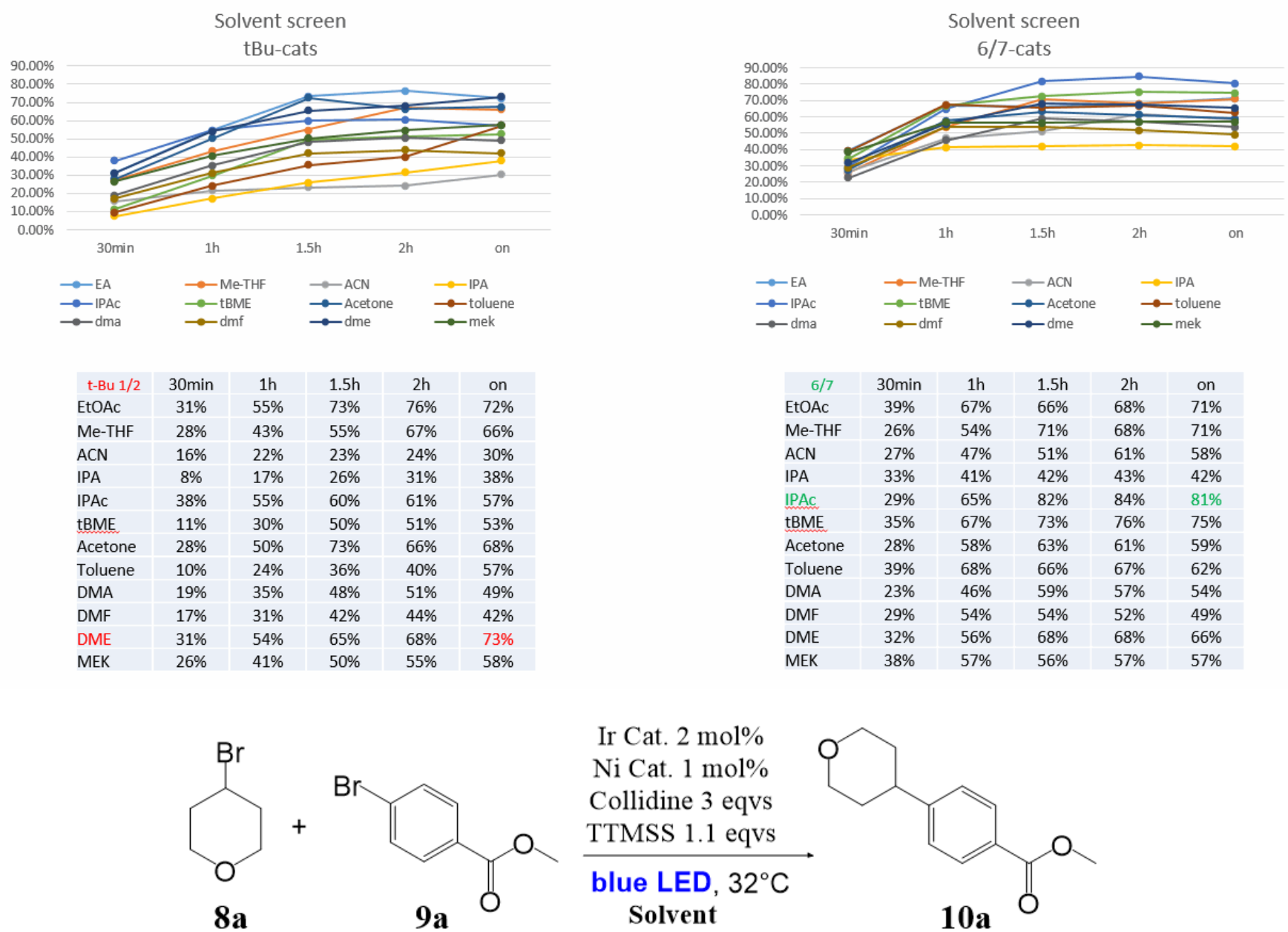

\section{Procedure for solvent study using calibration curve for model substrate 10a.}

Using a $10 \mathrm{~mL}$ volumetric flask, two $0.05 \mathrm{M}$ stock solutions of product (P) and an internal standard (IS) were prepared. Stock solution of the product 10a (methyl 4-(tetrahydro-2H-pyran-4-yl)benzoate) was prepared by dissolving 10a $(111 \mathrm{mg}, 0.5 \mathrm{mmol})$ in $10 \mathrm{ml}$ of $\mathrm{MeOH}$. Stock solution 2: the internal standard (IS) biphenyl (77.4935 mg, $0.500 \mathrm{mmol}$ ) was dissolved in $10 \mathrm{ml}$ of $\mathrm{MeOH}$. From these two stock solutions, a total of 8 solutions were prepared from the stock solutions:

Solution 1: $200 \mu \mathrm{l}$ Stock solution 1 and 16.6 $\mu$ l Stock solution 2

Solution 2: $200 \mu 1$ Stock solution 1 and $20 \mu 1$ Stock solution 2

Solution 3: $200 \mu 1$ Stock solution 1 and $25 \mu 1$ Stock solution 2

Solution 4: $200 \mu \mathrm{l}$ Stock solution 1 and $33.3 \mu 1$ Stock solution 2 
Solution 5: $200 \mu \mathrm{l}$ Stock solution 1 and $40 \mu \mathrm{l}$ Stock solution 2

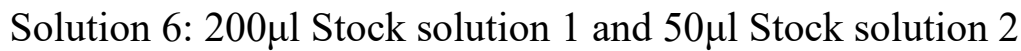
Solution 7: $200 \mu \mathrm{l}$ Stock solution 1 and $100 \mu$ l Stock solution 2 Solution 8: $200 \mu \mathrm{l}$ Stock solution 1 and $200 \mu \mathrm{l}$ Stock solution 2 Each solution was diluted with $3 \mathrm{ml} \mathrm{MeOH}$ and $100 \mu \mathrm{l}$ of each solution was diluted with $\sim 200 \mu \mathrm{l}$ ACN and then analyzed by reversed-phase UPLC-MS (Waters AcQuity system using a C18 $1.7 \mu \mathrm{m}$ column size with PDA, ELS and QDa detectors) with $0.1 \%$ formic acid/water and $0.1 \%$ formic acid/acetonitrile as co-eluents with a 2 to $98 \%$ acetonitrile in $0.1 \%$ formic acid in water over a $2 \mathrm{~min}$ at $1 \mathrm{~mL} / \mathrm{min}$. The area under curve (AUC) for each solution of the product 10a (RT=0.91 $\mathrm{min}$ ) and IS (RT=1.15 $\mathrm{min}$ ) using UV254 nm detector was used to calculate Area from (P)/(IS) for each stock solution concentration. The units and concentration are outline in the tables below along with the calibration curve graph generated by this process.

\section{Experimental procedure for solvent screen of the Iridium/Nickel duel catalyst (1/2 and 6/7).} The SynLED Parallel Photoreactor was utilized for this study with 2-dram septum borosilicate glass vials (x12), stir bars (x12) for each catalyst system. Stock solutions of internal standard were prepared:

ISTD solution 1: Biphenyl (130 mg, $0.837 \mathrm{mmol})$ was dissolved in $12 \mathrm{ml}$ Ethyl acetate

ISTD solution 2: Biphenyl (130 mg, $0.837 \mathrm{mmol}$ ) was dissolved in $12 \mathrm{ml} \mathrm{Me-THF}$

ISTD solution 3: Biphenyl (130 mg, $0.837 \mathrm{mmol})$ was dissolved in $12 \mathrm{ml} \mathrm{ACN}$

ISTD solution 4: Biphenyl (130 mg, $0.837 \mathrm{mmol}$ ) was dissolved in $12 \mathrm{ml} \mathrm{IPA}$

ISTD solution 5: Biphenyl (130 mg, $0.837 \mathrm{mmol})$ was dissolved in 12ml IPAc

ISTD solution 6: Biphenyl $(130 \mathrm{mg}, 0.837 \mathrm{mmol})$ was dissolved in $12 \mathrm{ml} \mathrm{tBME}$

ISTD solution 7: Biphenyl $(130 \mathrm{mg}, 0.837 \mathrm{mmol})$ was dissolved in $12 \mathrm{ml}$ acetone

ISTD solution 8: Biphenyl $(130 \mathrm{mg}, 0.837 \mathrm{mmol})$ was dissolved in $12 \mathrm{ml}$ toluene

ISTD solution 9: Biphenyl (130 mg, $0.837 \mathrm{mmol})$ was dissolved in $12 \mathrm{ml}$ DMA

ISTD solution 10: Biphenyl (130 mg, $0.837 \mathrm{mmol}$ ) was dissolved in $12 \mathrm{ml} \mathrm{DMF}$

ISTD solution 11: Biphenyl (130 mg, $0.837 \mathrm{mmol})$ was dissolved in 12ml DME

ISTD solution 12: Biphenyl $(130 \mathrm{mg}, 0.837 \mathrm{mmol})$ was dissolved in $12 \mathrm{ml} \mathrm{MEK}$

Procedure for screening t-Bu catalyst system $\mathbf{1 / 2}$

A stock solution of methyl-4-bromobenzoate (360 mg, $1.674 \mathrm{mmol})$, (Ir[dF(CF3)ppy]2(dtbpy))PF6 (1, $39.5 \mathrm{mg}, 0.033 \mathrm{mmol}$ ) , NiCl2(dtbbpy) $(\mathbf{2}, 7.01 \mathrm{mg}, 0.017 \mathrm{mmol})$ in $12 \mathrm{ml}$ of $\mathrm{MeOH}$ was evenly distributed in 12 2-dram septum vials ( $1 \mathrm{ml}$ stock solution each). The solvent of each vial was evaporated, then the vials were equipped with $1 \mathrm{ml}$ of each ISTD stock solution as follows: 1) EtOAc (ISTD solution 1), 2) MeTHF (ISTD solution 2), 3) ACN (ISTD solution 3, 4) IPA (ISTD solution 4), 5) IPAc (ISTD solution 5), 6) tBME (ISTD solution 6), 7) Acetone (ISTD solution 7), 8) Toluene (ISTD solution 8), 9) DMA (ISTD solution 9), 10) DMF (ISTD solution 10), 11) DME (ISTD solution 11), 12) MEK (ISTD solution 12). Total amount of biphenyl in each system: $10.833 \mathrm{mg}$ (50mol\% compared to $30 \mathrm{mg}$ methyl-4bromobenzoate). To each vial was added 1.5eq 4-bromotetrahydropyran $(24 \mu \mathrm{L}, 0.213 \mathrm{mmol}), 1.1 \mathrm{eq}$ TTMSS $(47 \mu \mathrm{L}, 0.152 \mathrm{mmol})$ and $3 \mathrm{eq}$ collidine $(56 \mu \mathrm{L}, 0.421 \mathrm{mmol})$. The vials were flushed with $\mathrm{N} 2$ for $\sim 30 \mathrm{sec}$ before sonicating for $\sim 15 \mathrm{sec}$ and irridiated with Blue LEDs while stirring at ambient for $18 \mathrm{hrs}$. 
Procedure for screening the Tree catalyst system 6/7,

A stock solution of methyl-4-bromobenzoate $(360 \mathrm{mg}, 1.674 \mathrm{mmol})$, Iridium catalyst $(\mathbf{6}, 52.4 \mathrm{mg}, 0.033$ $\mathrm{mmol})$, Nickel catalyst $(\mathbf{7}, 13.44 \mathrm{mg}, 0.017 \mathrm{mmol})$ in $12 \mathrm{ml}$ acetone was evenly distributed in 12 -dram septum vials ( $1 \mathrm{ml}$ stock solution each). The solvent of each vial was evaporated, then the vials were equipped with $1 \mathrm{ml}$ of each ISTD stock solution as follows: 1) EtOAc (ISTD solution 1), 2) Me-THF (ISTD solution 2), 3) ACN (ISTD solution 3, 4) IPA (ISTD solution 4), 5) IPAc (ISTD solution 5), 6) tBME (ISTD solution 6), 7) Acetone (ISTD solution 7), 8) Toluene (ISTD solution 8), 9) DMA (ISTD solution 9), 10) DMF (ISTD solution 10), 11) DME (ISTD solution 11), 12) MEK (ISTD solution 12). Total amount of biphenyl in each system was $10.833 \mathrm{mg}$ (50mol\% compared to 30mg methyl-4bromobenzoate). To each vial was added 1.5eq 4-bromotetrahydropyran $(24 \mu \mathrm{L}, 0.213 \mathrm{mmol}), 1.1 \mathrm{eq}$ TTMSS $(47 \mu \mathrm{L}, 0.152 \mathrm{mmol})$ and 3eq collidine $(56 \mu \mathrm{L}, 0.421 \mathrm{mmol})$, the vials were flushed with $\mathrm{N} 2$ for $\sim 30 \mathrm{sec}$ before sonicating for $\sim 15 \mathrm{sec}$ and irridiated with Blue LEDs while stirring at rt over night.

The conversion for each photoreaction was moniter by UPLC-MS at intervals of $30 \mathrm{mins}, 1 \mathrm{~h}, 1.5 \mathrm{~h}, 2 \mathrm{~h}$ and ON (18hrs). The conversion calculated with ISTD described above.

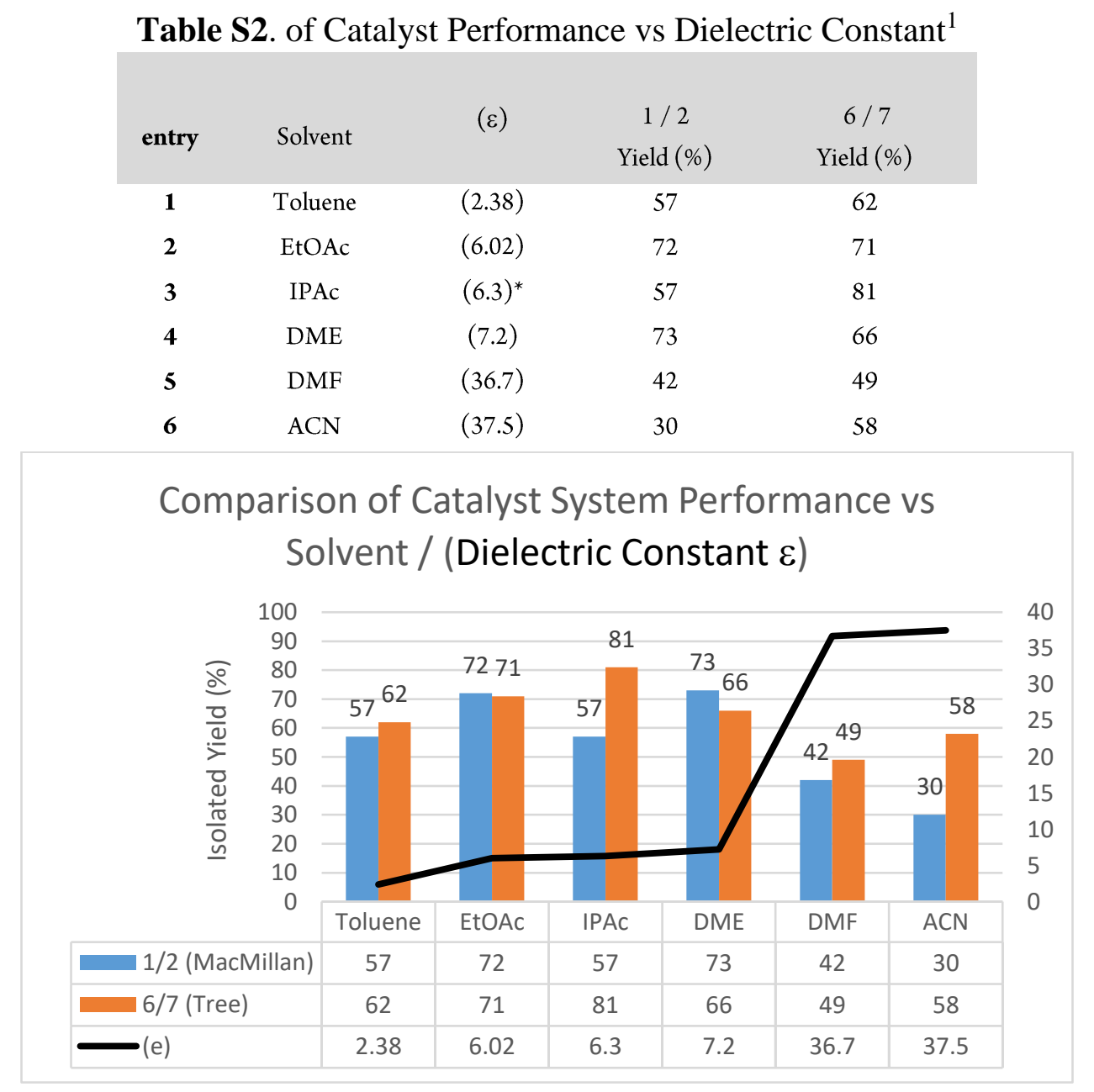


III. Table S3. Solvent Comparison of Tree Vs T-Bu Dual Catalyst System for Br-Br Cross Coupling ${ }^{1}$

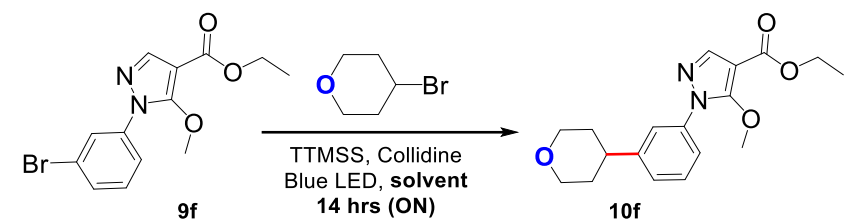

$\begin{array}{ccc}\text { Solvent(s) } & \begin{array}{c}\text { Yield for } \\ \text { Tree } 6 / 7\end{array} & \begin{array}{c}\text { Yield for } \\ \text { tBu 1/2 }\end{array} \\ & 2 \%(10 \mathbf{f}) & <1 \%(10 \mathbf{f}) \\ \text { DME/DMA } & 15 \% \text { DMA-adduct } & 26 \% \text { DMA-adduct } \\ & 43 \% \text { Des-Br } & 40 \% \text { Des-Br } \\ \text { Ethyl Acetate } & 75 \% 1 & 17 \% \\ \text { Isopropyl Acetate } & 36 \% & 7 \% \\ 1 \text { isolated yields }(\%) . \text { Ratio of DMA to DME: } 9 / 1 .\end{array}$


IV. Typical solution of reaction mixture prior and after exposure to blue LED
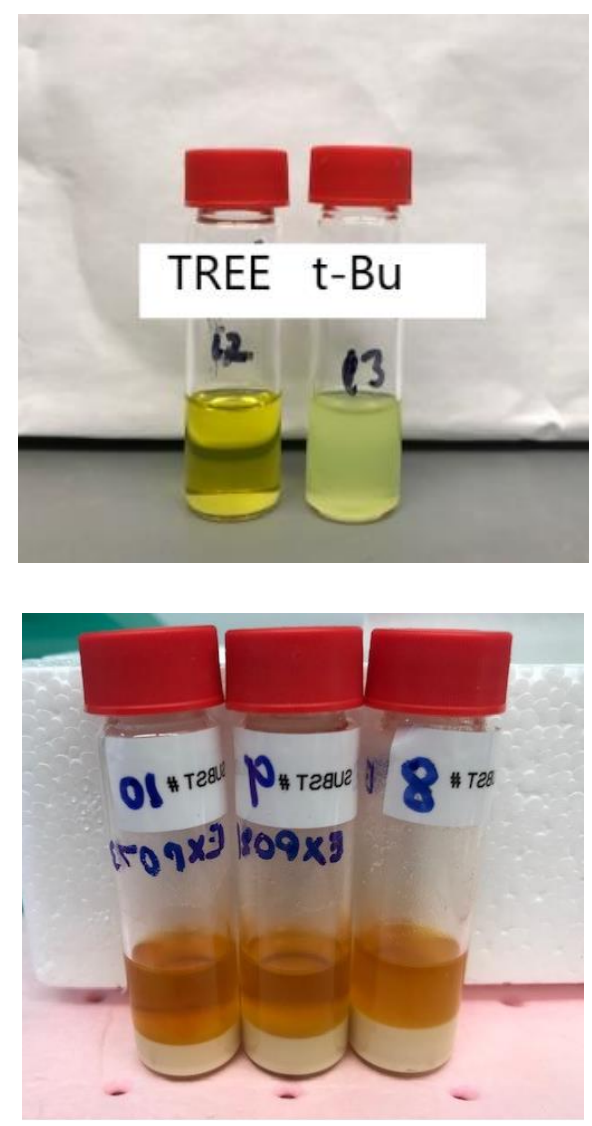

Collidine $\mathrm{HCl}$ salt settling 
V. Figure S1 and S2: Typical examples of the reaction mixture LC-MS results that clearly shows the presence of the DME-adduct in the photoredox reaction as compared to the IPAc run.

Figure S1

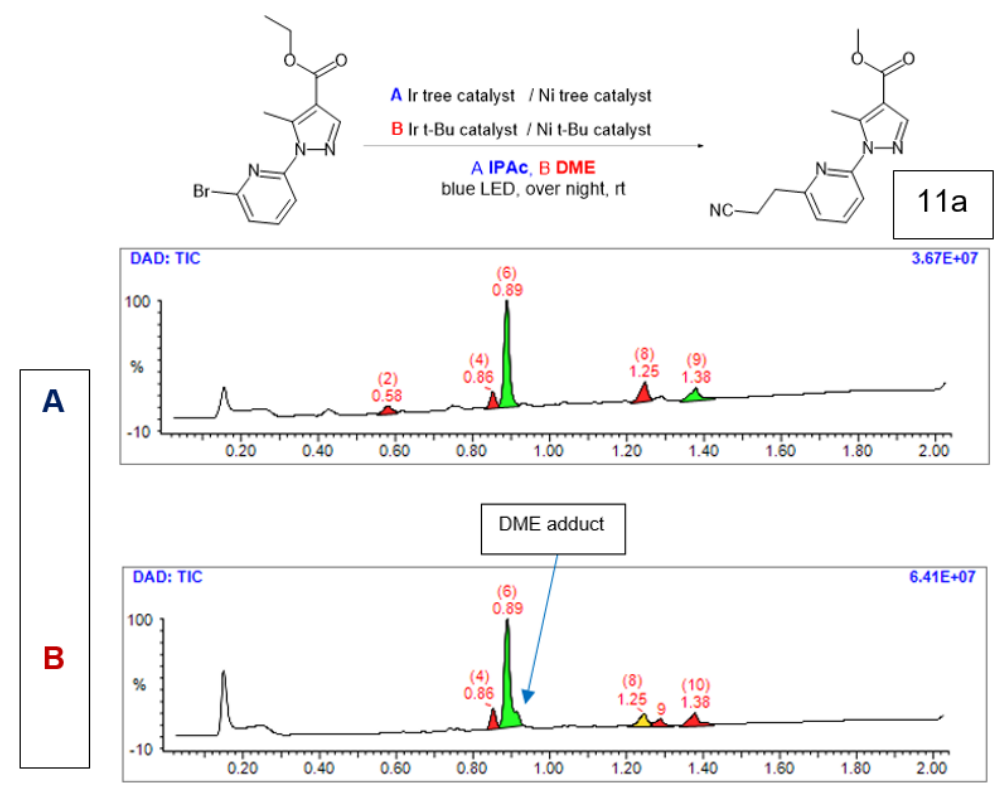

Figure S2

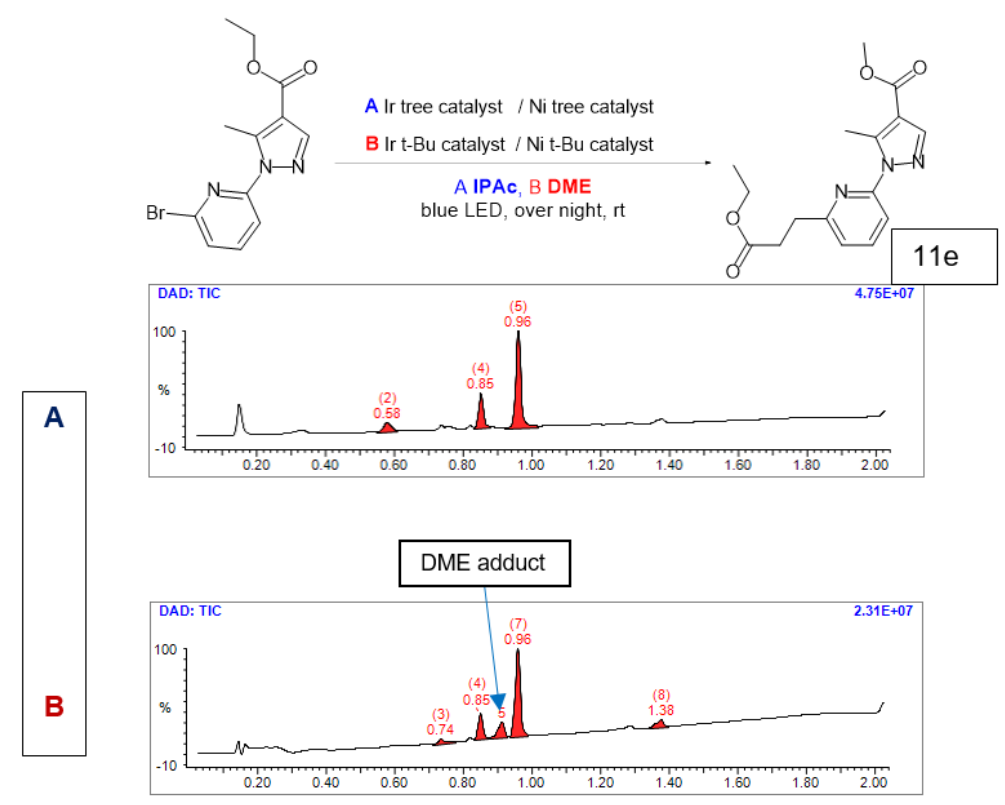

Reaction progress was monitored by reversed-phase UPLC-MS (Waters AcQuity system using a C18 1.7 $\mu \mathrm{m}$ column size with PDA, ELS and QDa detectors) with $0.1 \%$ formic acid/water and 
$0.1 \%$ formic acid/acetonitrile as co-eluents and with gradient of 2 to $98 \%$ acetonitrile in $0.1 \%$ formic acid in water over $2.0 \mathrm{~min}$ at $1 \mathrm{~mL} / \mathrm{min}$.

\section{Solubility Experiment ${ }^{2,3}$}

\section{Materials, instrumentation, and sample preparations}

A. Photocatalysts were provided by the SynTech Group, Novartis Institutes for Biomedical Research (Cambridge, MA) and used without further purification. Additionally, SynTech provided $5 \mathrm{~mL}$ glass test tubes. Dimethoxyethane (DME), Ethyl Acetate (EA), and Isopropyl Acetate (IPAc) were purchased from Sigma-Aldrich. In addition, 96 shallow-well glass-coated (7MM RD) polypropylene plates and $1.5 \mathrm{~mL}$ glass vials with push caps were obtained from Thermo Fisher.

\section{Equipment}

\section{B. Solubility assay procedure; visual observation}

All experiments were run at ambient temperature. Following "General Procedure A" reported by Jespersen (2019) ${ }^{4}, 1-5 \mathrm{mg}$ of Iridium and Nickel photocatalysts were separately weighed into $5 \mathrm{~mL}$ test tubes. Addition of solvent occurred in 50-100 uL increments. Solutions were sonicated and centrifuged for 2-4 minutes, and visually inspected. If precipitation was observed, solvent was added. During this process, it was noted that some solvents yielded higher kinetic solubilities over the course of an hour compared to equilibrium. We decided to measure solubility at 30-60 minutes and at equilibrium (1624 hours). Final solubilities reported in this study are equilibrium solubility. Further, visual inspection presented challenges and was found to be potentially unreliable. Making use of available instrumentation in our lab, we developed an analytical method for visual confirmation of precipitation utilizing the Synergy H4 Microplate reader leading to a more robust solubility measurement procedure.

C. Development of solubility assay procedure; plate reader

Since photocatalysts in organic solvents are potentially not suited for UV or Mass Spec analytics, light scattering and/or light absorption at an appropriate wavelength is a feasible alternative. Following the work outlined by Goodner's report (Sen-TN, 2009) ${ }^{5}$, we used the Synergy H4 to determine degree of precipitation via absorption of light at $750 \mathrm{~nm}$. Further, traditional 96 well plates comprised of polystyrene or polypropylene were not suitable with all organic solvents. We elected to use glass coated 96 shallow well, polypropylene plates.

All experiments were run at ambient temperature. Similar to the approach of visual observation as detection of precipitation, $1-5 \mathrm{mg}$ of the Iridium and Nickel photocatalysts were weighed into $1.5 \mathrm{~mL}$ glass vials. Solvent was added in increments of 50-100 uL, vortexed, and sonicated for 1 minute. The solution was transferred to a glass coated microplate and absorbance at $750 \mathrm{~nm}$ was determined on the plate reader. Each plate contained two wells with blank solvent to determine a base line. This process continued over 30-60 minutes with the incremental addition of solvent until the catalysts were in solution. Precipitation was determined as $20 \%$ above base line reading. This allowed us to graph the 
data, confirm visual observation, and tract precipitation over time. Finally, readings were taken at 1624 hours to determine equilibrium solubility.

$$
\begin{aligned}
& \text { Ir-t-butyl Catalyst in Ethyl Acetate } \\
& <1 \mathrm{hr} \text { and } 24 \mathrm{hrs}
\end{aligned}
$$

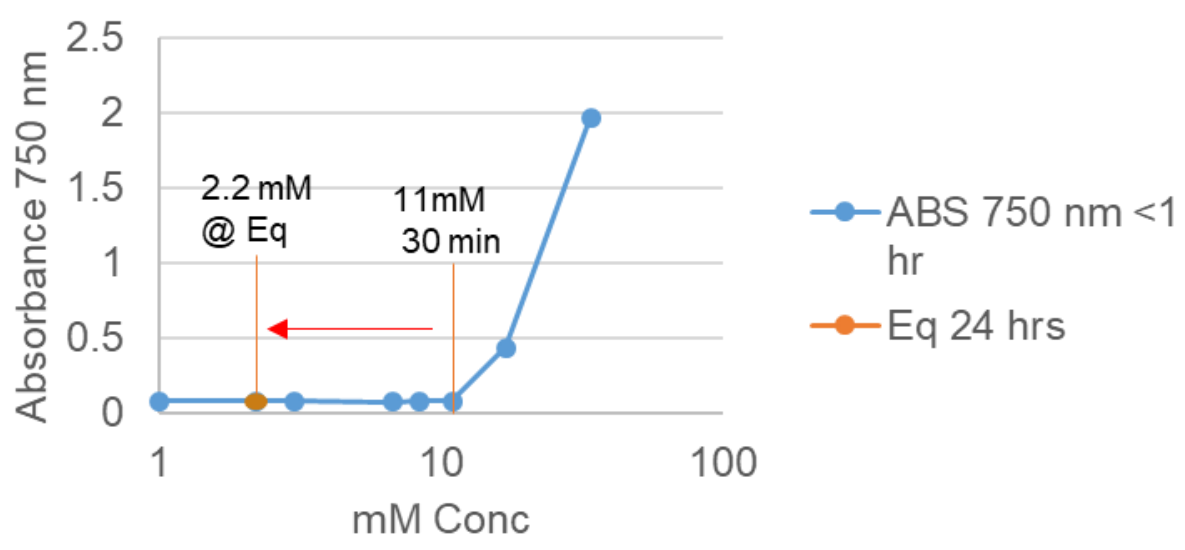

D. Solubility experiments

For the rest of the solubility experiments, following the validation that reading absorbance at $750 \mathrm{~nm}$ on the Synergy H4 was reliable, absorbance readings were taken selectively to confirm visual inspection of clear solutions. The two t-butyl iridium and nickel photocatalysts and two tree-iridium and nickel photocatalysts were separately weighed into twelve $1.5 \mathrm{~mL}$ glass vials. Each catalyst was measured for kinetic and equilibrium solubility in DME, EA, and IPAc in 50-100 uL aliquots. When visual inspection indicated a clear solution a reading was taken at $750 \mathrm{~nm}$ with the solvent blank. If readings deviated more than $20 \%$, solvent was added and the reading was taken again. This was repeated at 1 hour for a kinetic solubility and at 24 hours for an equilibrium solubility.

\begin{tabular}{|c|c|c|c|c|c|c|}
\hline Solvent & $\begin{array}{c}\text { Ir-t-butyl } \\
\text { target }\end{array}$ & $\begin{array}{c}\text { Ni-t- } \\
\text { butyl } \\
\text { target }\end{array}$ & $\begin{array}{l}\text { Ir-t-butyl } \\
\text { Eq. Sol }\end{array}$ & $\begin{array}{l}\text { Ir-Tree } \\
\text { Eq. Sol }\end{array}$ & $\begin{array}{c}\text { Ni-t-butyl } \\
\text { Eq. sol }\end{array}$ & $\begin{array}{c}\text { Ni-Tree } \\
\text { Eq. Sol }\end{array}$ \\
\hline $\begin{array}{c}\text { 1,2- } \\
\text { Dimethoxyethane } \\
\text { (DME) }\end{array}$ & $2.2 \mathrm{mM}$ & $1 \mathrm{mM}$ & $3.4 \mathrm{mM}$ & $21.2 \mathrm{mM}$ & $0.385 \mathrm{mM}$ & $1.4 \mathrm{mM}$ \\
\hline $\begin{array}{c}\text { Ethyl Acetate } \\
\text { (EA) }\end{array}$ & $2.2 \mathrm{mM}$ & $1 \mathrm{mM}$ & $2.3 \mathrm{mM}$ & $36 \mathrm{mM}$ & $0.620 \mathrm{mM}$ & $1.6 \mathrm{mM}$ \\
\hline $\begin{array}{c}\text { Isopropyl Acetate } \\
\text { (IPAc) }\end{array}$ & $2.2 \mathrm{mM}$ & $1 \mathrm{mM}$ & $1.25 \mathrm{mM}$ & $188 \mathrm{mM}$ & $0.251 \mathrm{mM}$ & $0.712 \mathrm{mM}$ \\
\hline
\end{tabular}




\section{Determination of CV redox potential}

The cyclic voltametry (CV) redox potential of the Ir TREE catalyst (6) was ca Metrohm Autolab M204, Nova2.1 software,WE: GC-electrode tip Metrohm 6.1204.600 ,CE: GC-electrode tip 2mm Metrohm 6.1247.000, Reference electrode: BASi non aqueous reference electrode MW-1085, filled with $0.1 \mathrm{M}$ $\mathrm{Bu} 4 \mathrm{~N} * \mathrm{PF} 6$ solution containing $0.01 \mathrm{M} \mathrm{AgNO3}$ in $\mathrm{ACN}$

Chemicals: Bu4NPF6: Sigma-Aldrich 86879 for electrochemical analyis; CAS 3109-63-5

Procedure:

Preparation of a $0.1 \mathrm{M}$ Bu4NPF6 $(3.87 \mathrm{~g} / 100 \mathrm{ml})$ solution in ACN as electrolyte; degassed thorougly in ultrasonic bath. All solutions degassed in ultra sonic bath and then with argon for 10 min directly before each measurement. Solution of $\mathbf{6}$ took $20 \mathrm{~min}$ in ultra-sonic bath until clear solution observed.

Preparation of 0.01M solutions of $\mathbf{6}$ and $\mathbf{1}$ cat CAS 870987-63-6 (two samples of each), and blank + Ferrocene also measured. CV run with $200 \mathrm{mV} / \mathrm{s}$.

\section{Attached data points not corrected; for exact E0 recalculation with Ferrocene/blank data necessary}
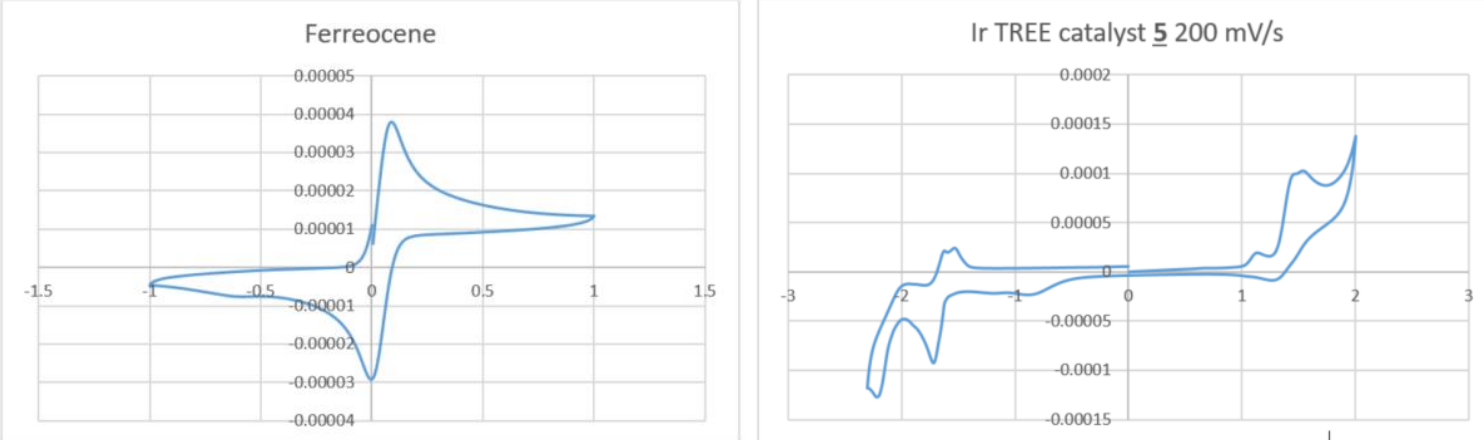


\section{Copies of NMR Spectra}

${ }^{1}$ H-NMR Spectrum of of 4,4'-bis(5,9-diethyltridecan-7-yl)-2,2'-bipyridine (5).

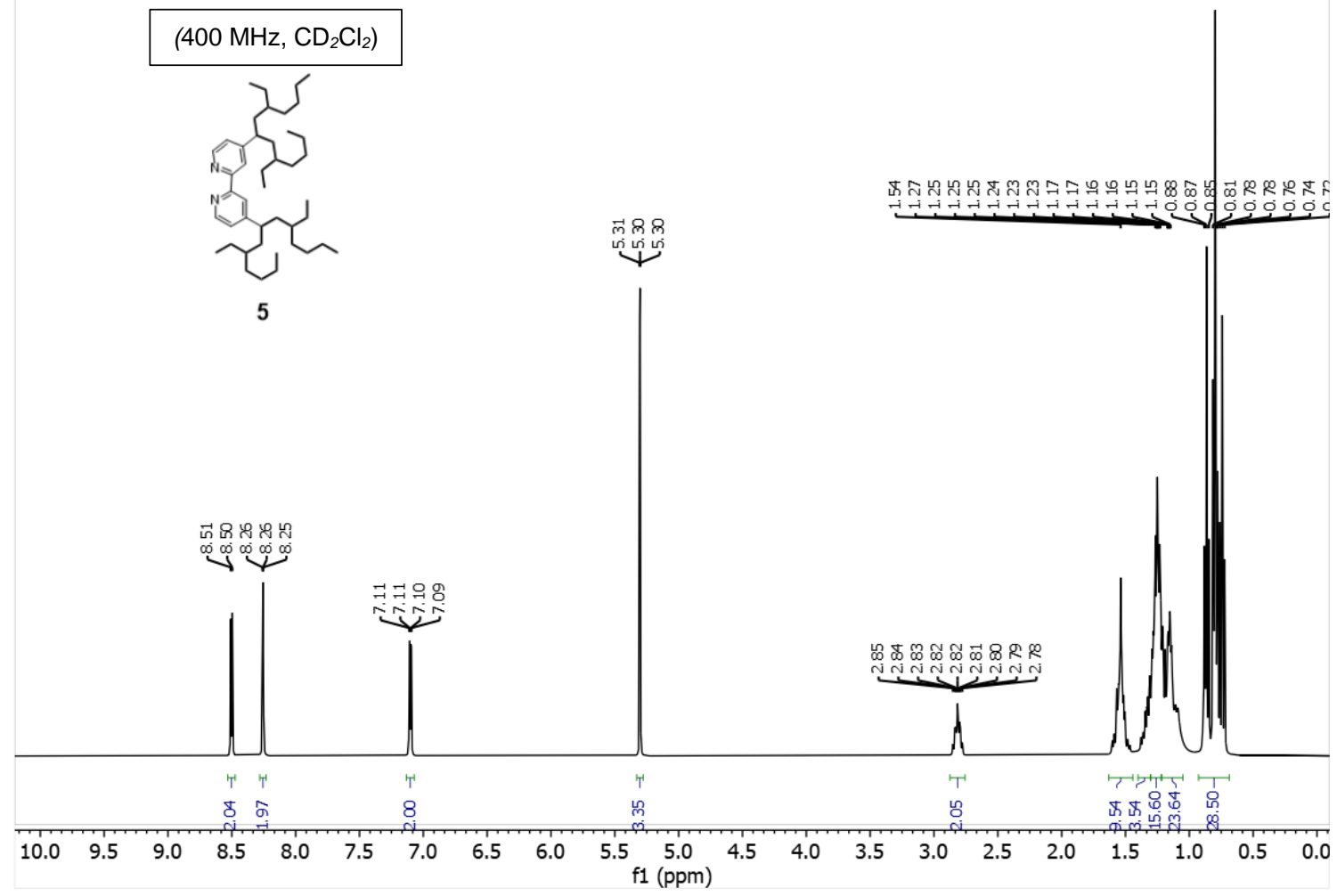

${ }^{13} \mathrm{C}\left\{{ }^{1} \mathrm{H}\right\}$-NMR Spectrum of 4,4'-bis(5,9-diethyltridecan-7-yl) -2,2'-bipyridine (5).
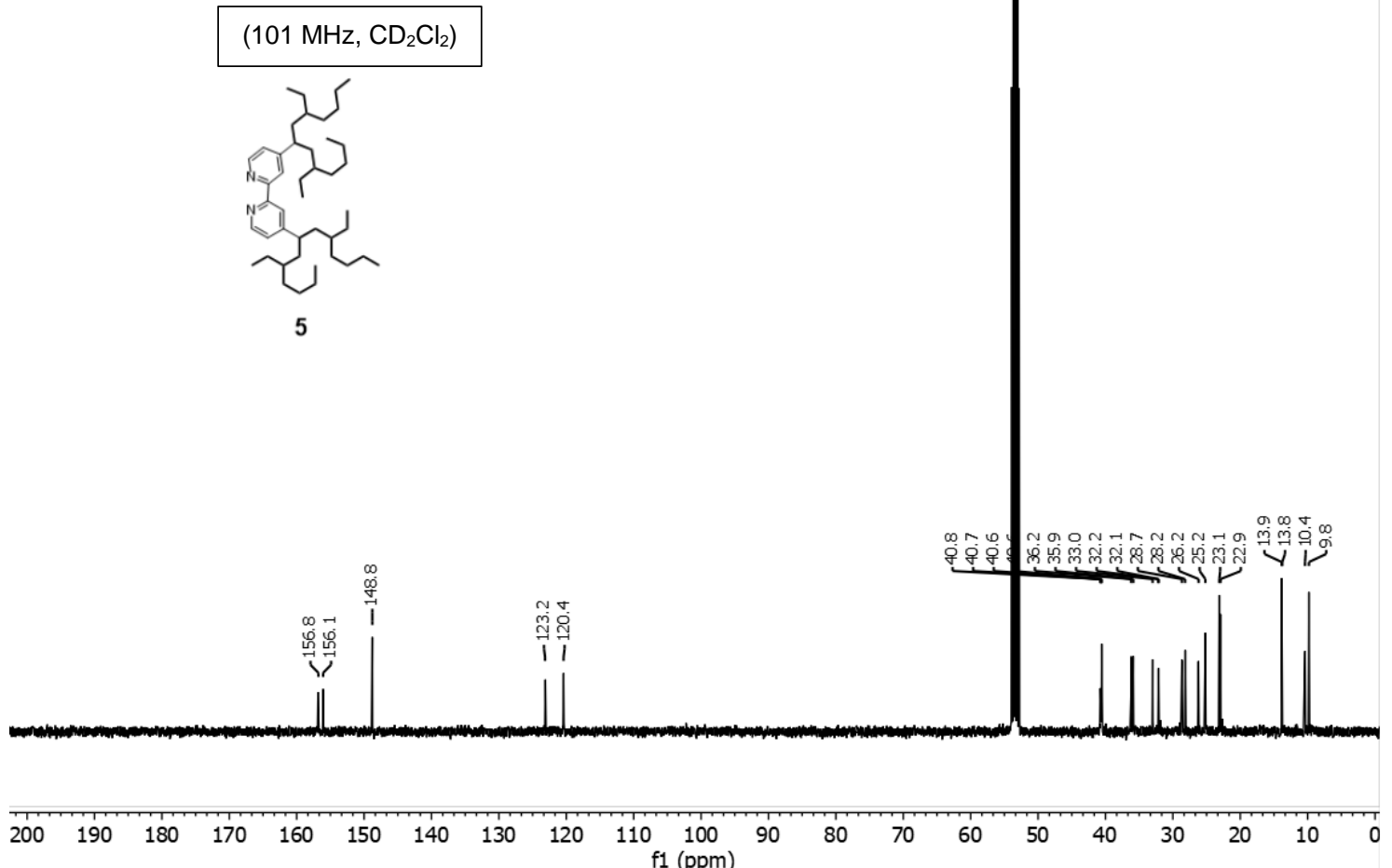


\section{${ }^{1}$ H-NMR Spectrum of (6).}

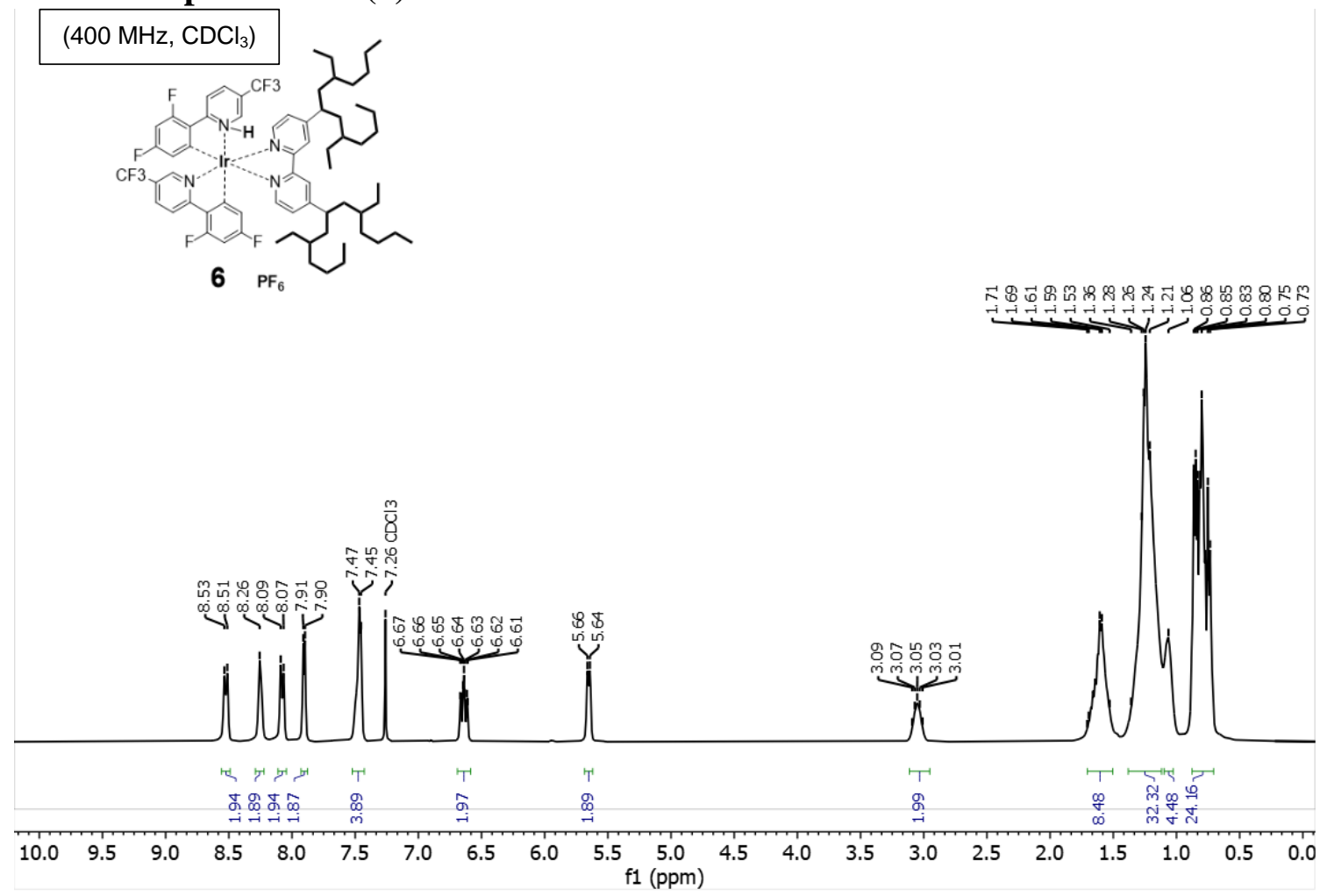

\section{${ }^{13} \mathrm{C}\left\{{ }^{1} \mathrm{H}\right\}$-NMR Spectrum of (6).}

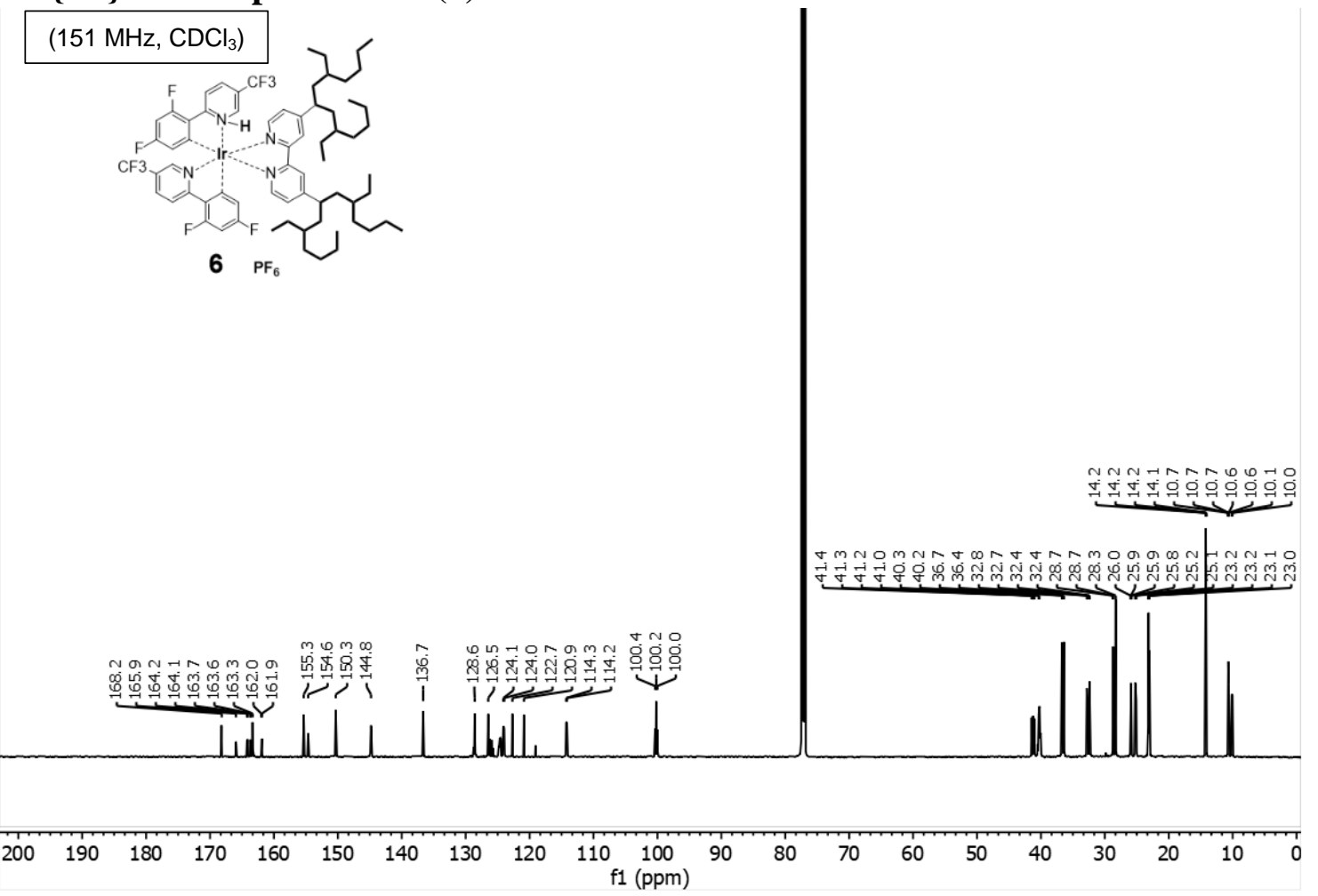


${ }^{19}$ F-NMR Spectrum of (6).

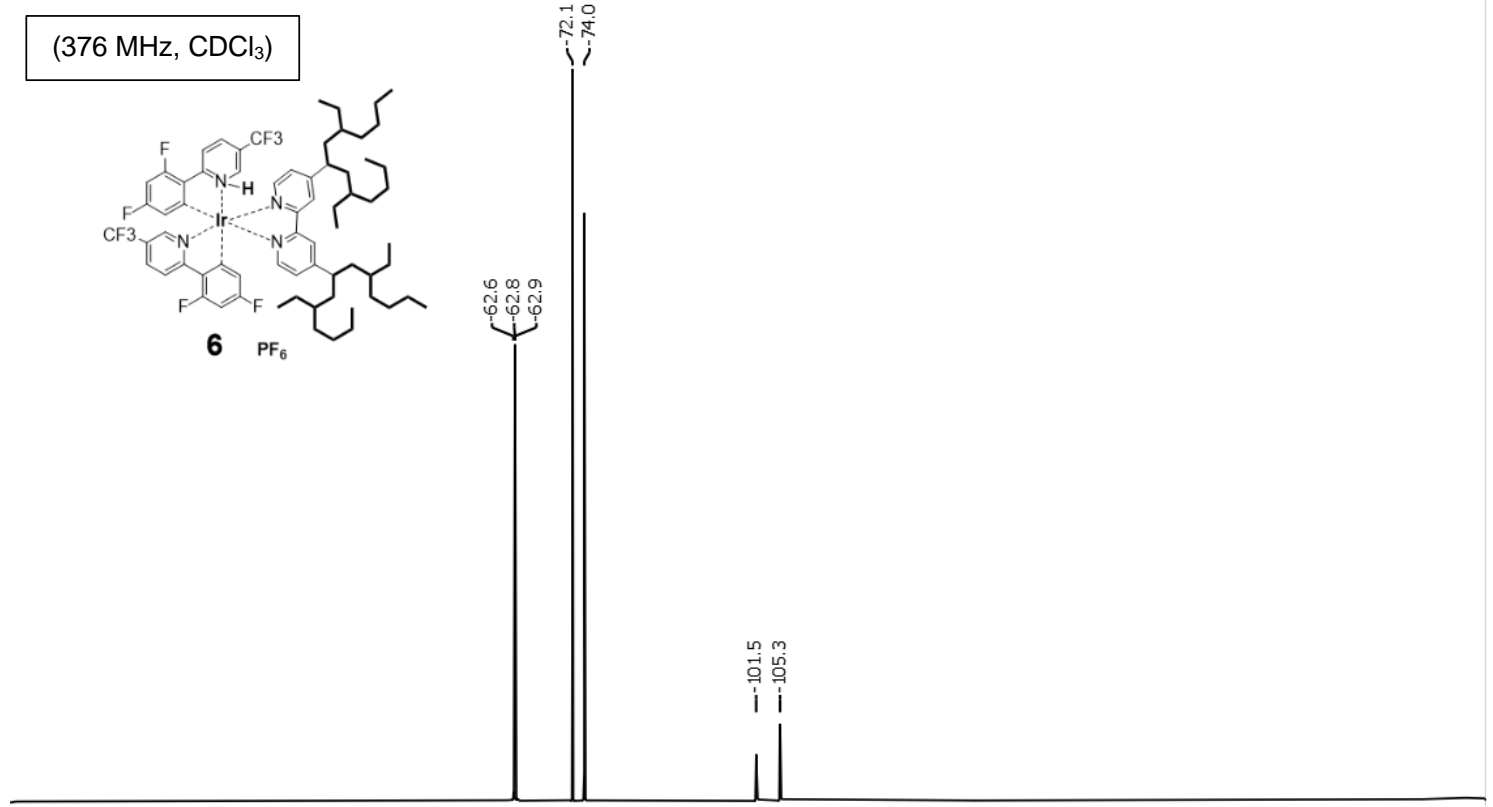

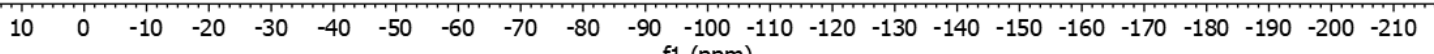




\section{${ }^{1}$ H-NMR Spectrum of (7).}

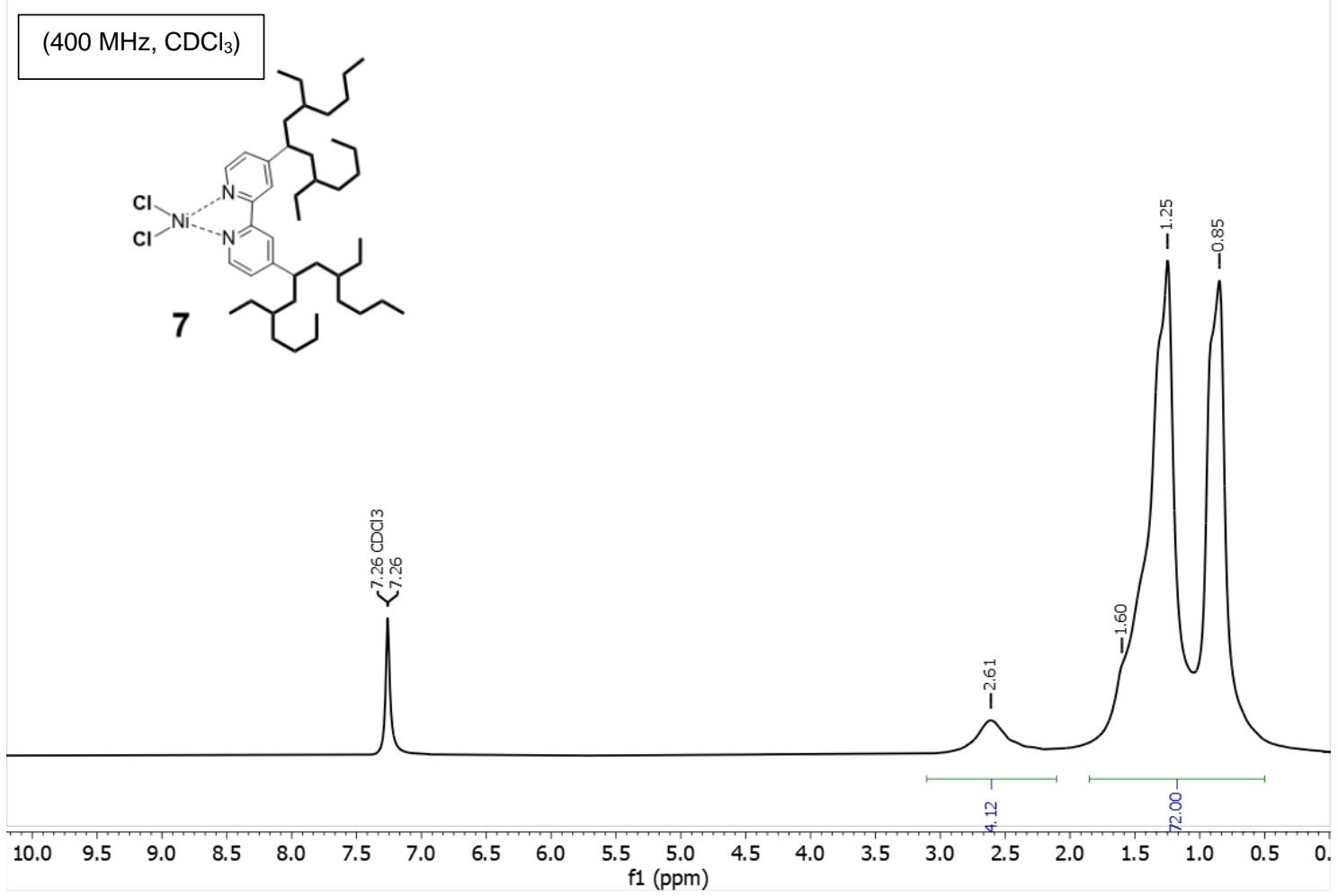

\section{${ }^{13} \mathrm{C}\left\{{ }^{1} \mathrm{H}\right\}$-NMR Spectrum of (7).}

(101 MHz, DMSO- $d_{6}$ )
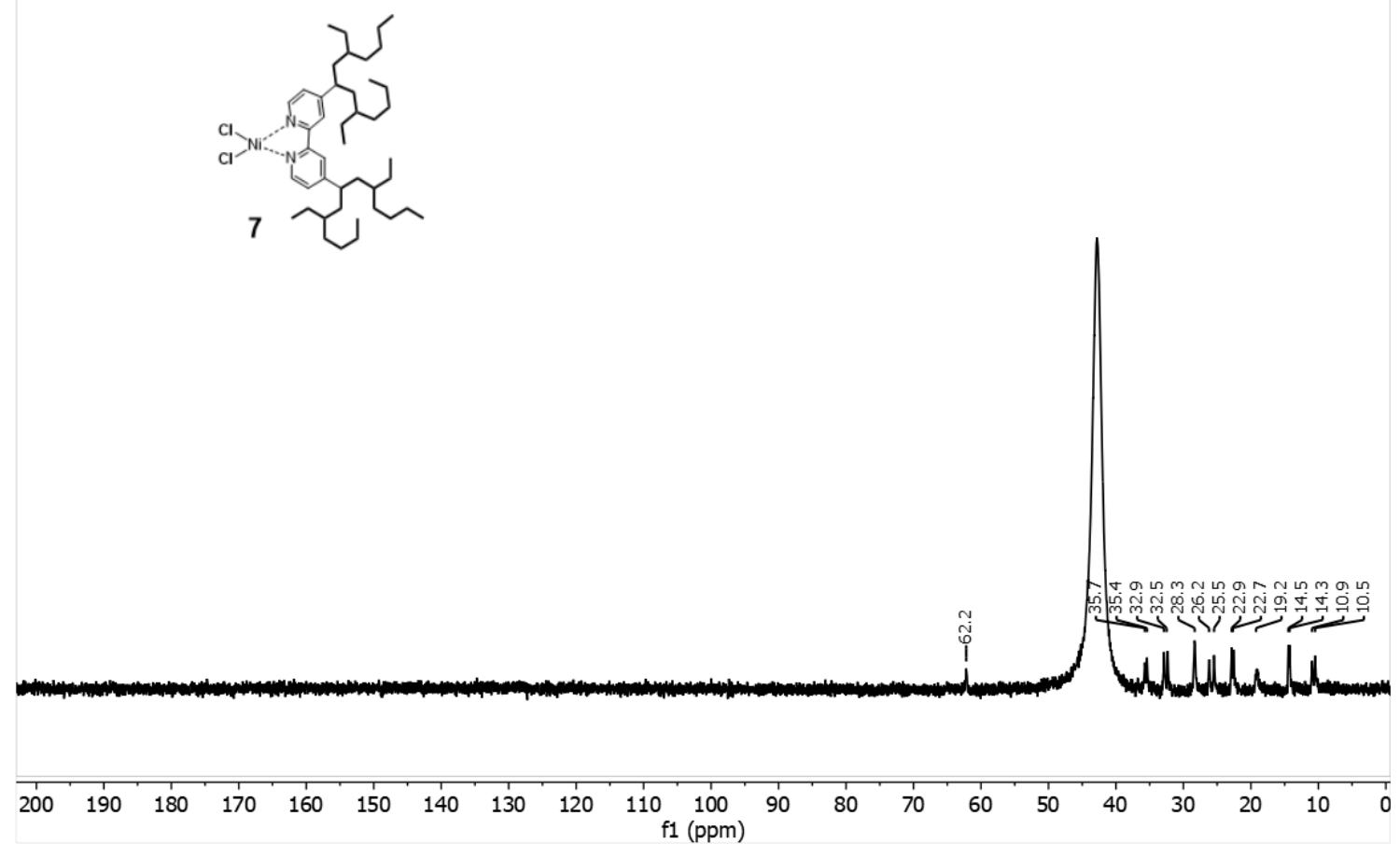
${ }^{1}$ H-NMR Spectrum of methyl 4-(tetrahydro-2H-pyran-4-yl)benzoate (10a)

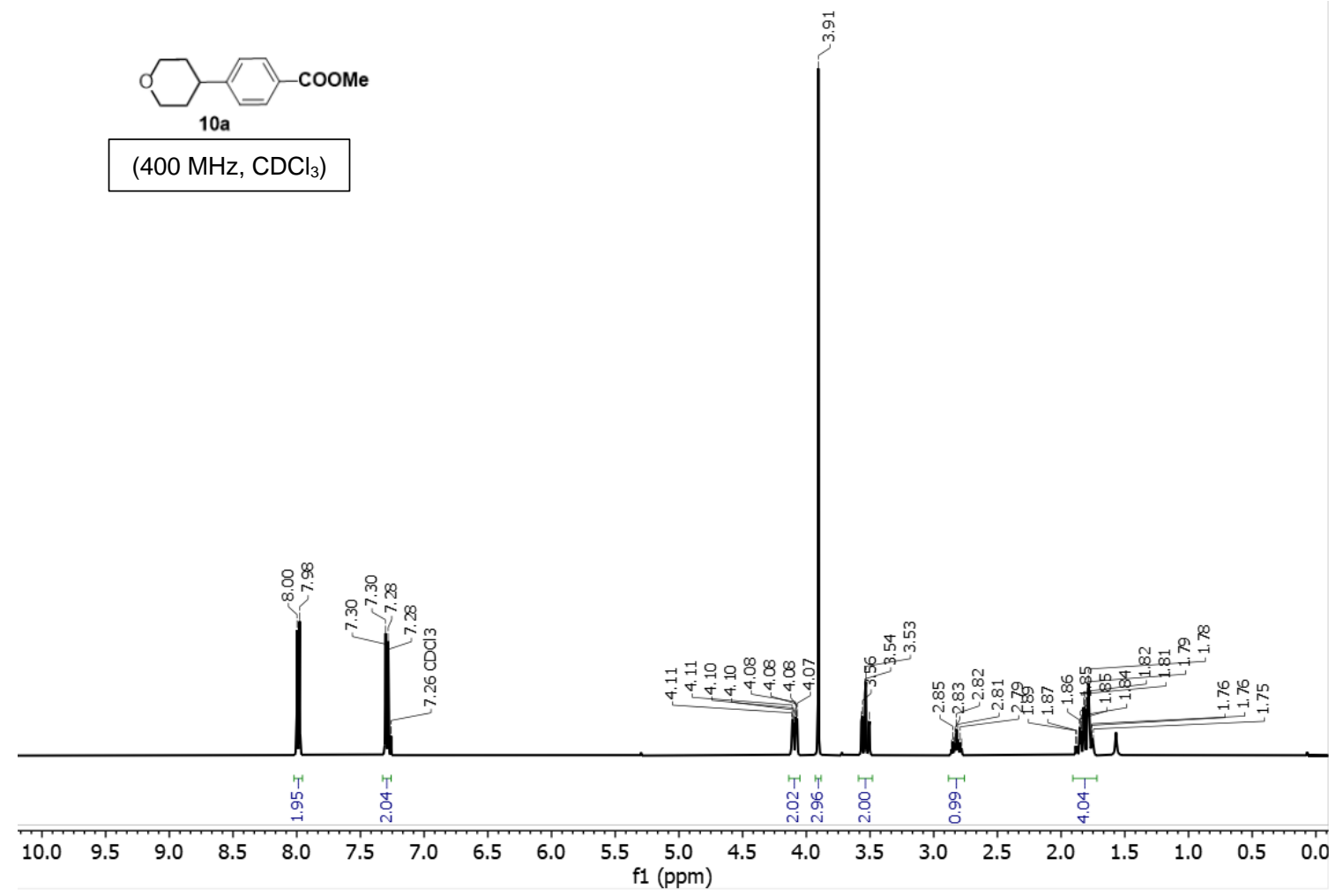


${ }^{1}$ H-NMR Spectrum of tert-butyl 6-(tetrahydro-2H-pyran-4-yl)-1H-indole-1-carboxylate (10b)

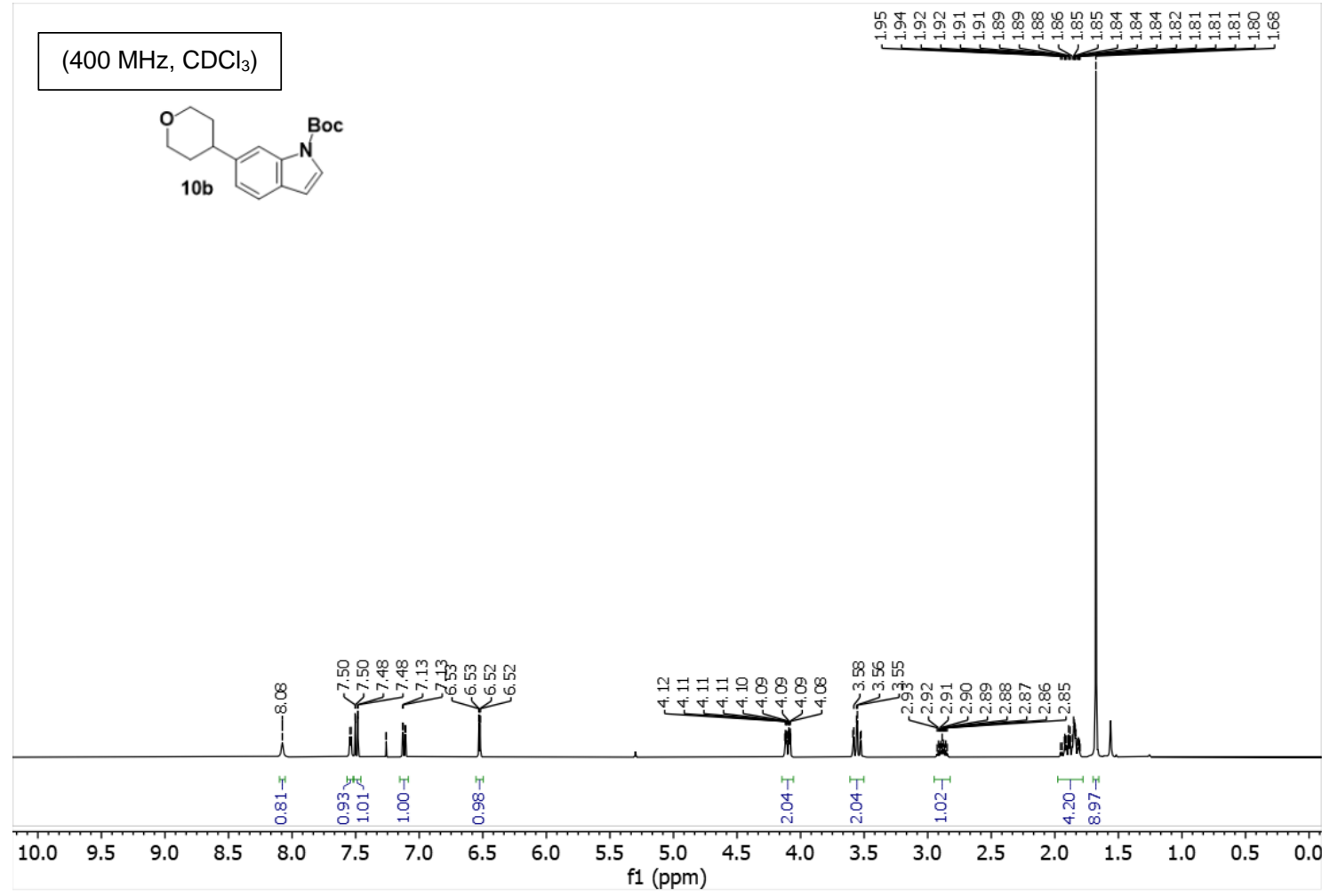

${ }^{13} \mathrm{C}\left\{{ }^{1} \mathrm{H}\right\}-N M R$ Spectrum of tert-butyl 6-(tetrahydro-2H-pyran-4-yl)-1H-indole-1-carboxylate (10b).

$\left(101 \mathrm{MHz} \mathrm{CDCl}_{3}\right)$
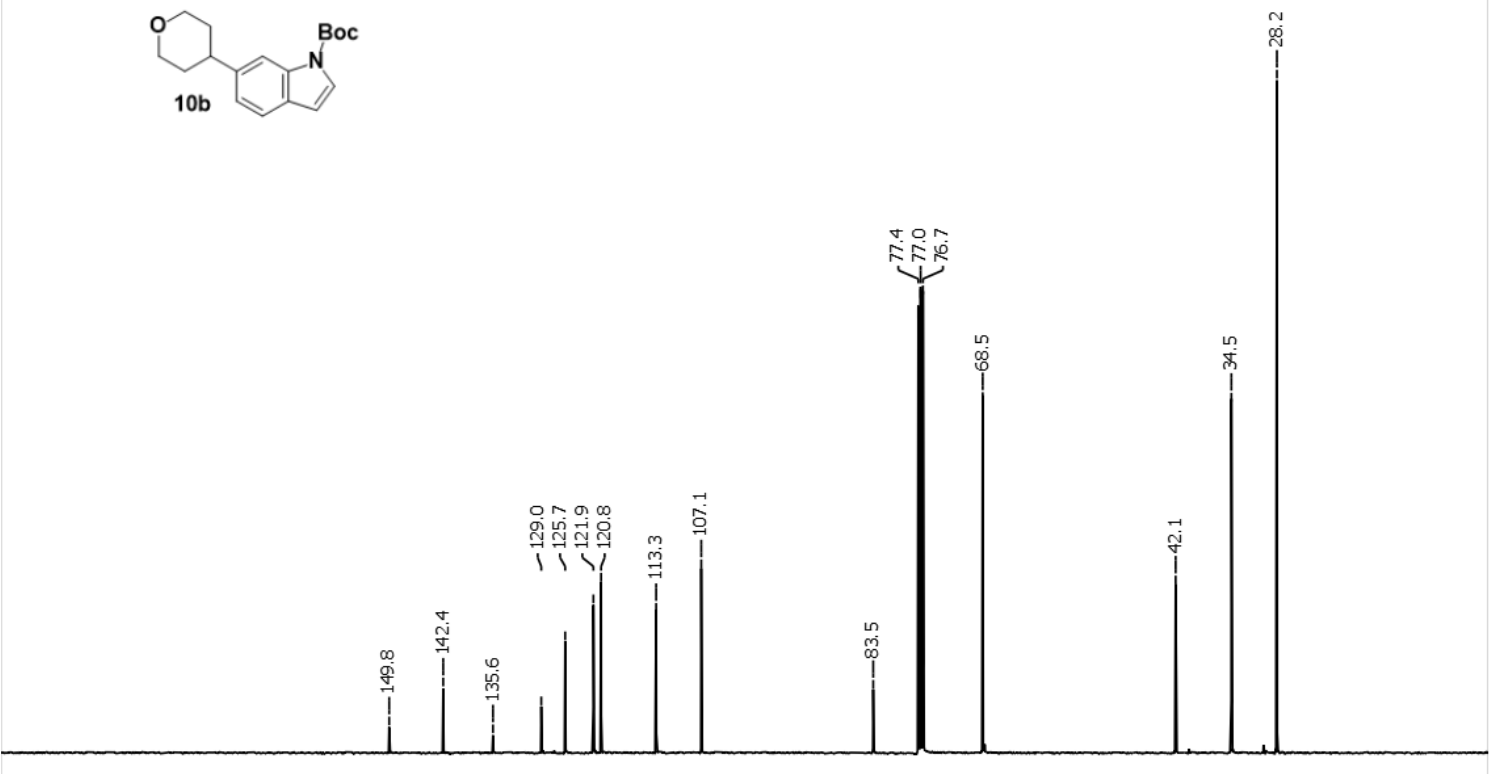

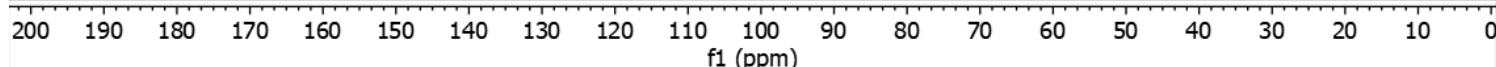


${ }^{1} \mathrm{H}-\mathrm{NMR}$ Spectrum of pyrrolidin-1-yl(4-(tetrahydro-2H-pyran-4-yl)phenyl)methanone (10c).

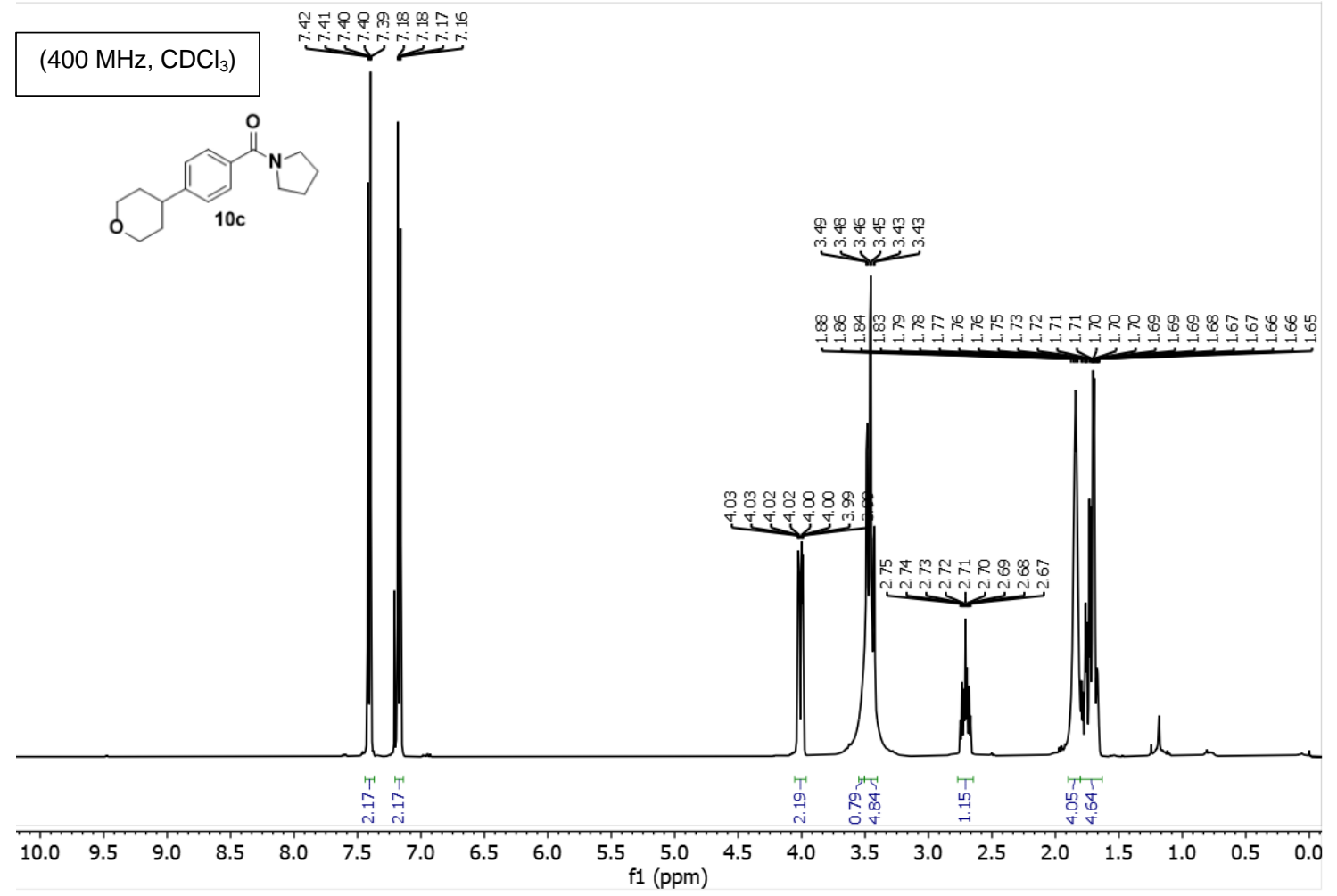

${ }^{13} \mathrm{C}\left\{{ }^{1} \mathrm{H}\right\}$-NMR Spectrum of pyrrolidin-1-yl(4-(tetrahydro-2H-pyran-4-yl)phenyl)methanone (10c).

(101 MHz, $\mathrm{CDCl}_{3}$ )
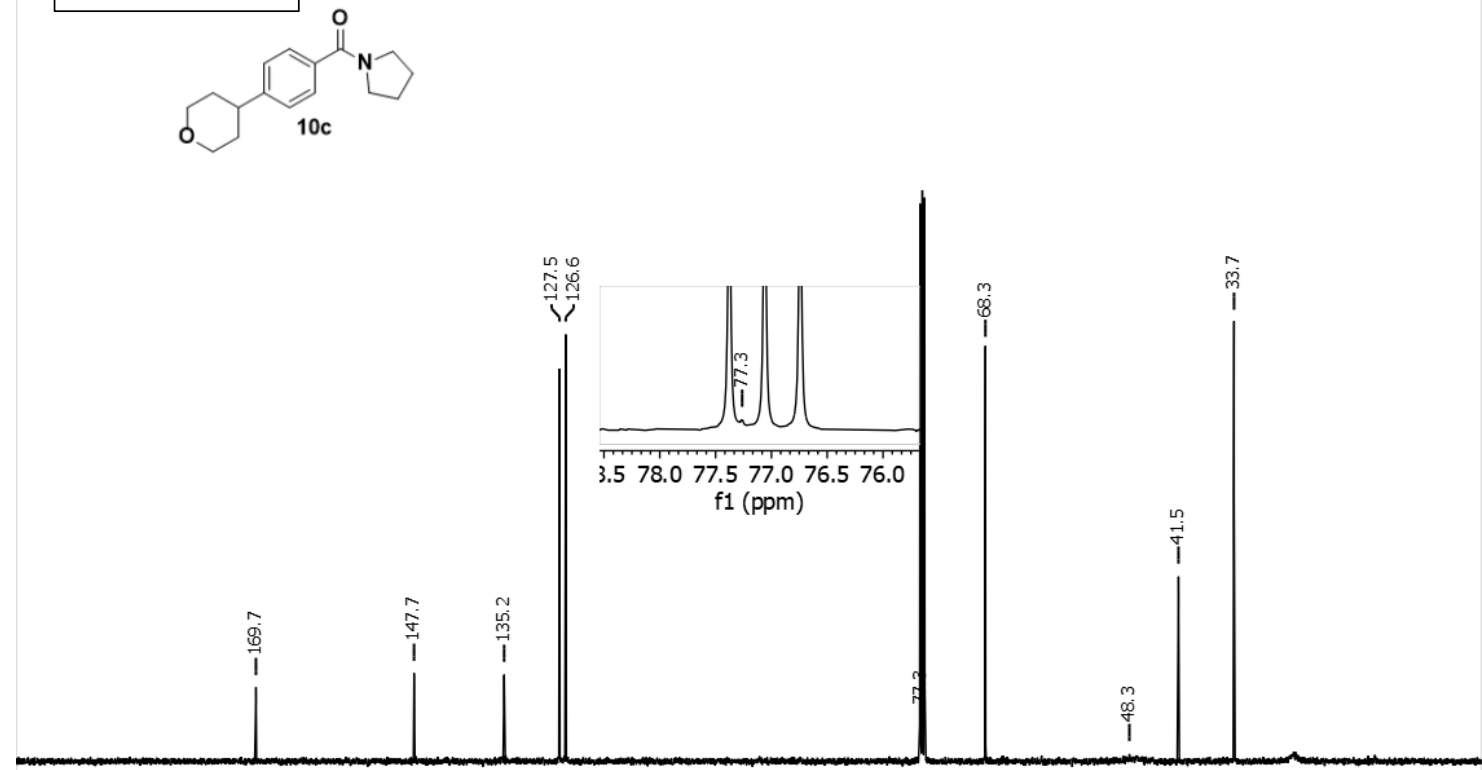

200

190

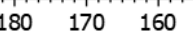

$\begin{array}{lll}150 & 140 \quad 130\end{array}$

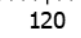

110100

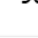


${ }^{1}$ H-NMR Spectrum of 2-(2-oxo-2-(4-(tetrahydro-2H-pyran-4-yl)phenyl)ethyl)isoindoline-1,3dion (10d)

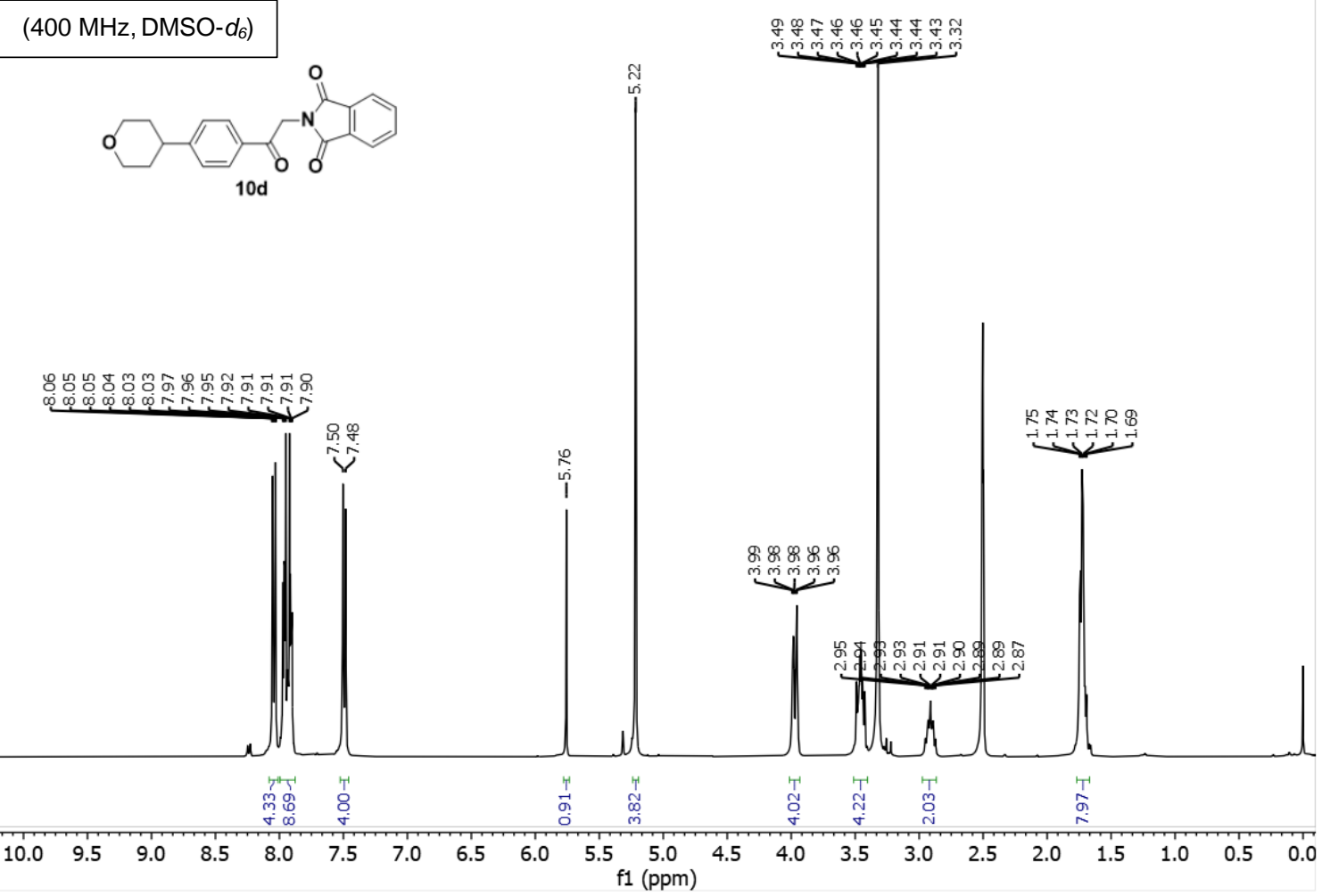

${ }^{13} \mathrm{C}\left\{{ }^{1} \mathrm{H}\right\}-N M R$ Spectrum of 2-(2-oxo-2-(4-(tetrahydro-2H-pyran-4-yl)phenyl)ethyl)isoindoline1,3-dion (10d)
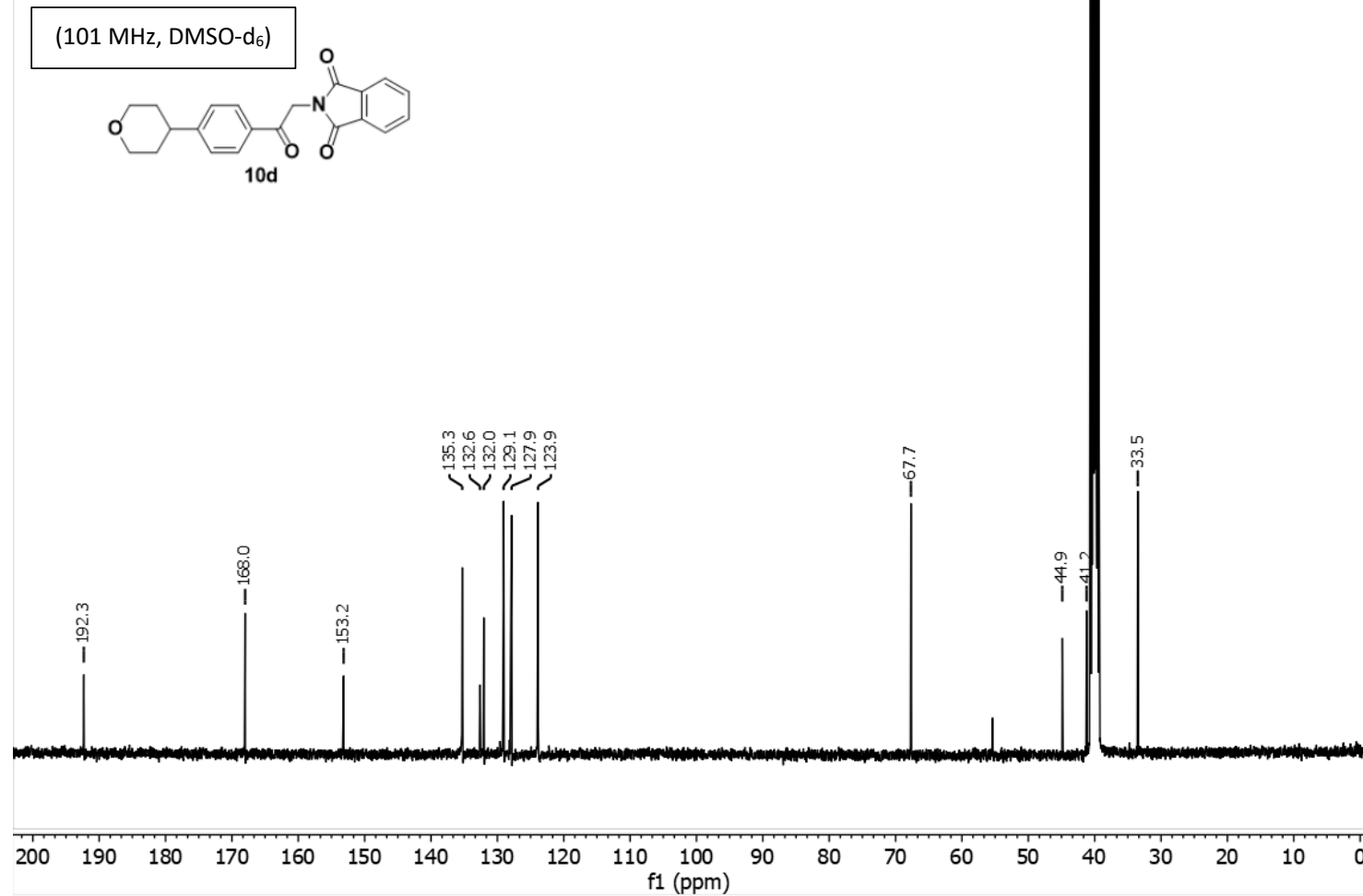
${ }^{1} \mathrm{H}$-NMR Spectrum of methyl 2-(tetrahydro-2H-pyran-4-yl)isonicotinate (10e)

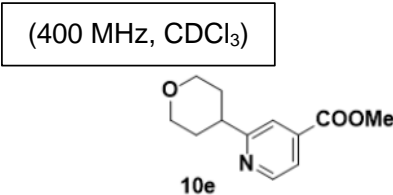

$10 \mathrm{e}$
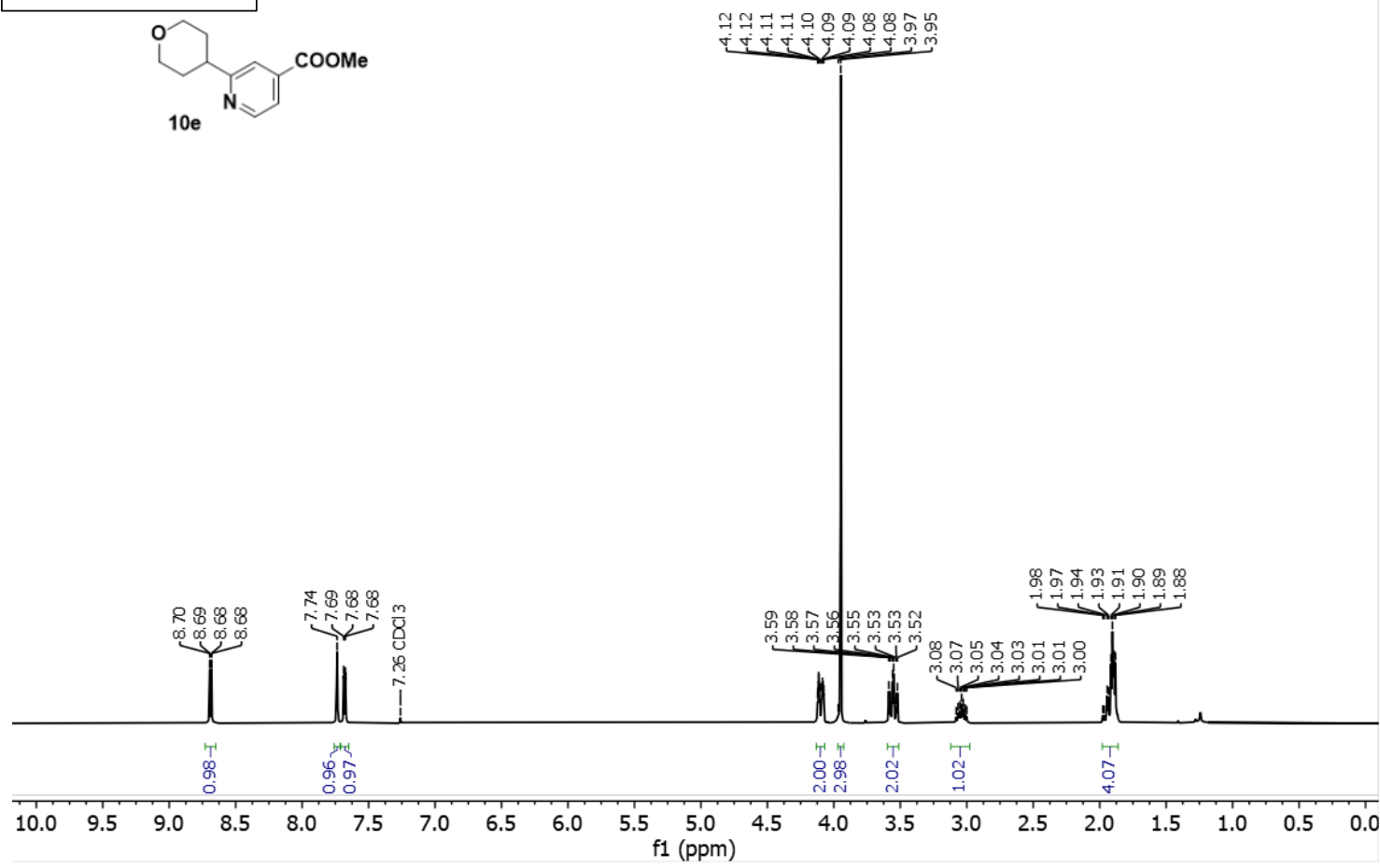

${ }^{13} \mathrm{C}\left\{{ }^{1} \mathrm{H}\right\}$-NMR Spectrum of methyl 2-(tetrahydro-2H-pyran-4-yl)isonicotinate (10e). $\left(101 \mathrm{MHz} \mathrm{CDCl}_{3}\right)$
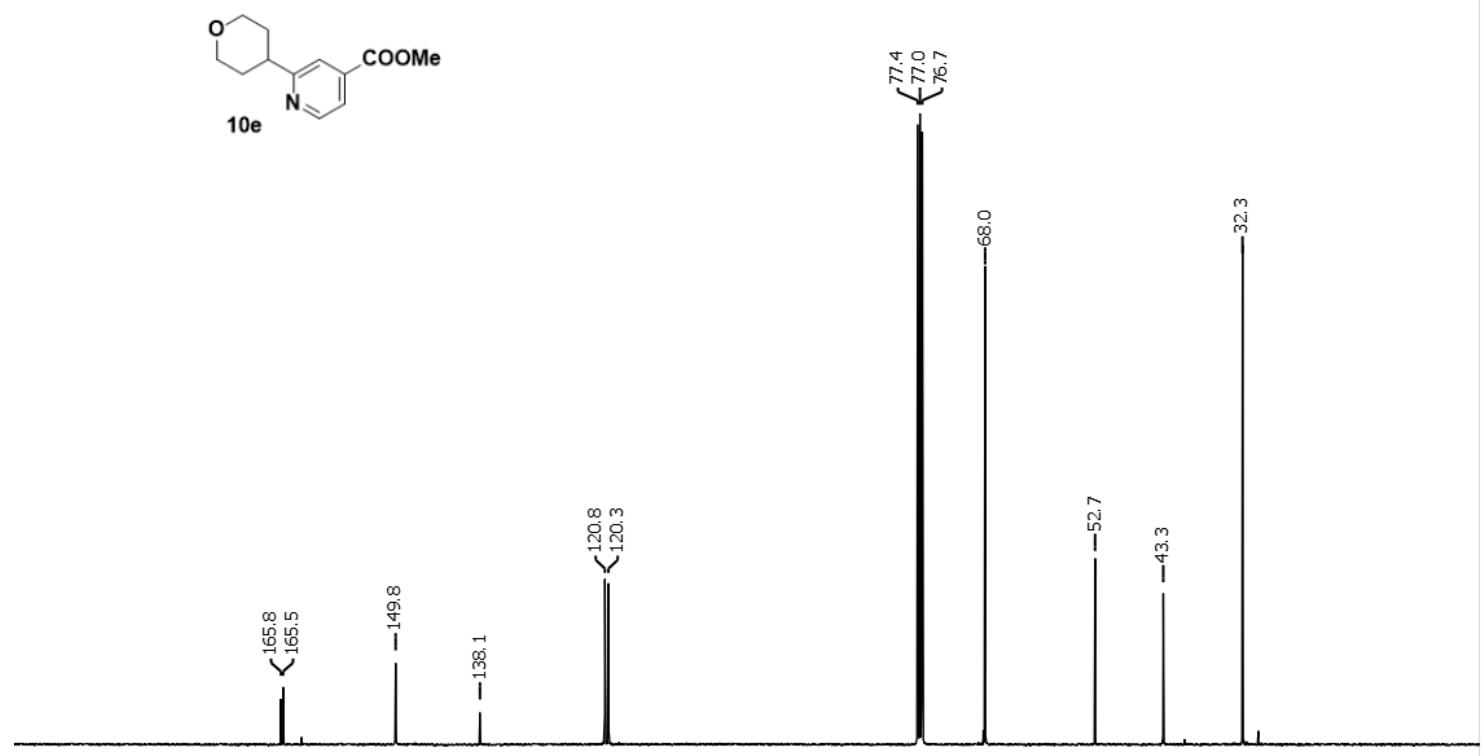

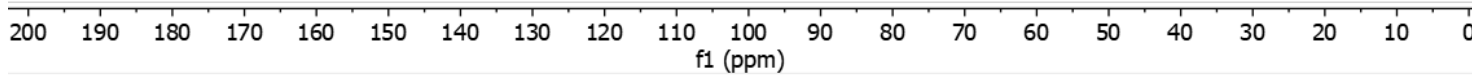


${ }^{1}$ H-NMR Spectrum of ethyl 5-methoxy-1-(3-(tetrahydro-2H-pyran-4-yl)phenyl)-1H-pyrazole-4carboxylate (10f).

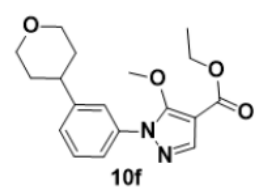

$\left(400 \mathrm{MHz}, \mathrm{CDCl}_{3}\right)$

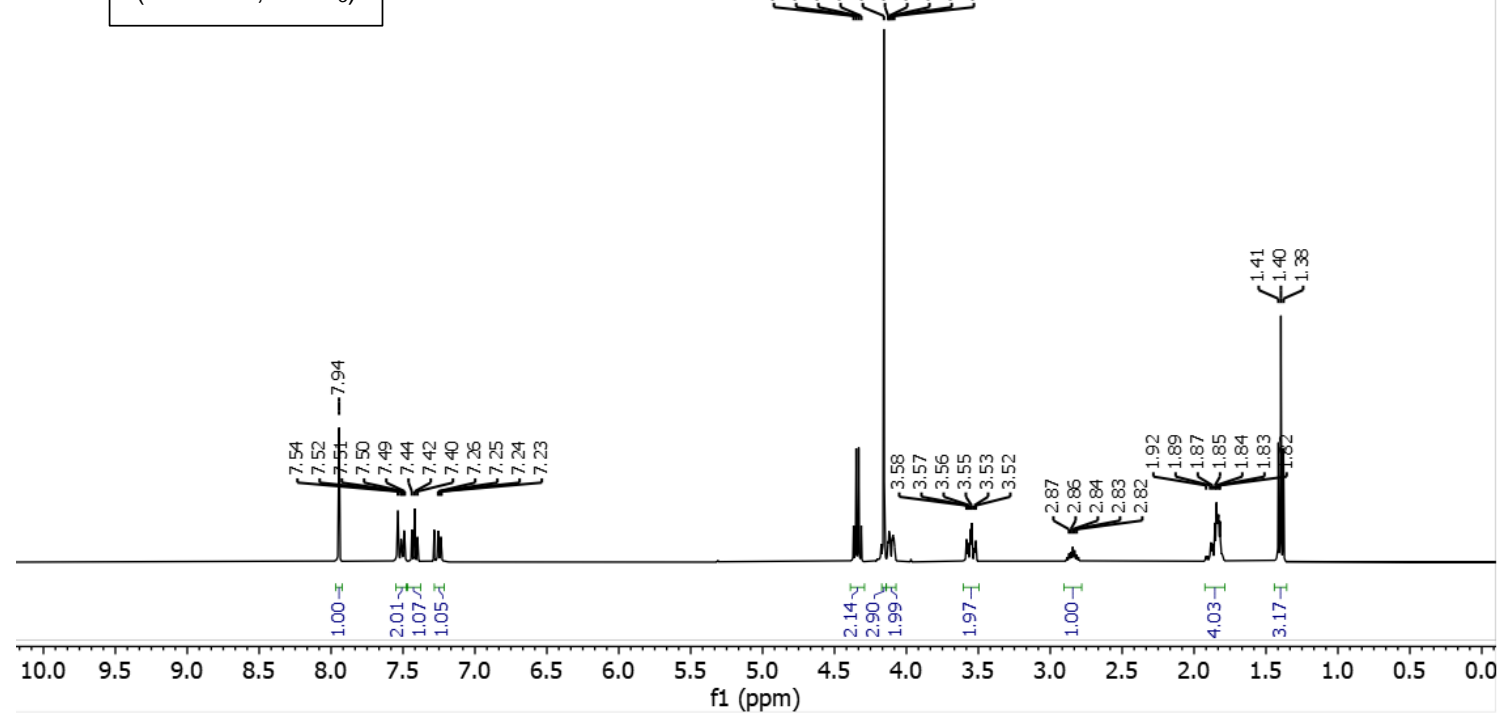

${ }^{13} \mathrm{C}\left\{{ }^{1} \mathrm{H}\right\}-N M R$ Spectrum of ethyl 5-methoxy-1-(3-(tetrahydro-2H-pyran-4-yl)phenyl)-1Hpyrazole-4-carboxylate (10f).

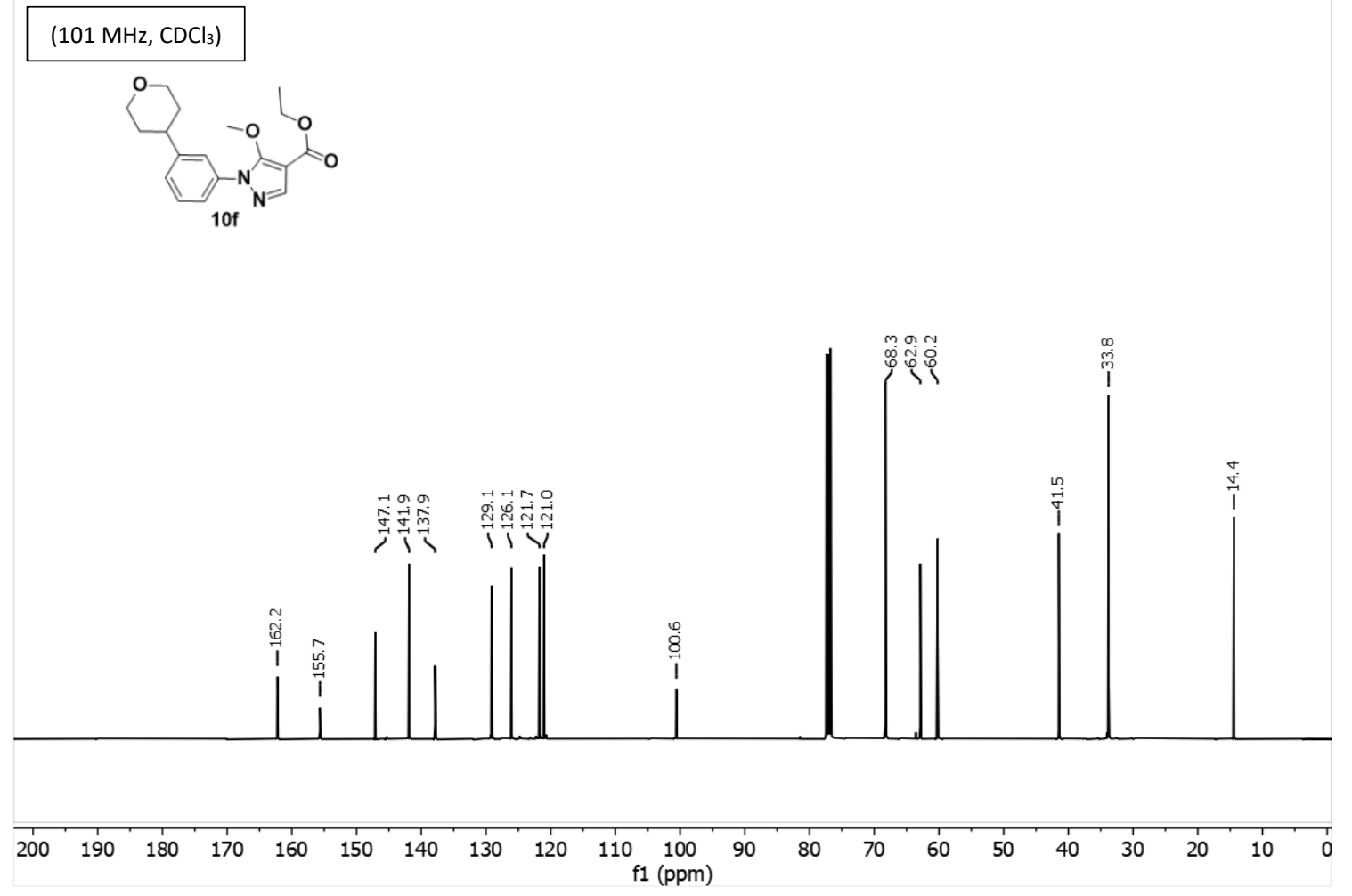


${ }^{1} \mathrm{H}-N M R$ Spectrum of 4-(5-(tetrahydro-2H-pyran-4-yl)pyridin-2-yl)morpholine (10g).
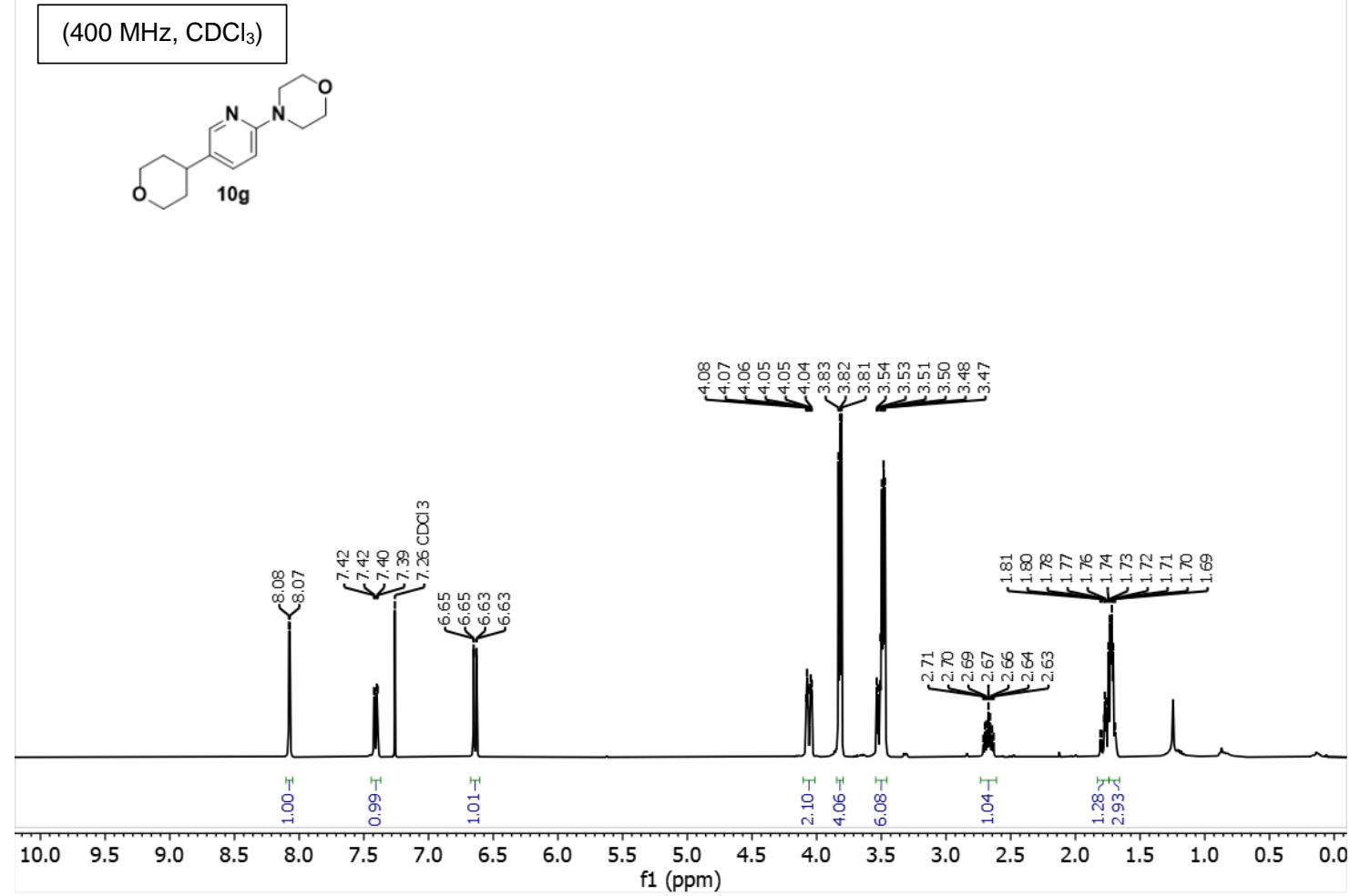

${ }^{13} \mathrm{C}_{\{}\{\mathrm{H}\}$-Spectrum of 4-(5-(tetrahydro-2H-pyran-4-yl)pyridin-2-yl)morpholine (10g ). (101 MHz, $\mathrm{CDCl}_{3}$ )
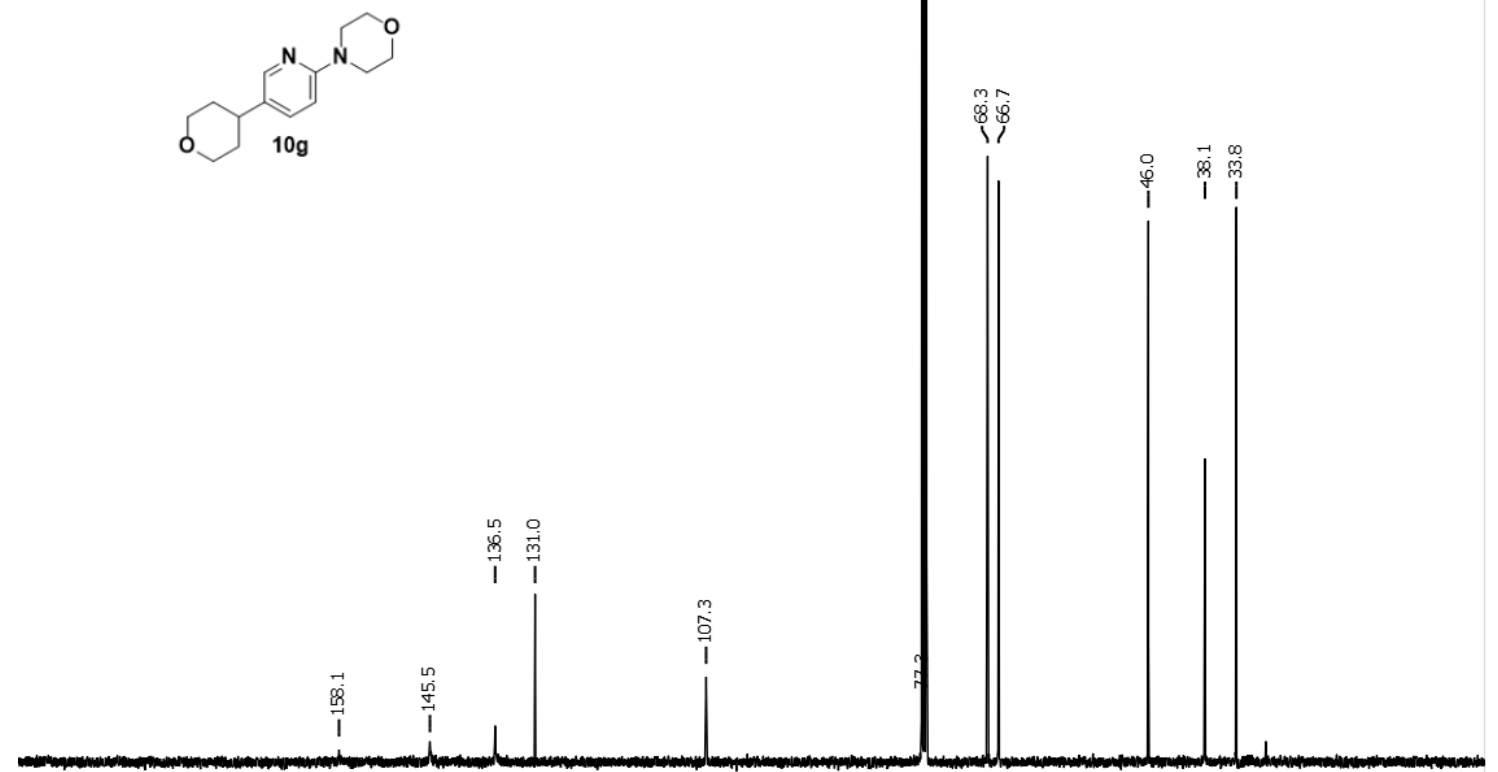

200

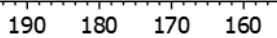

150

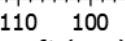

f1 (ppm) 
${ }^{1} \mathrm{H}-$ Spectrum of 6-(tetrahydro-2H-pyran-4-yl)quinazoline-2,4-diol (10i).
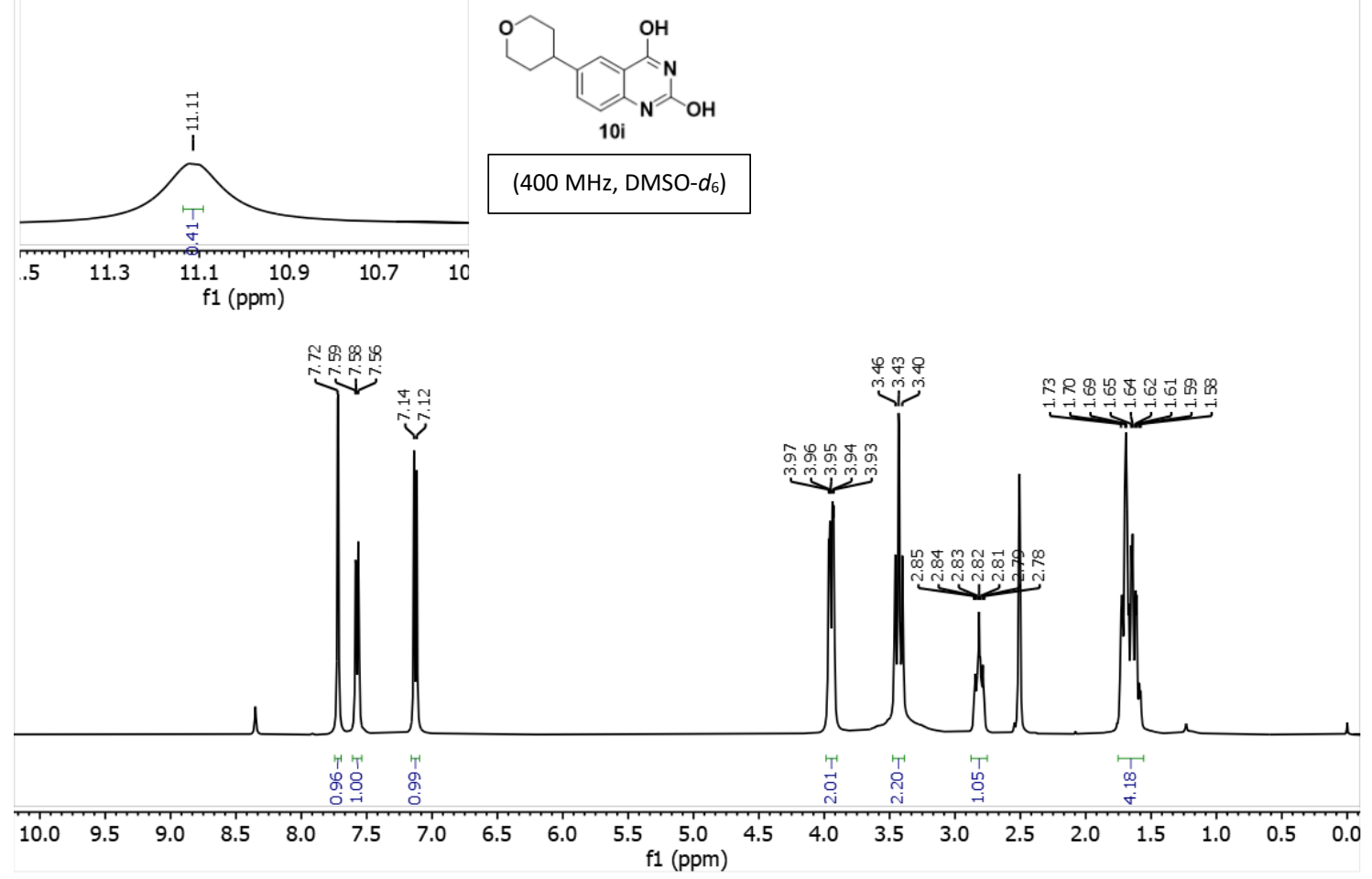

${ }^{13} \mathrm{C}\left\{{ }^{1} \mathrm{H}\right\}$-NMR Spectrum of 6-(tetrahydro-2H-pyran-4-yl)quinazoline-2,4-diol (10i). (101 MHz, DMSO- $d_{6}$ )

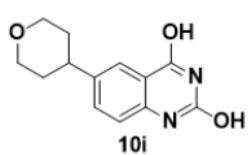

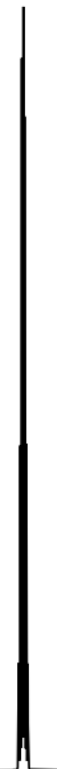

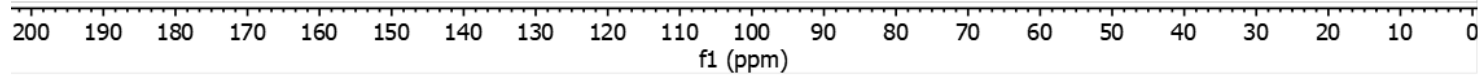


${ }^{13}$ C-NMR (DEPT) of 6-(tetrahydro-2H-pyran-4-yl)quinazoline-2,4-diol (10i).

$\left(101 \mathrm{MHz}, \mathrm{DMSO}-d_{6}\right)$
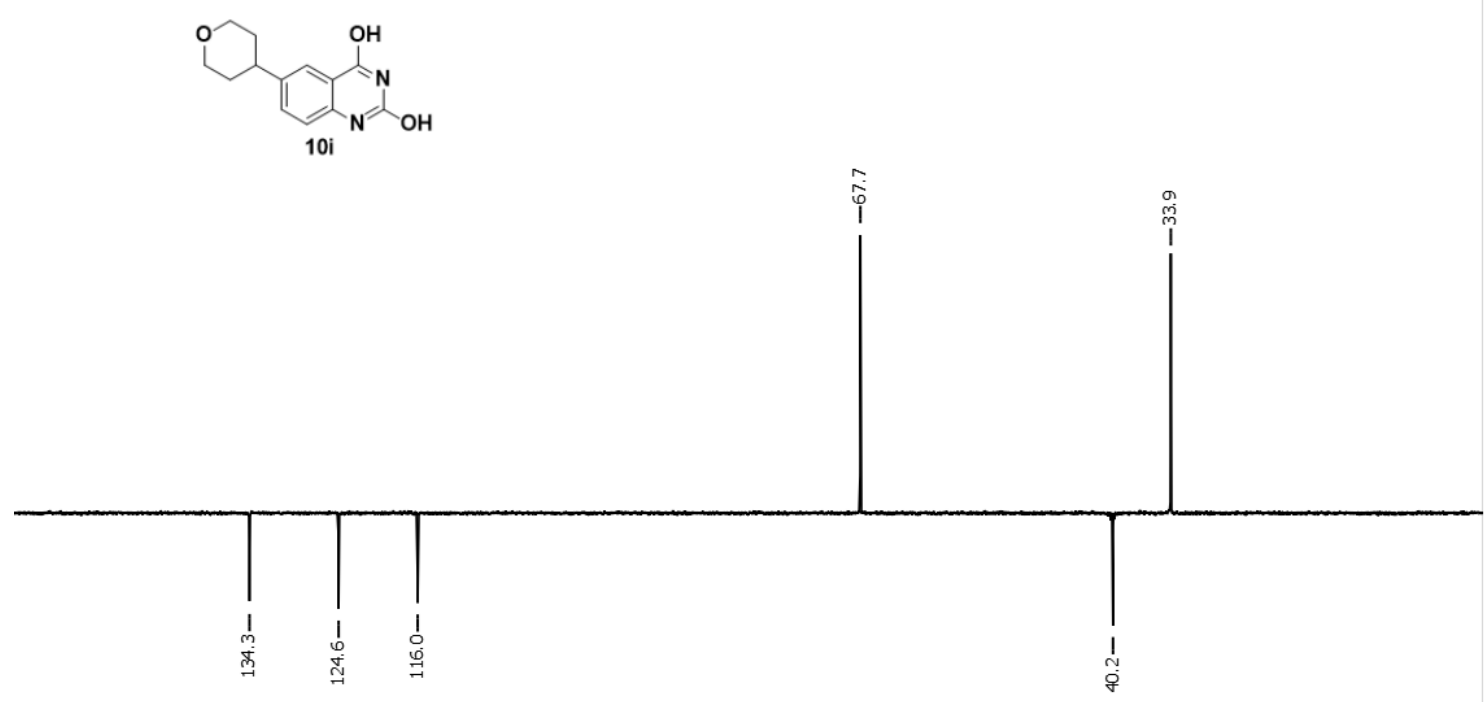

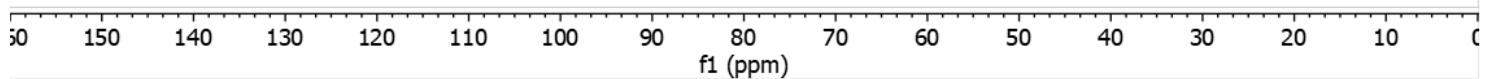


${ }^{1}$ H-NMR Spectrum of ethyl 5-ethyl-1-(6-(tetrahydro-2H-pyran-4-yl)pyridin-2-yl)-1H-pyrazole4-carboxylate $(10 \mathrm{j})$.
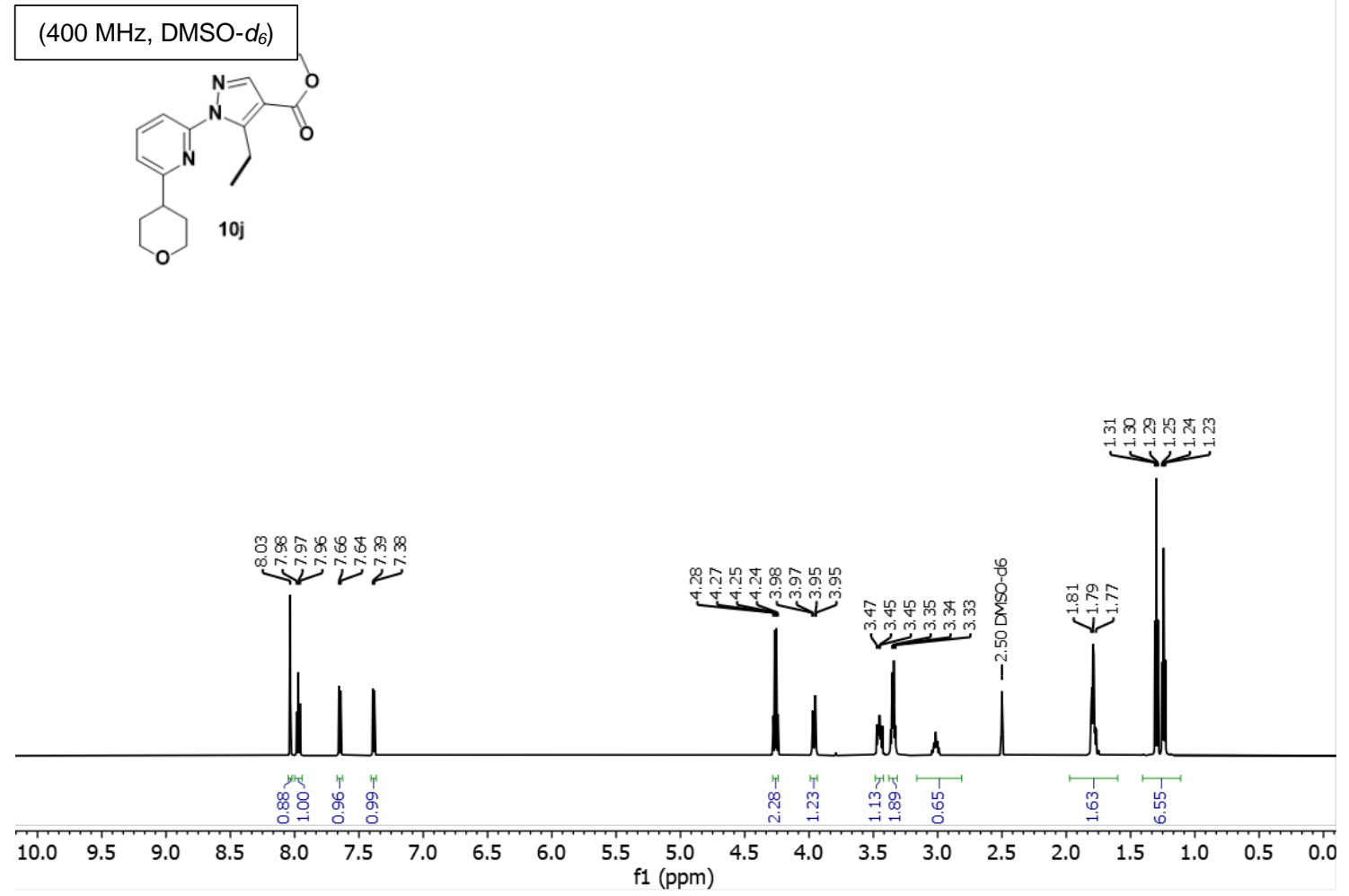

${ }^{13} \mathrm{C}\left\{{ }^{1} \mathrm{H}\right\}-N M R$ Spectrum of ethyl 5-ethyl-1-(6-(tetrahydro-2H-pyran-4-yl)pyridin-2-yl)-1Hpyrazole-4-carboxylate $(10 j)$.

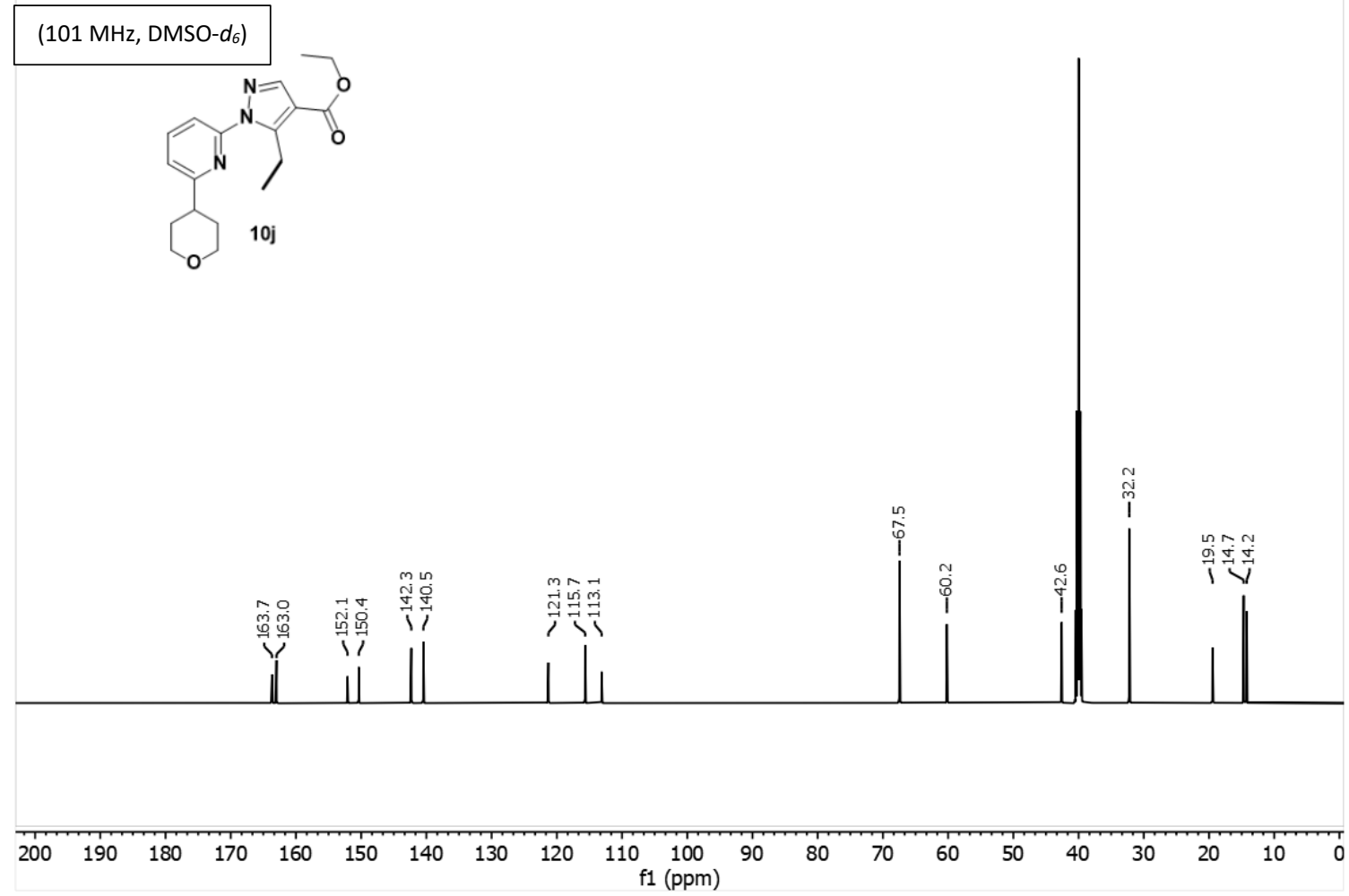


${ }^{1} \mathrm{H}-$ Spectrum of 5-(4-(1-(hydroxymethyl)cyclopropyl)phenyl)picolinonitrile (10k).

$\left(400 \mathrm{MHz}, \mathrm{CDCl}_{3}\right)$
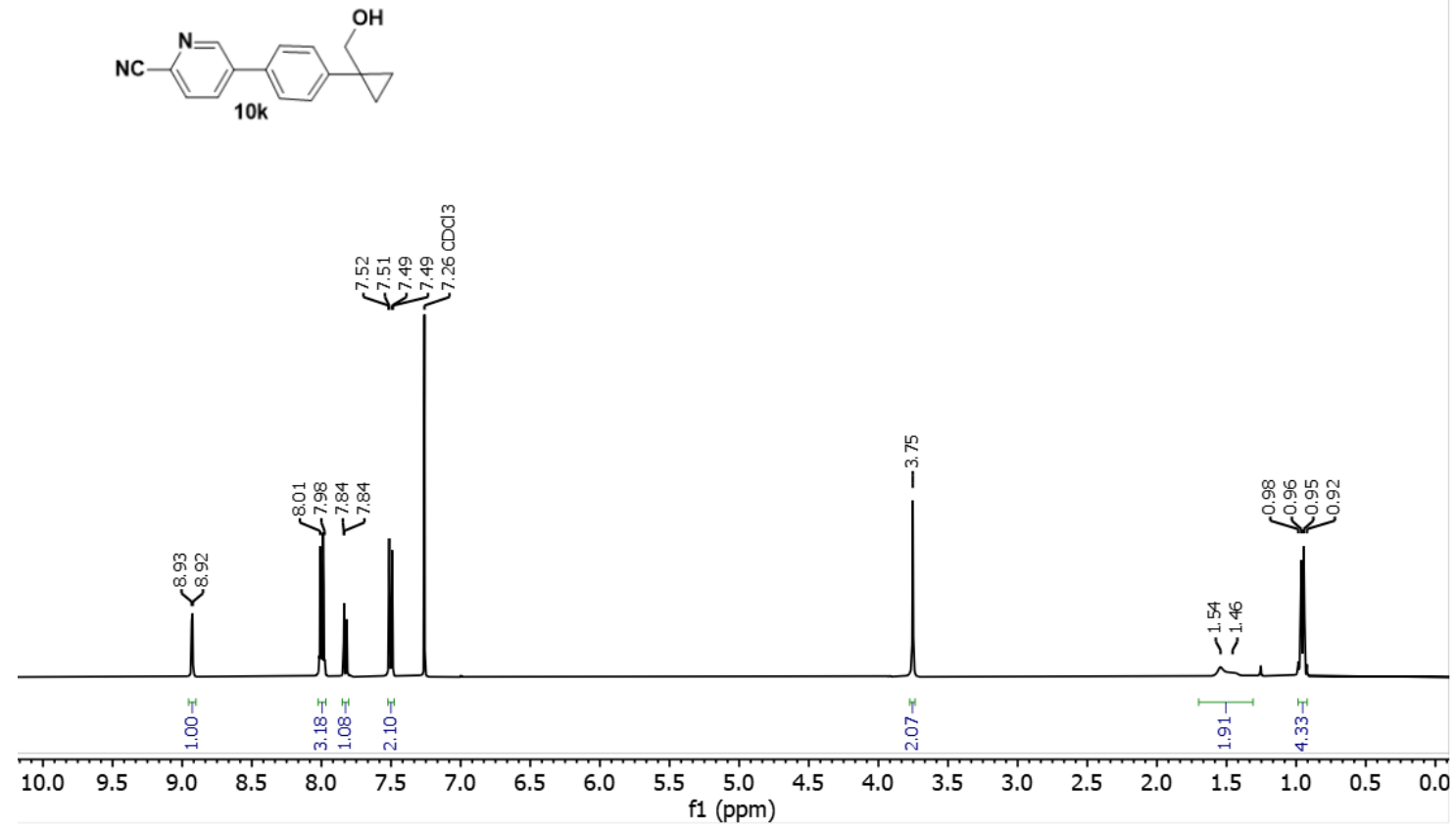

${ }^{13} \mathrm{C}\left\{{ }^{1} \mathrm{H}\right\}$-NMR Spectrum of 5-(4-(1-(hydroxymethyl)cyclopropyl)phenyl)picolinonitrile (10k)

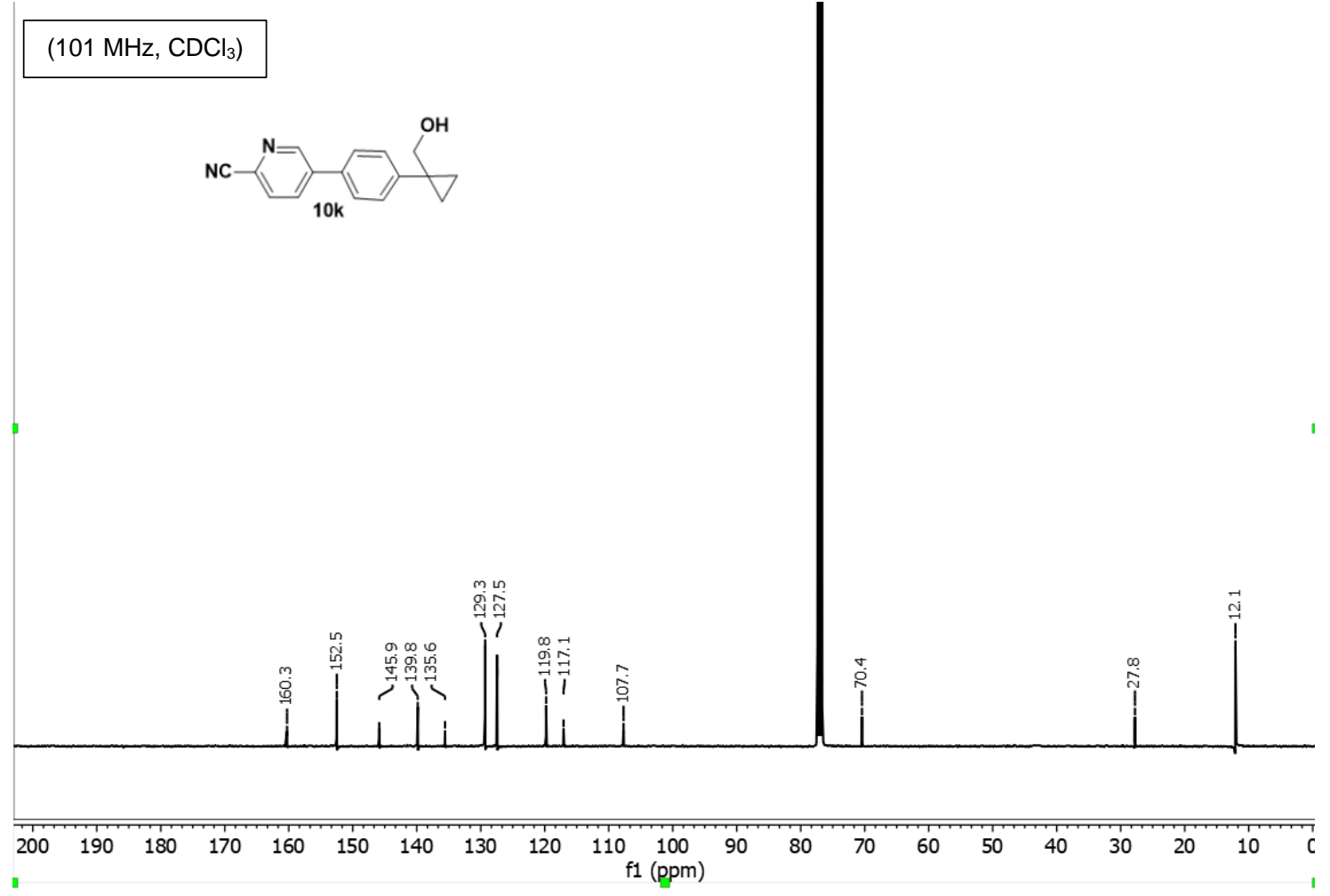


${ }^{1}$ H-NMR Spectrum of 5-(4-(3,3-difluorocyclobutyl)phenyl)picolinonitrile (101).

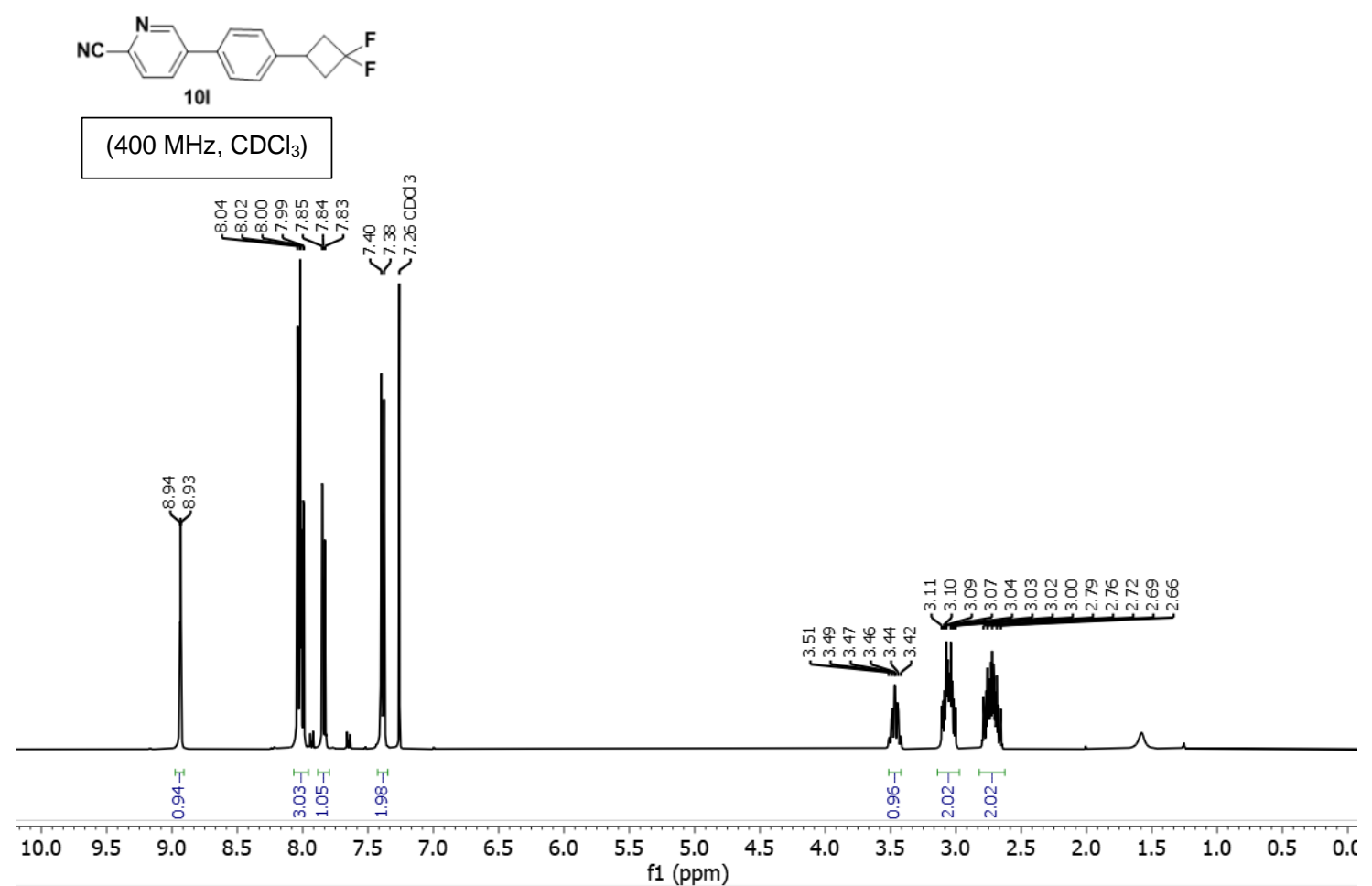

${ }^{13} \mathrm{C}\left\{{ }^{1} \mathrm{H}\right\}$-NMR Spectrum of 5-(4-(3,3-difluorocyclobutyl)phenyl)picolinonitrile (10I). $\left(101 \mathrm{MHz}, \mathrm{CDCl}_{3}\right)$<smiles>[CH-]=Cc1ccc(-c2ccc(CC(F)F)cc2)cn1</smiles>

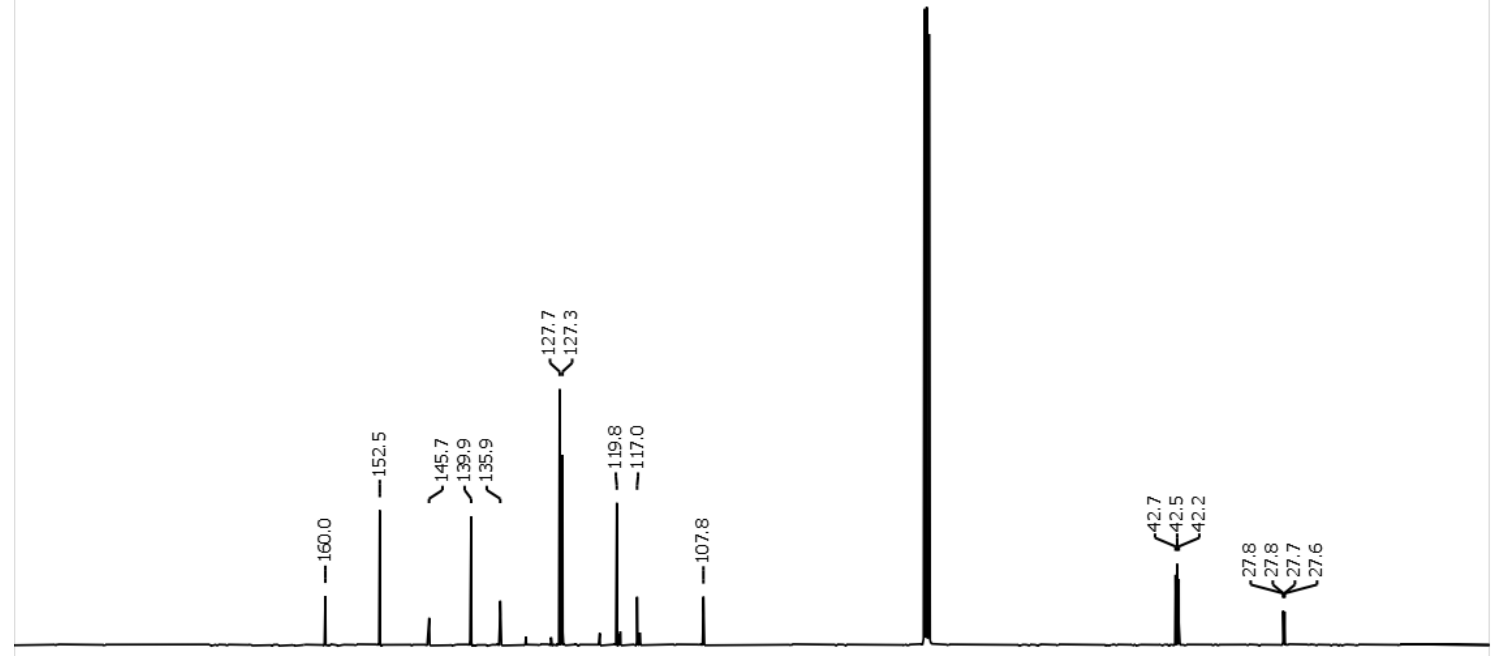

$\begin{array}{lllllllllllllllllllllllllllll}200 & 190 & 180 & 170 & 160 & 150 & 140 & 130 & 120 & 110 & 100 & 90 & 80 & 70 & 60 & 50 & 40 & 30 & 20 & 10 & 0\end{array}$ 
${ }^{19}$ F-NMR Spectrum of 5-(4-(3,3-difluorocyclobutyl)phenyl)picolinonitrile (101).

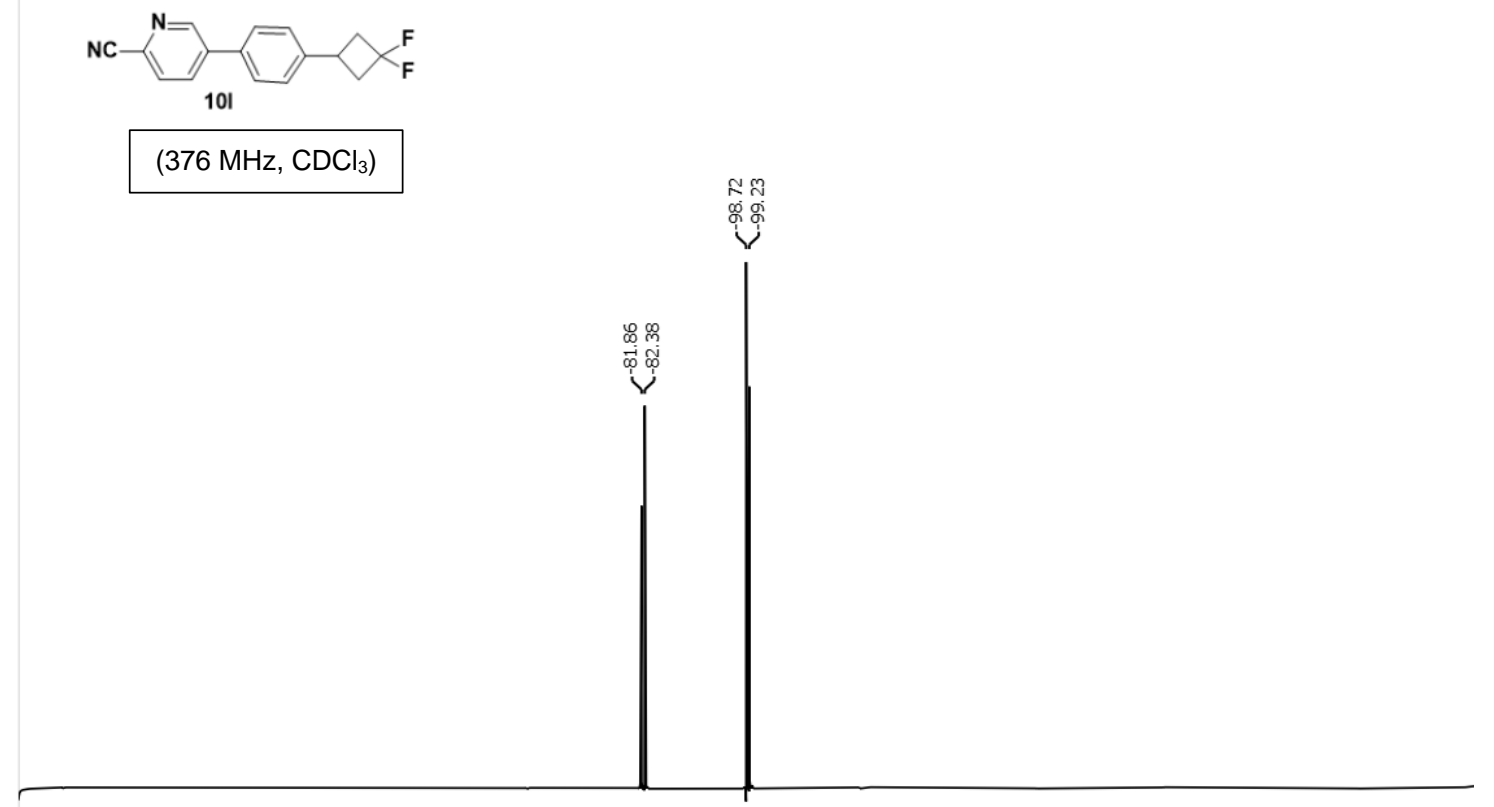

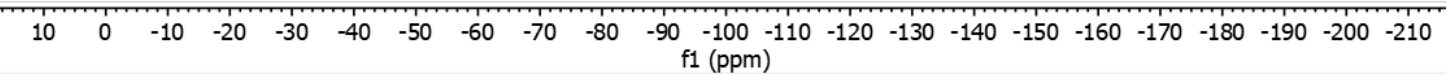


${ }^{1} \mathrm{H}-\mathrm{NMR}$ Spectrum of ethyl 1-(6-(2-cyanoethyl)pyridin-2-yl)-5-methyl-1H-pyrazole-4carboxylate (11a).

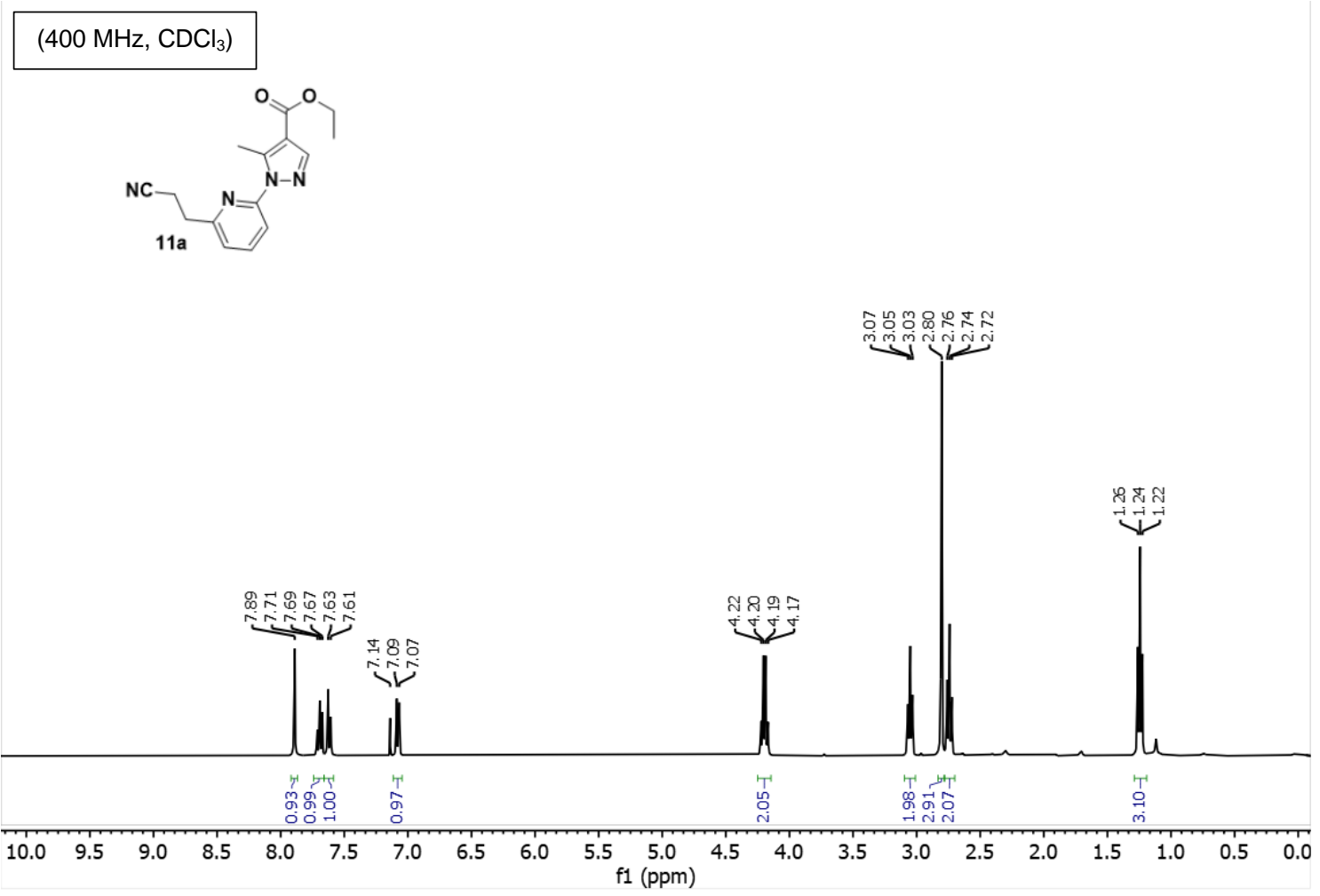

${ }^{13} \mathrm{C}\left\{{ }^{1} \mathrm{H}\right\}$-NMR Spectrum of ethyl 1-(6-(2-cyanoethyl)pyridin-2-yl)-5-methyl-1H-pyrazole-4carboxylate (11a).

(101 MHz, $\mathrm{CDCl}_{3}$ )
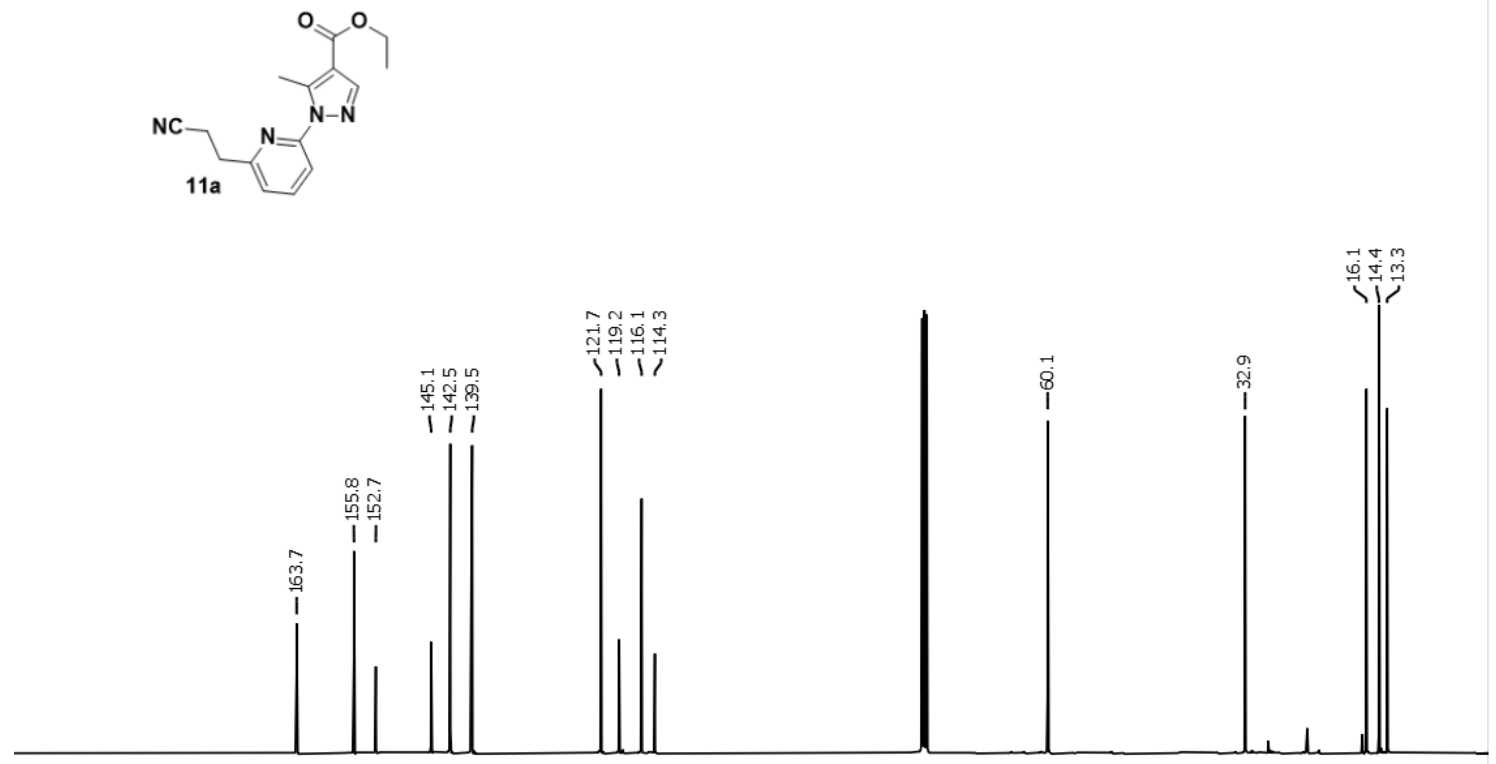

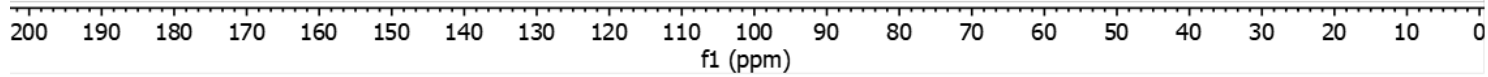


${ }^{1}$ H-NMR Spectrum of ethyl 5-methyl-1-(6-(oxetan-3-yl)pyridin-2-yl)-1H-pyrazole-4carboxylate (11b).

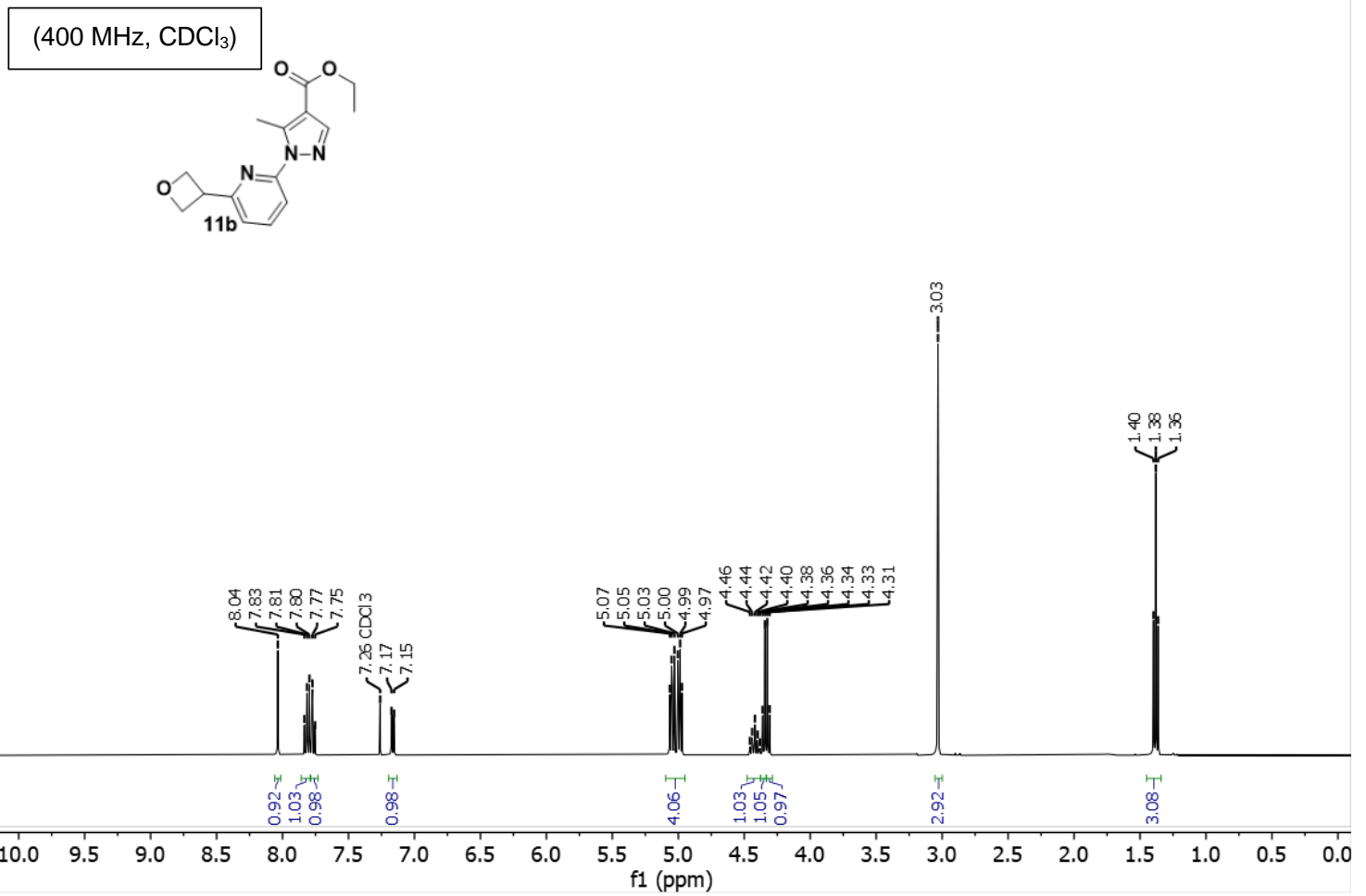

${ }^{13} \mathrm{C}\left\{{ }^{1} \mathrm{H}\right\}$-Spectrum of ethyl 5-methyl-1-(6-(oxetan-3-yl)pyridin-2-yl)-1H-pyrazole-4-carboxylate (11b).

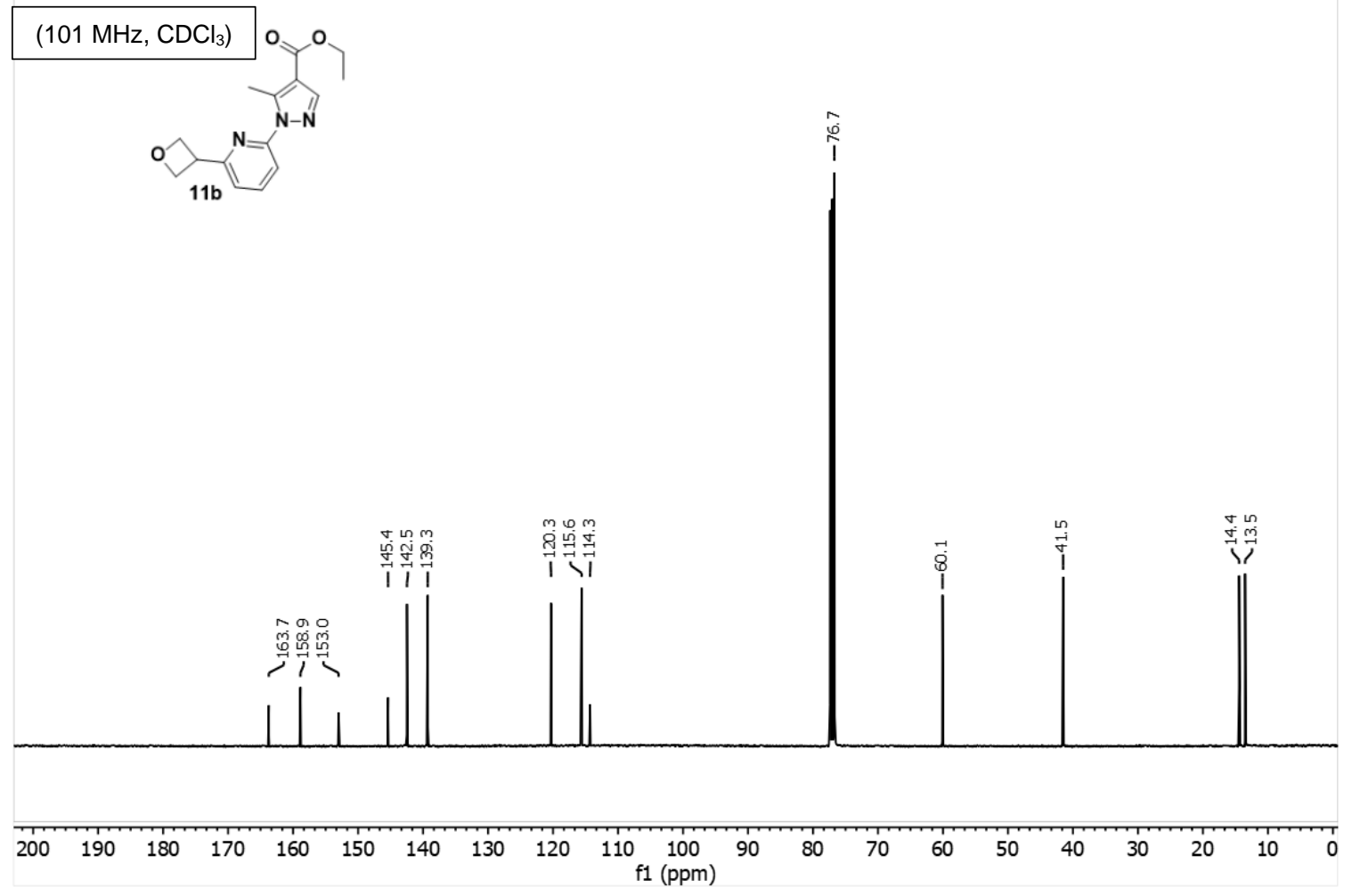


${ }^{1}$ H-NMR Spectrum of ethyl 5-methyl-1-(6-(tetrahydrofuran-3-yl)pyridin-2-yl)-1H-pyrazole-4carboxylate (11c).

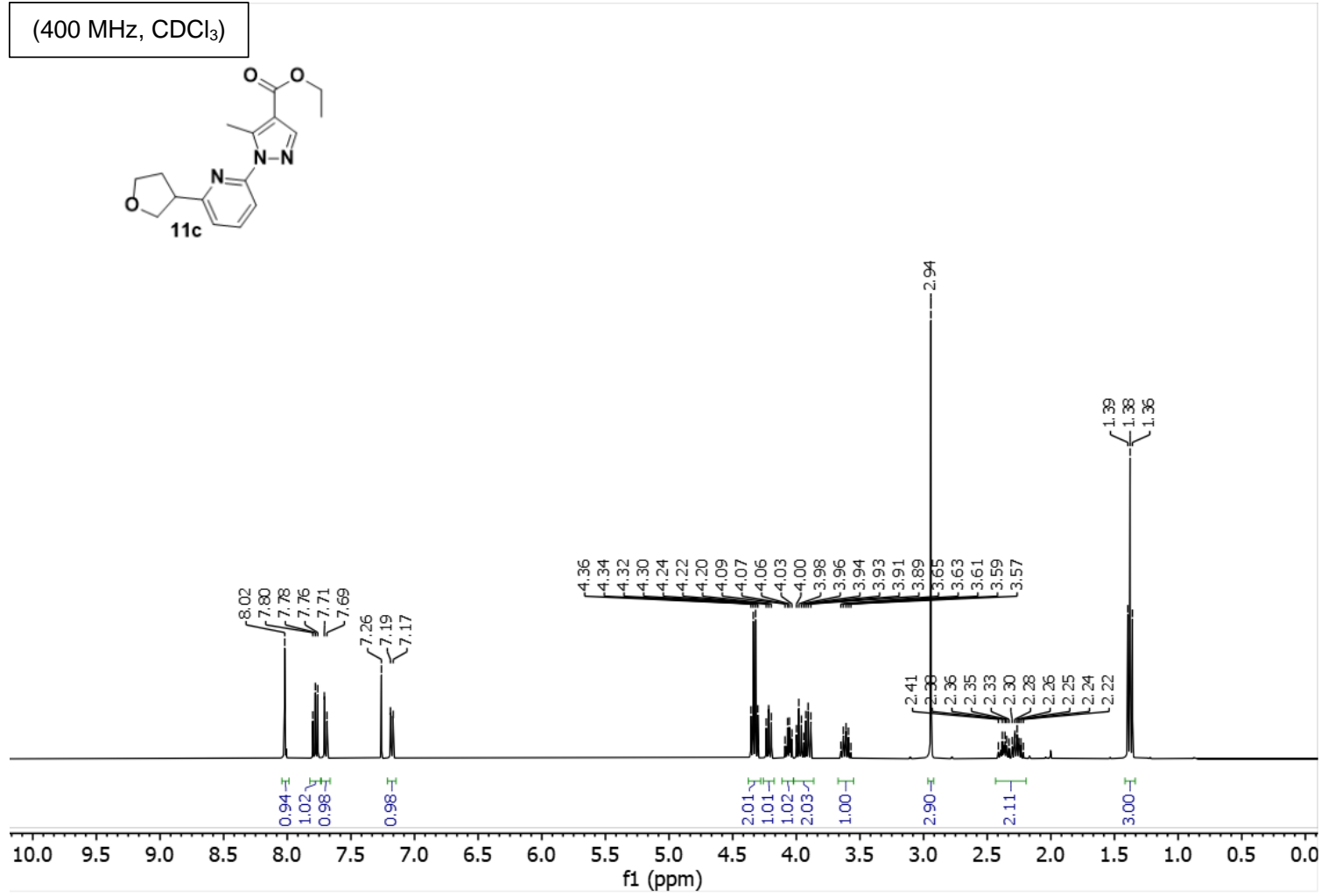

${ }^{13} \mathrm{C}\left\{{ }^{1} \mathrm{H}\right\}$-NMR Spectrum of ethyl 5-methyl-1-(6-(tetrahydrofuran-3-yl)pyridin-2-yl)-1Hpyrazole-4-carboxylate (11c).
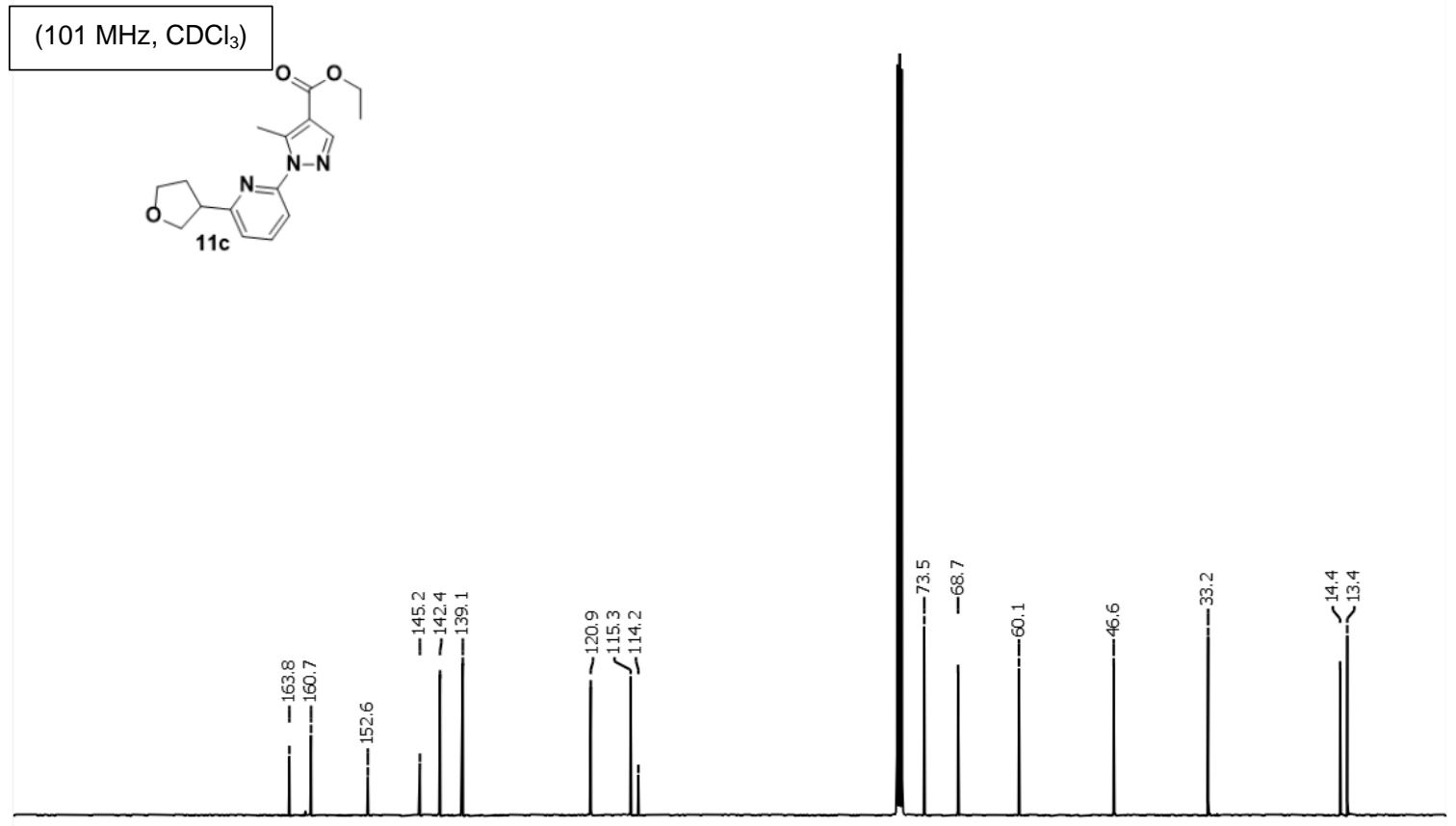

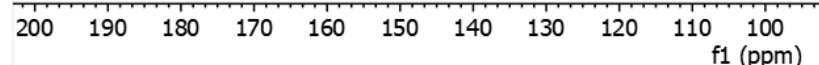


${ }^{1} \mathrm{H}$ Spectrum of ethyl 5-methyl-1-(6-(tetrahydro-2H-pyran-4-yl)pyridin-2-yl)-1H-pyrazole-4carboxylate (11d).

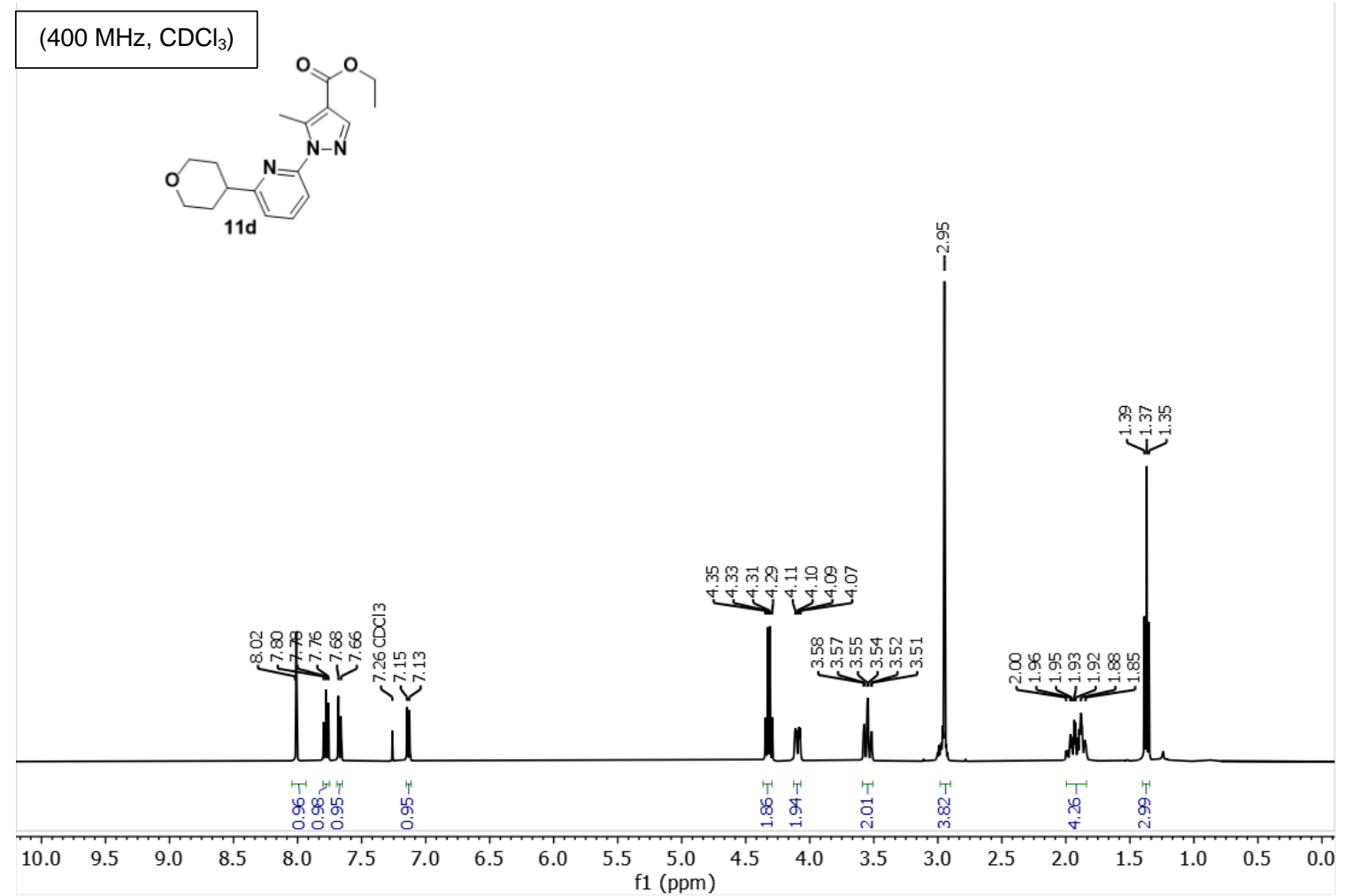

${ }^{13} \mathrm{C}\left\{{ }^{1} \mathrm{H}\right\}-N M R$ Spectrum of ethyl 5-methyl-1-(6-(tetrahydro-2H-pyran-4-yl)pyridin-2-yl)-1Hpyrazole-4-carboxylate (11d).

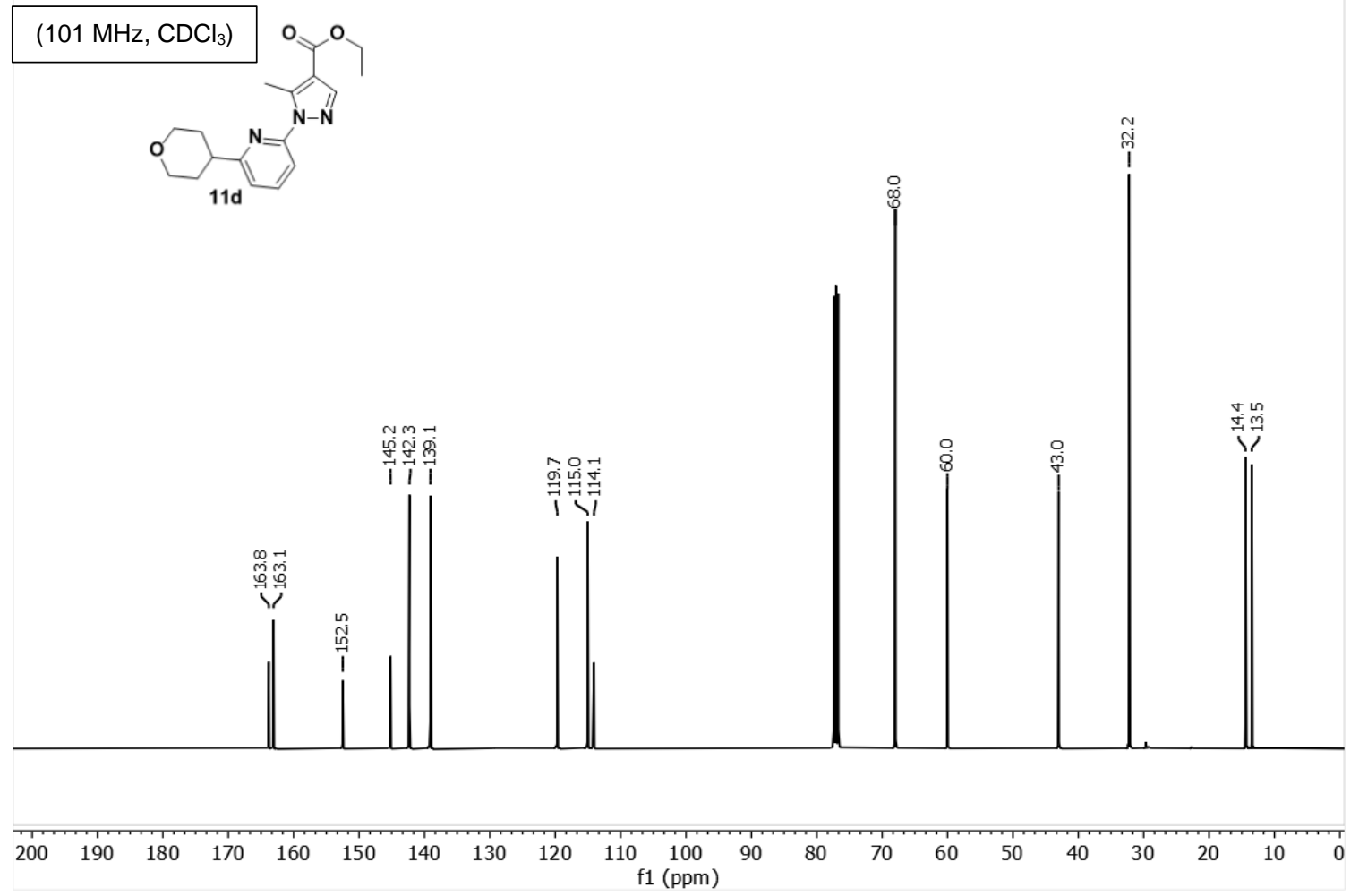


${ }^{1}$ H-NMR Spectrum of ethyl 1-(6-(3-methoxy-3-oxopropyl)pyridin-2-yl)-5-methyl-1H-pyrazole4-carboxylate (11e).
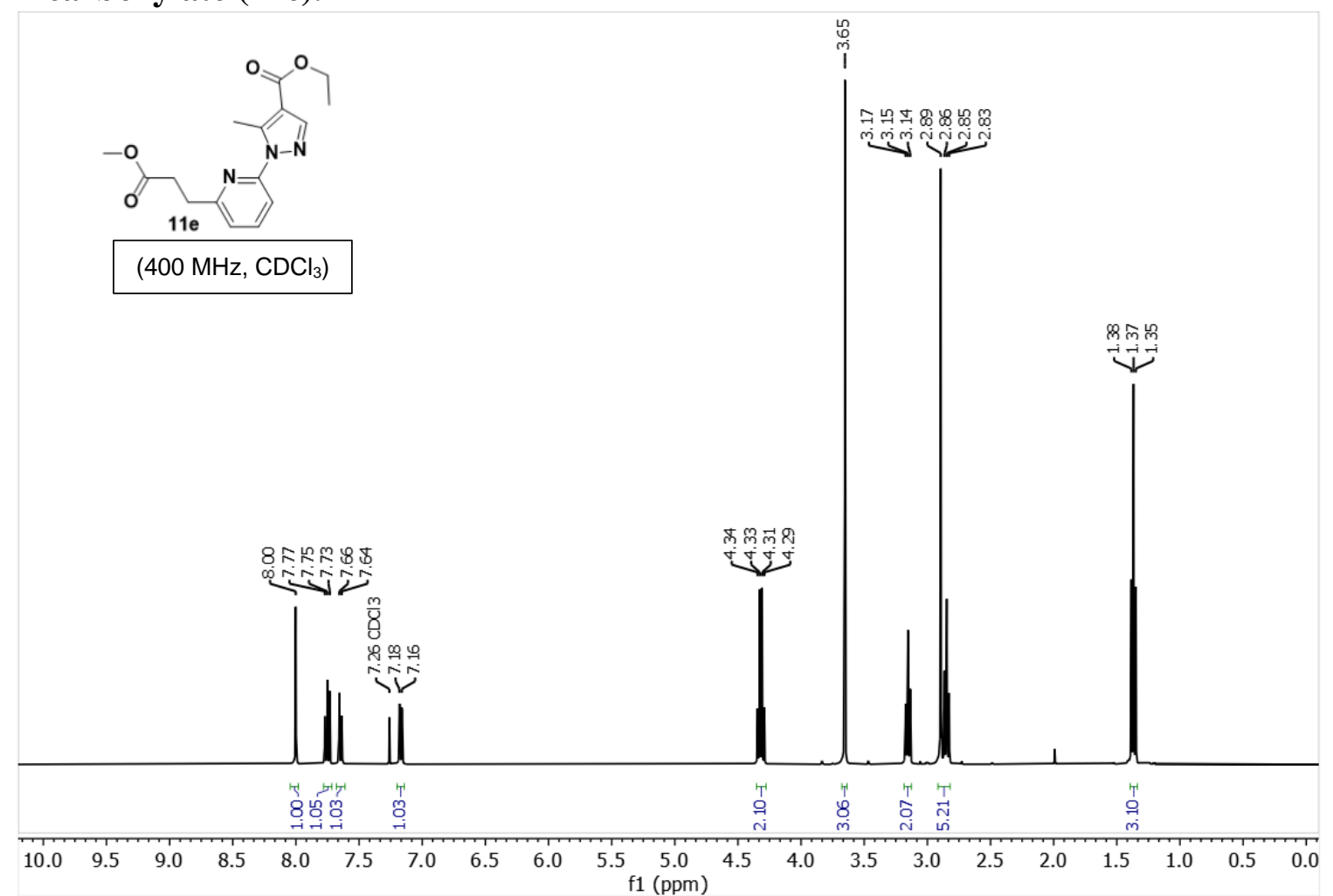

${ }^{13} \mathrm{C}\left\{{ }^{1} \mathrm{H}\right\}$-NMR Spectrum of ethyl 1-(6-(3-methoxy-3-oxopropyl)pyridin-2-yl)-5-methyl-1Hpyrazole-4-carboxylate (11e).

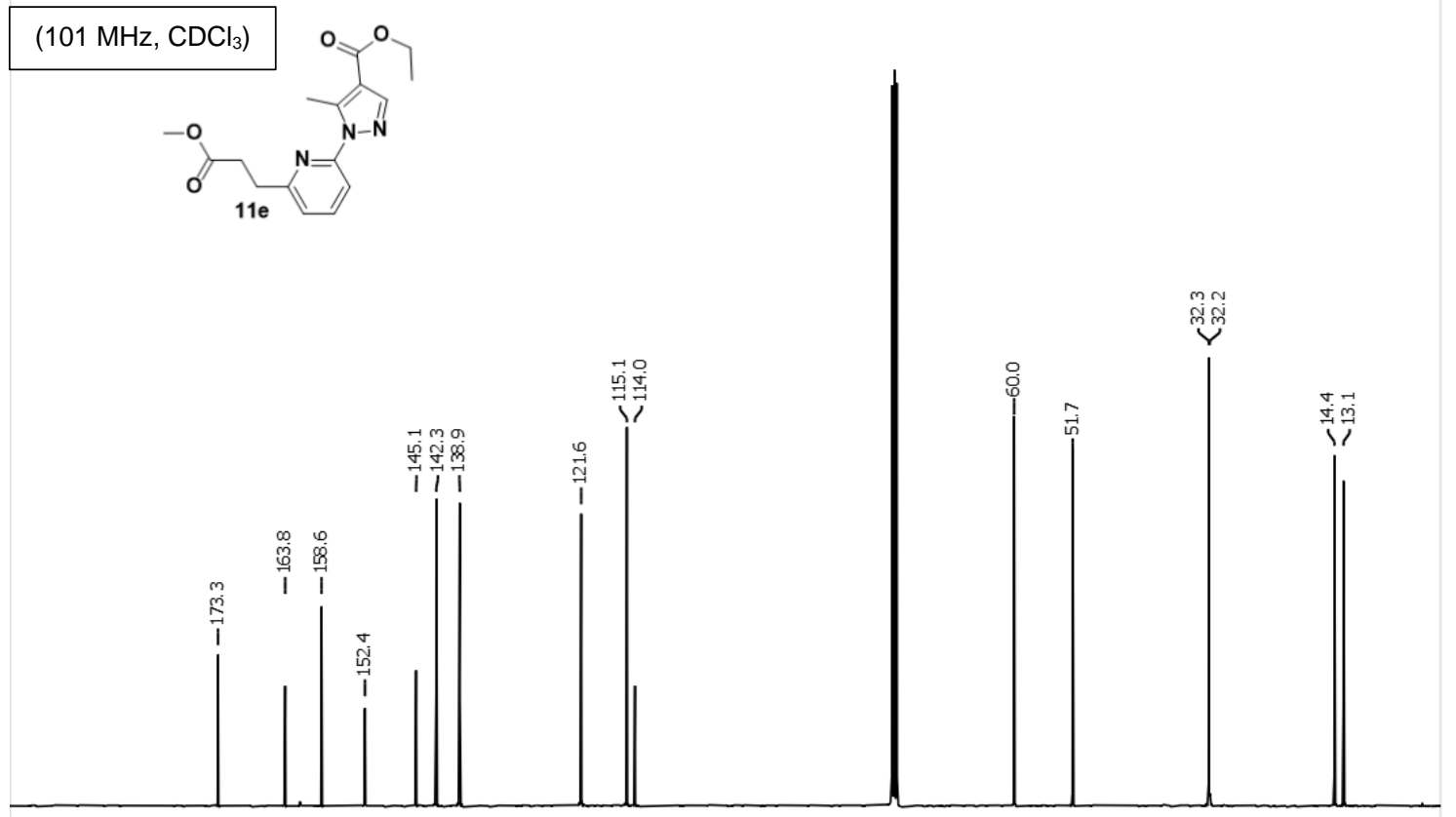

200

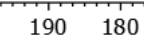

$\begin{array}{lll}80 & 170 \quad 160\end{array}$

$140 \quad 130$

$110 \quad 100$

80

60

50 
${ }^{1}$ H-NMR Spectrum for ethyl 5-methyl-1-(6-(4-oxocyclohexyl)pyridin-2-yl)-1H-pyrazole-4carboxylate (11f).
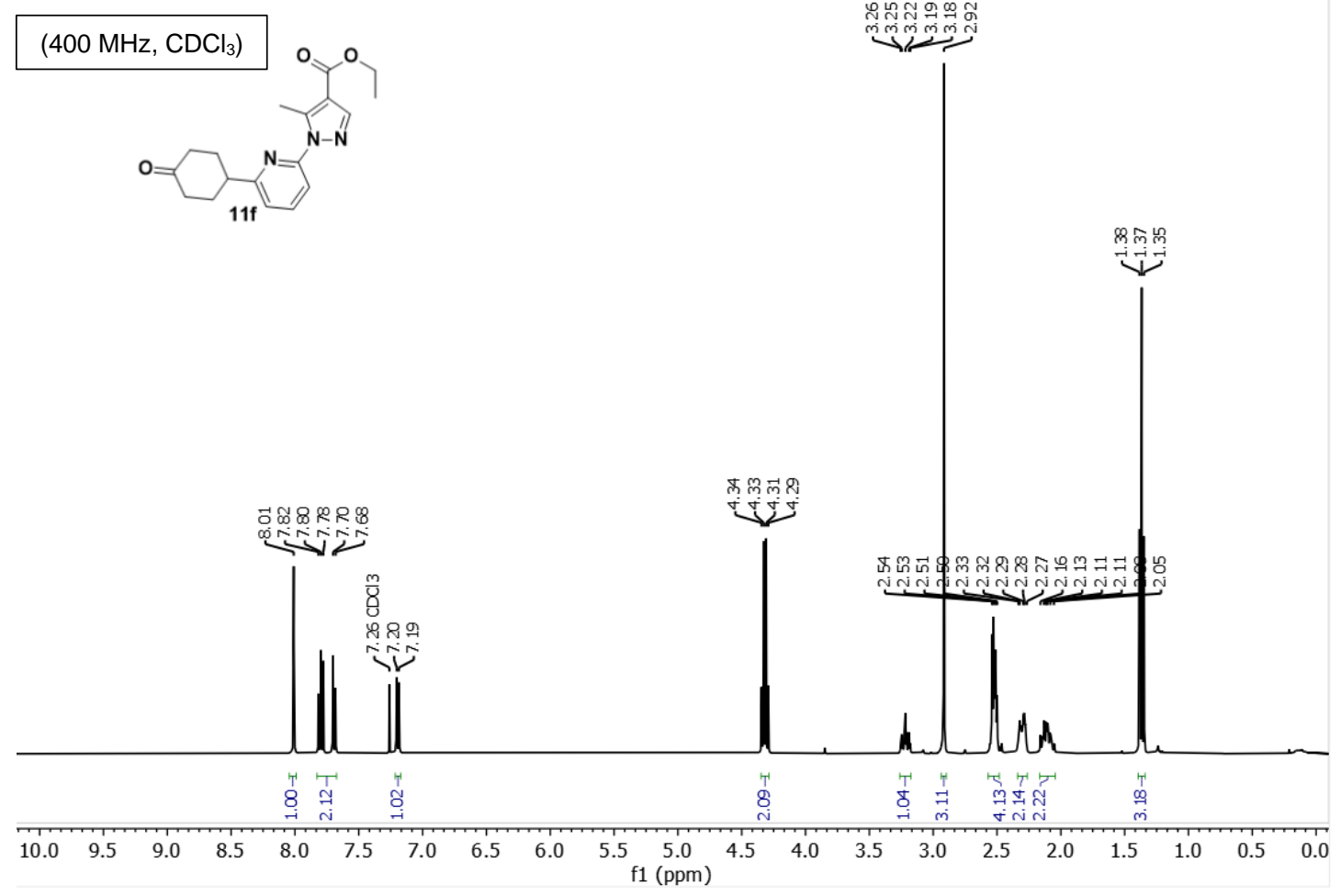

${ }^{13} \mathrm{C}\left\{{ }^{1} \mathrm{H}\right\}$-NMR Spectrum of ethyl 5-methyl-1-(6-(4-oxocyclohexyl)pyridin-2-yl)-1H-pyrazole-4carboxylate (11f).
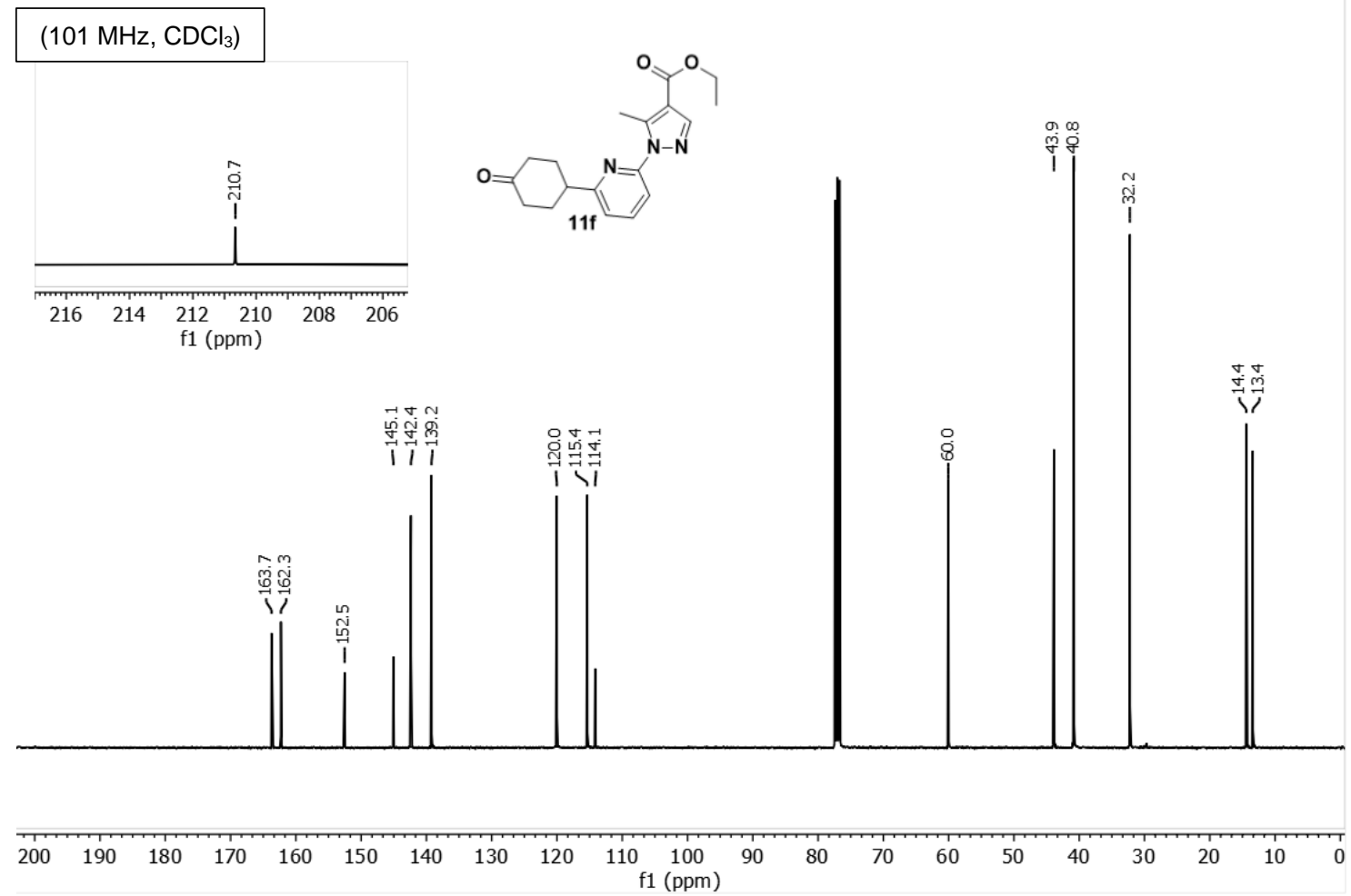
${ }^{1}$ H-NMR Spectrum of ethyl 5-methyl-1-(6-(2-(tetrahydro-2H-pyran-4-yl)ethyl)pyridin-2-yl)1H-pyrazole-4-carboxylate (11g).

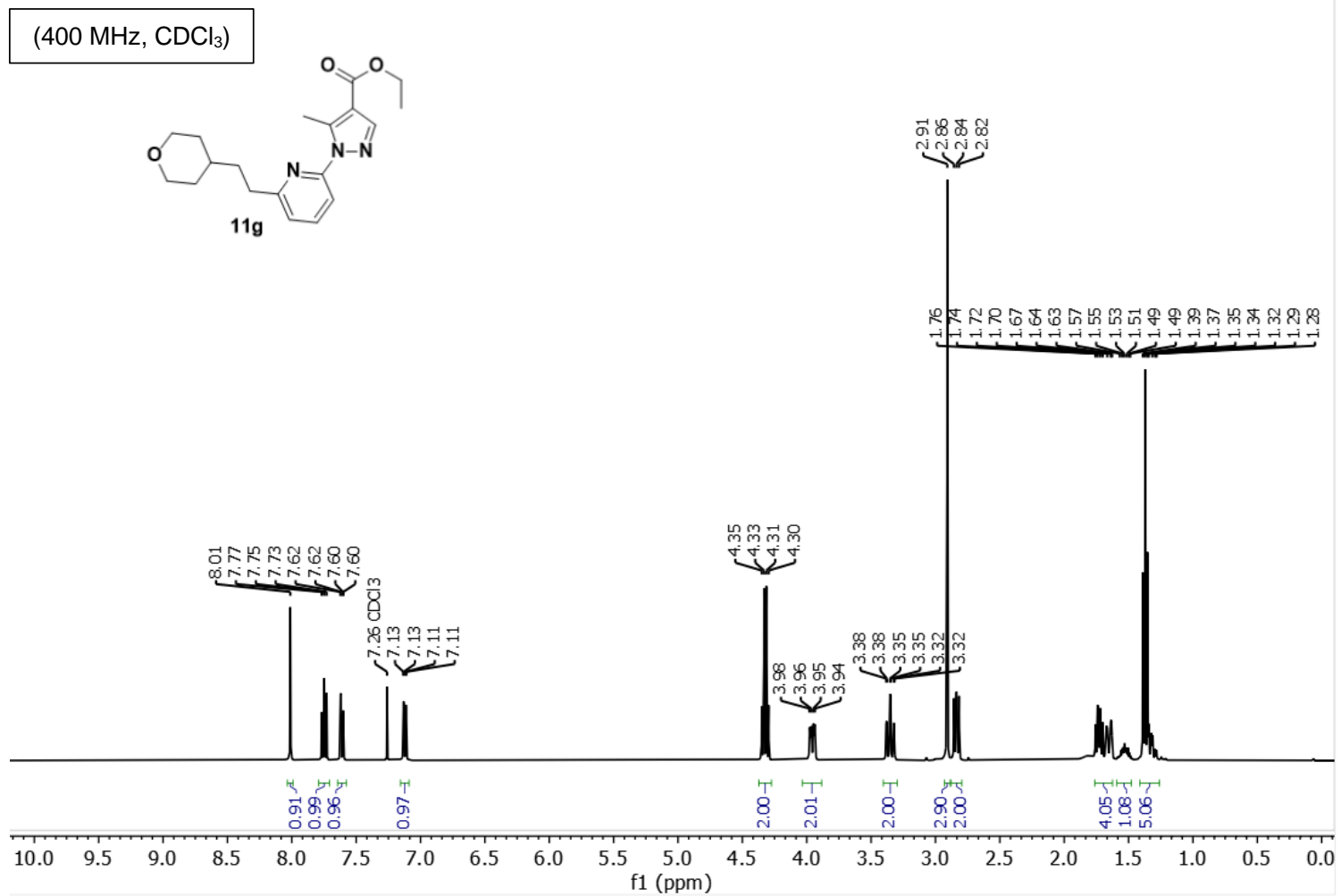

${ }^{13} \mathrm{C}\left\{{ }^{1} \mathrm{H}\right\}$-NMR Spectrum of ethyl 5-methyl-1-(6-(2-(tetrahydro-2H-pyran-4-yl)ethyl)pyridin-2yl)-1H-pyrazole-4-carboxylate (11g).
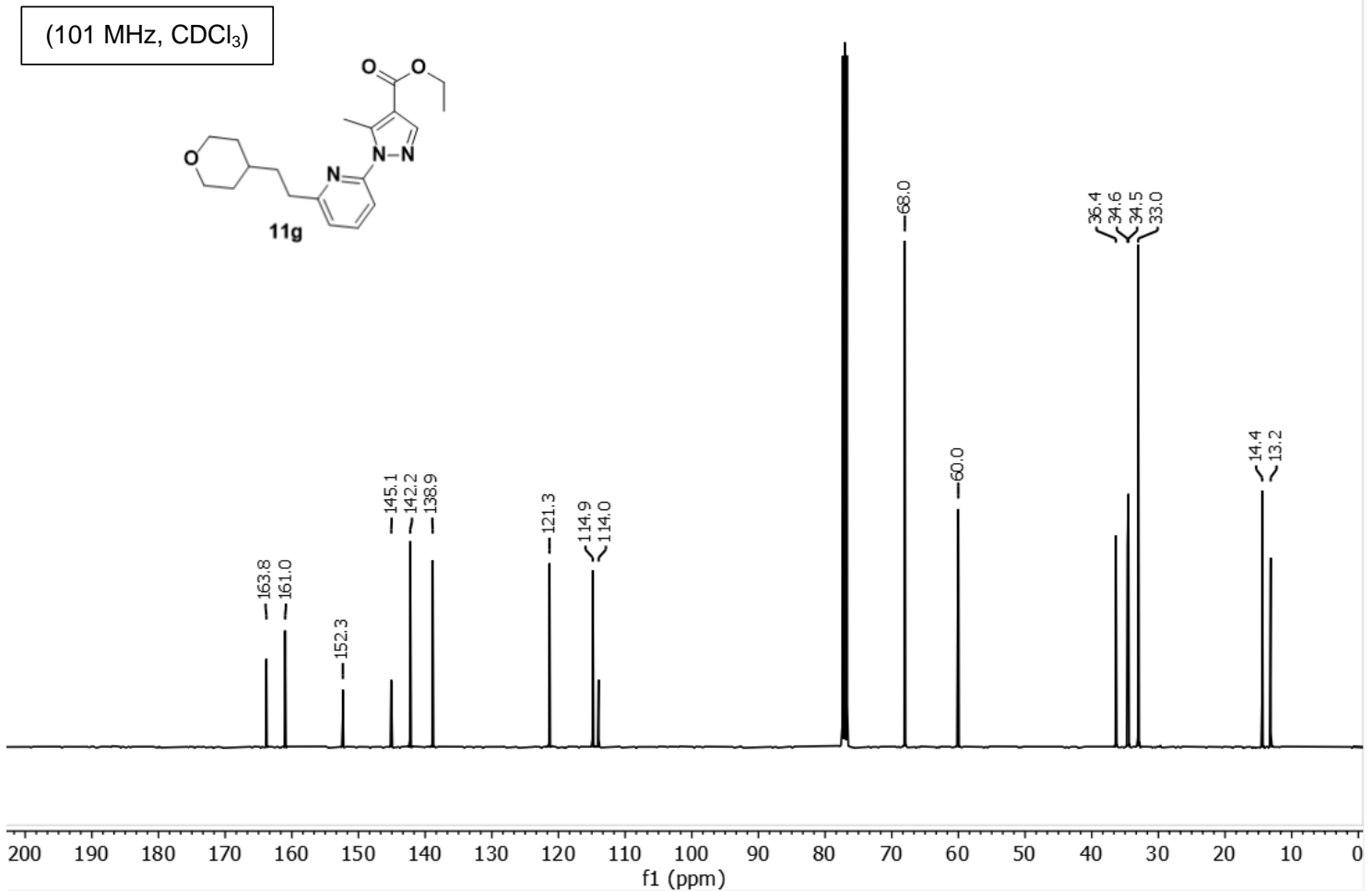
${ }^{1}$ H-NMR Spectrum of tert-butyl 4-(6-(4-(ethoxycarbonyl)-5-methyl-1H-pyrazol-1-yl)pyridin-2yl)piperidine-1-carboxylate (11h).

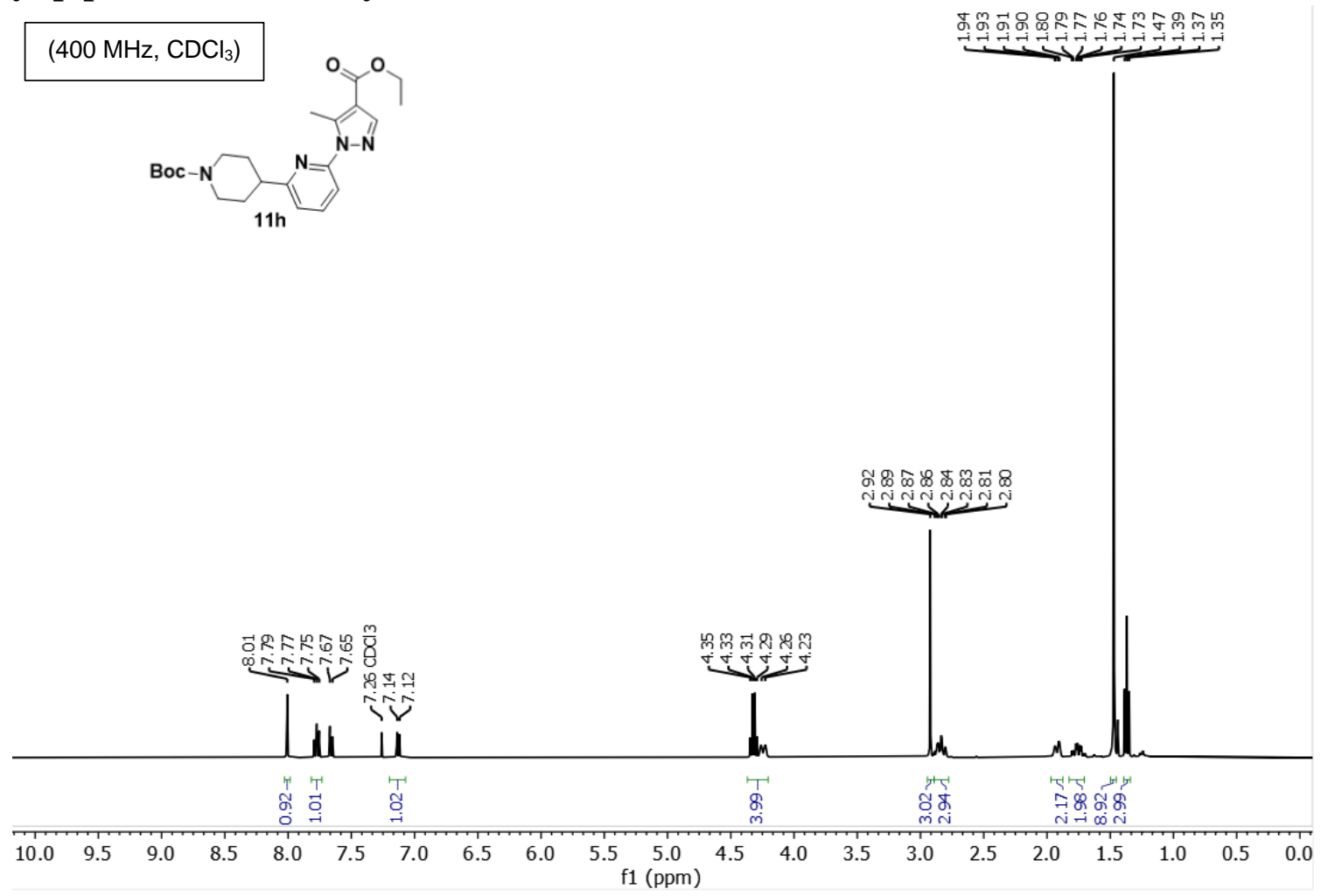

${ }^{13} \mathrm{C}\left\{{ }^{1} \mathrm{H}\right\}$-NMR Spectrum of tert-butyl 4-(6-(4-(ethoxycarbonyl)-5-methyl-1H-pyrazol-1yl)pyridin-2-yl)piperidine-1-carboxylate (11h).
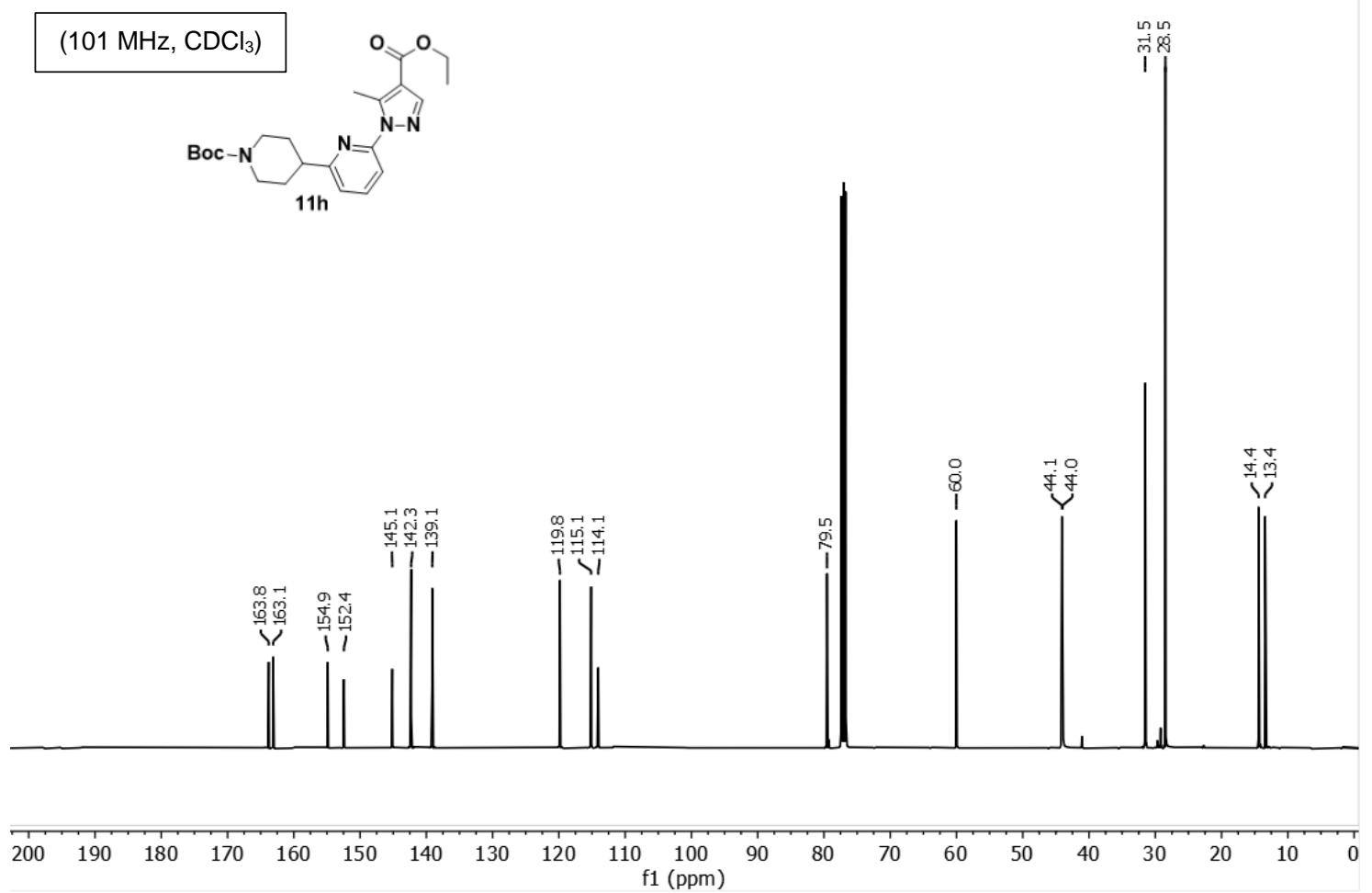
${ }^{1}$ H-NMR Spectrum of tert-butyl 4-((6-(4-(ethoxycarbonyl)-5-methyl-1H-pyrazol-1-yl)pyridin2-yl)methyl)piperidine-1-carboxylate (11i).

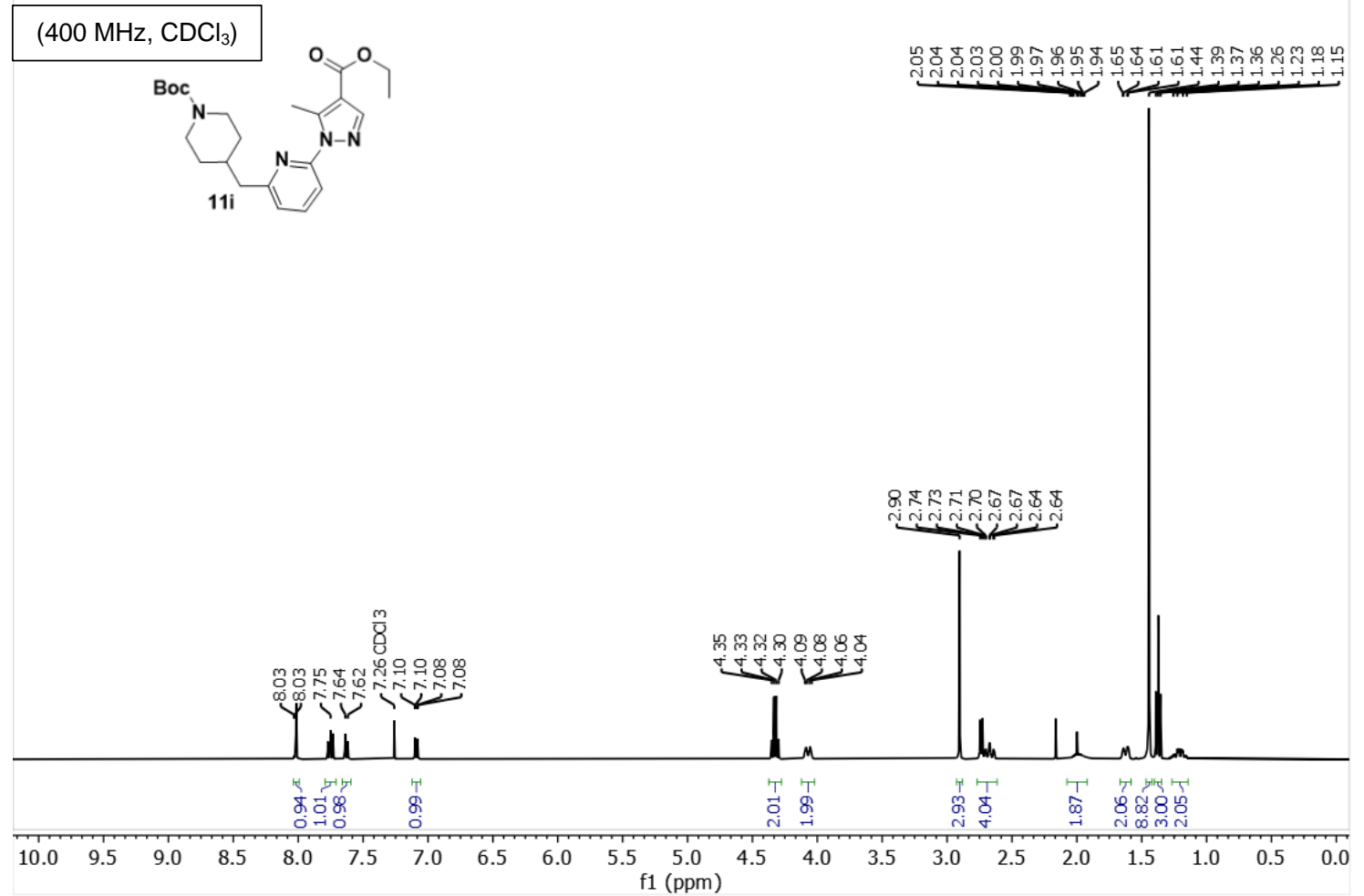

${ }^{13} \mathrm{C}\left\{{ }^{1} \mathrm{H}\right\}-N M R$ Spectrum of tert-butyl 4-((6-(4-(ethoxycarbonyl)-5-methyl-1H-pyrazol-1yl)pyridin-2-yl)methyl)piperidine-1-carboxylate (11i).

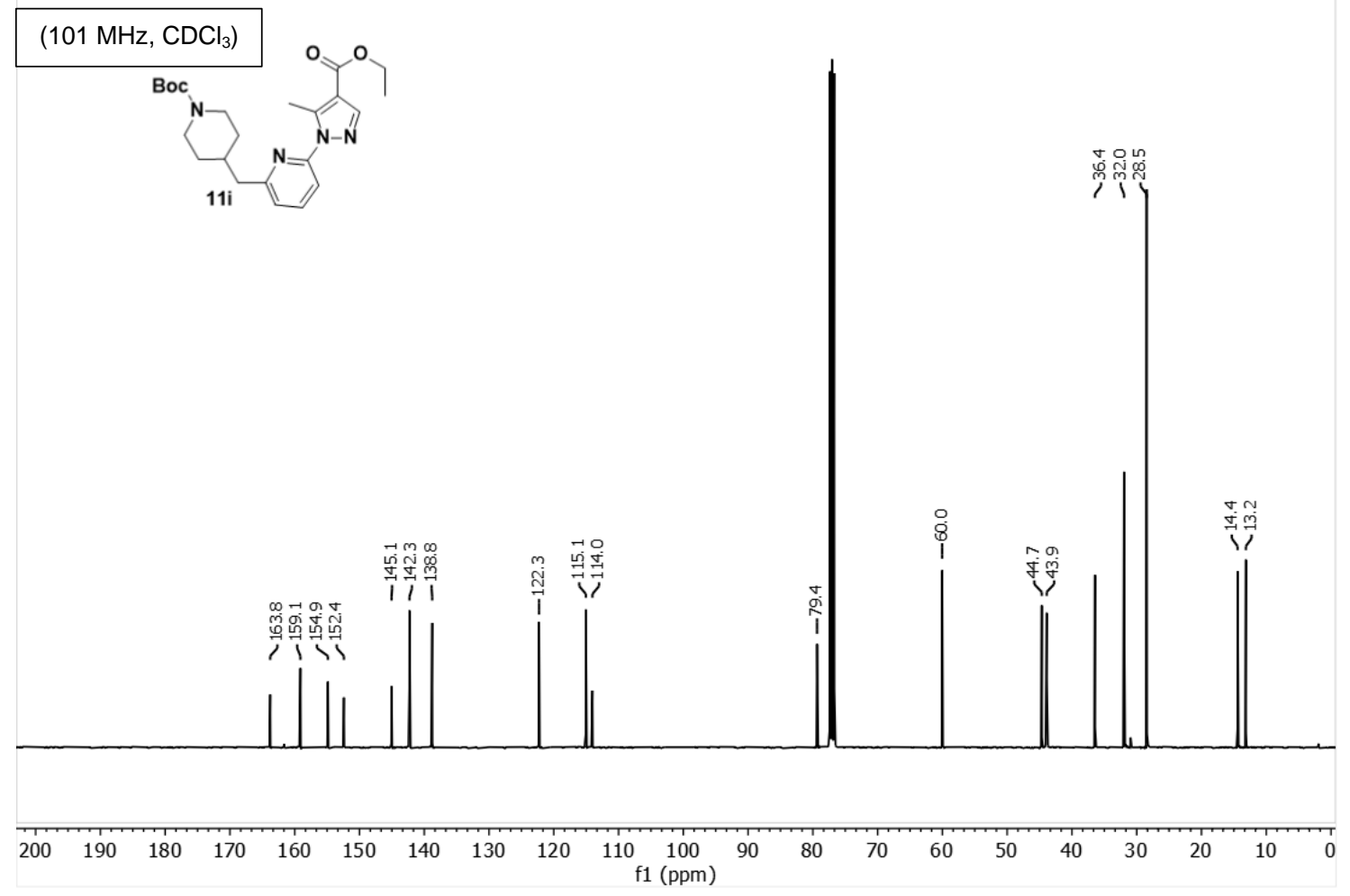


${ }^{1}$ H-NMR Spectrum of ethyl 1-(6-(3,3-difluorocyclobutyl)pyridin-2-yl)-5-methyl-1H-pyrazole-4carboxylate (11j).

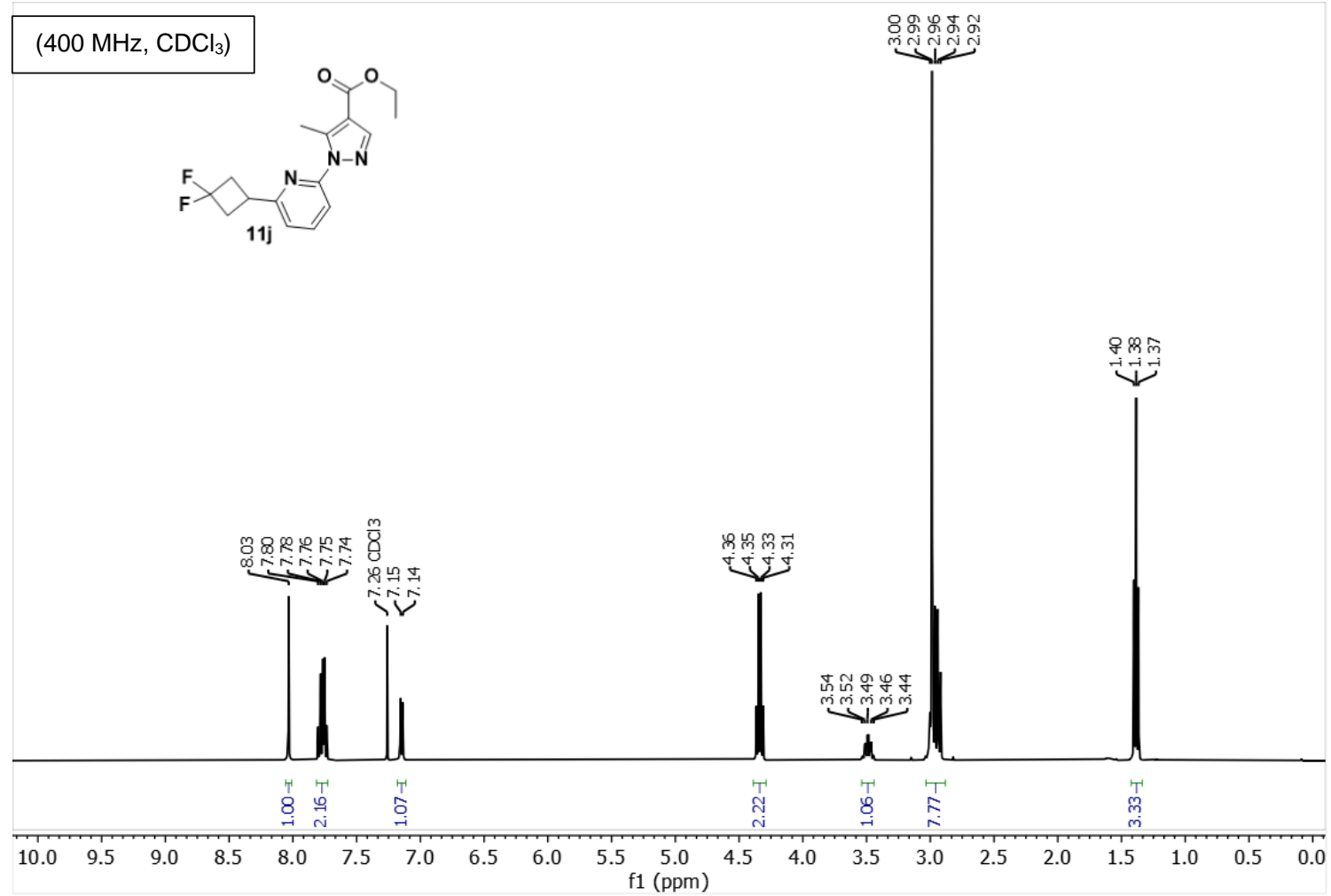

${ }^{13} \mathrm{C}\left\{{ }^{1} \mathrm{H}\right\}$-NMR Spectrum of ethyl 1-(6-(3,3-difluorocyclobutyl)pyridin-2-yl)-5-methyl-1Hpyrazole-4-carboxylate (11j).

(101 MHz, $\mathrm{CDCl}_{3}$ )
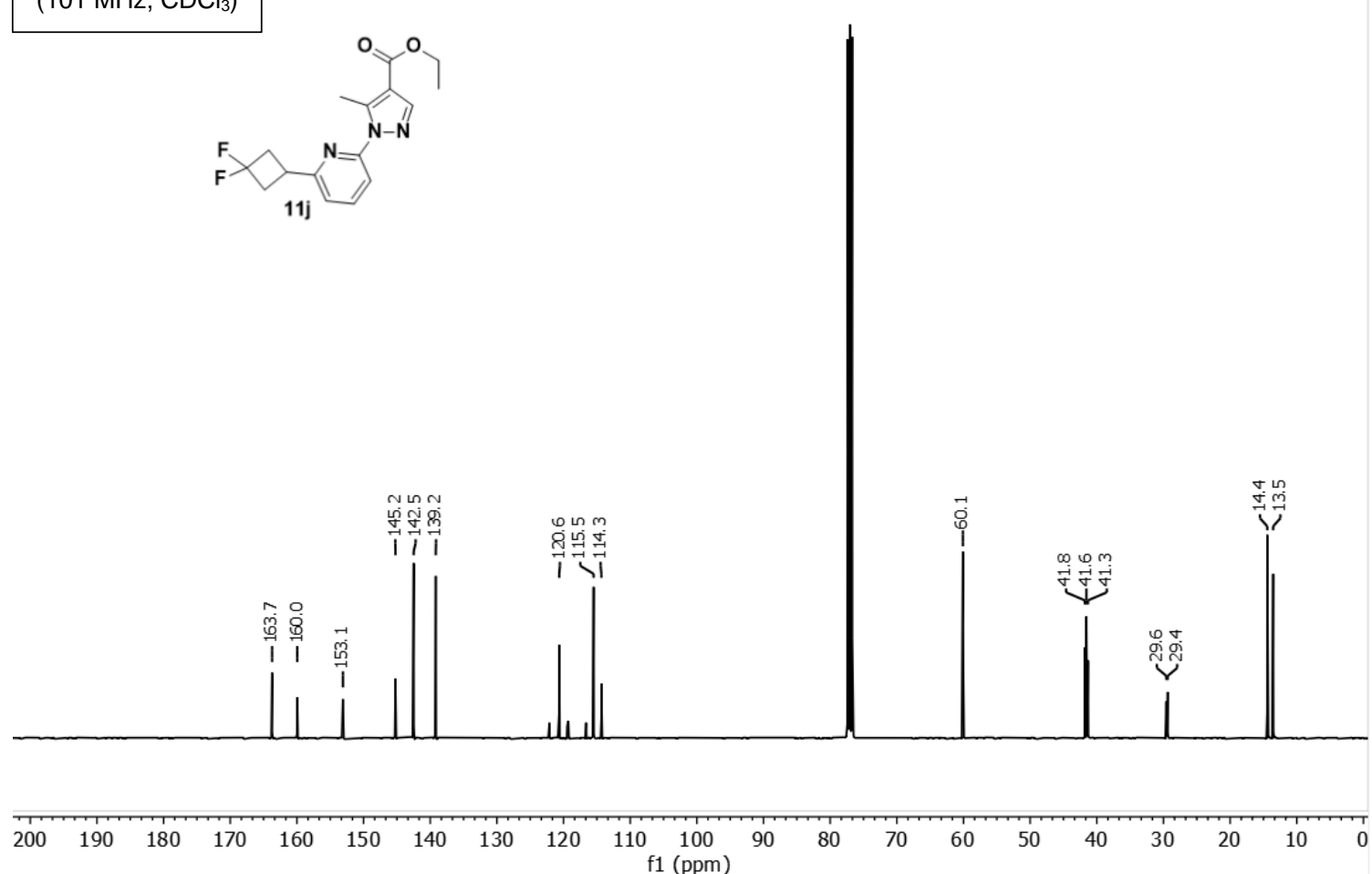
${ }^{19}$ F-NMR Spectrum of ethyl 1-(6-(3,3-difluorocyclobutyl)pyridin-2-yl)-5-methyl-1H-pyrazole4-carboxylate (11j)

$$
\left(376 \mathrm{MHz}, \mathrm{CDCl}_{3}\right)
$$
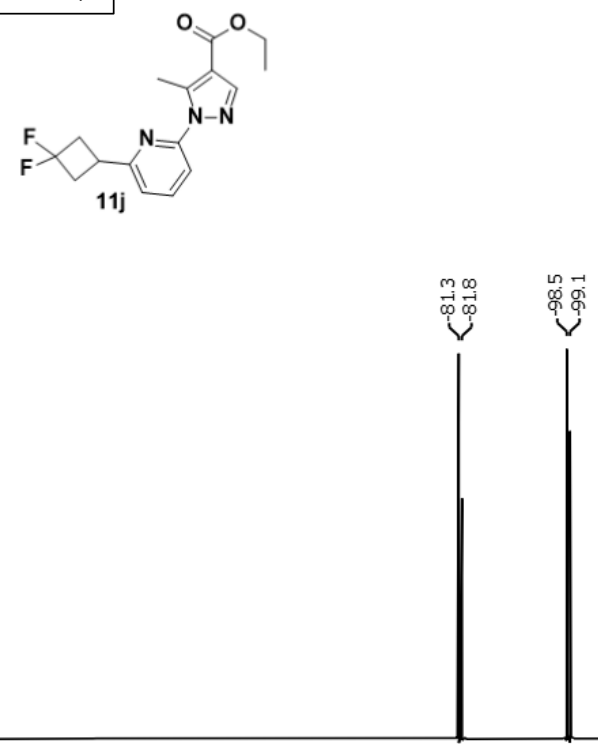

$\begin{array}{cccccccccccccccccccccccc}10 & 0 & -10 & -20 & -30 & -40 & -50 & -60 & -70 & -80 & -90 & -100 & -110 & -120 & -130 & -140 & -150 & -160 & -170 & -180 & -190 & -200 & -210 & 0\end{array}$


${ }^{1}$ H-NMR Spectrum of 4-(4-cyclohexylphenyl)-1-methylpiperidine (14).

$\left(400 \mathrm{MHz}, \mathrm{MeOD}-d_{4}\right)$
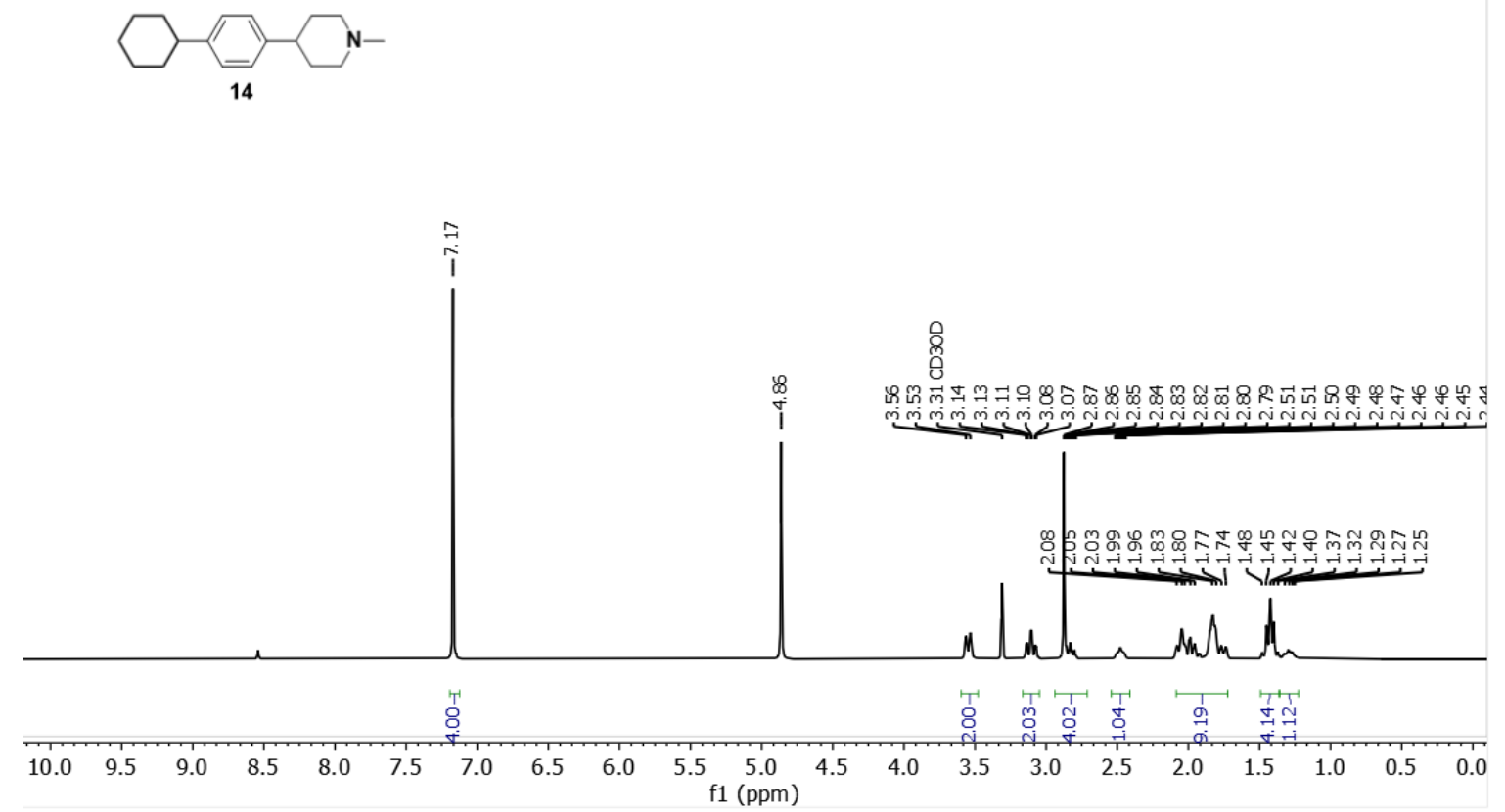

${ }^{13} \mathrm{C}\left\{{ }^{1} \mathrm{H}\right\}$ NMR Spectrum of 4-(4-cyclohexylphenyl)-1-methylpiperidine (14).

$\left(101 \mathrm{MHz}, \mathrm{MeOD}-d_{4}\right)$
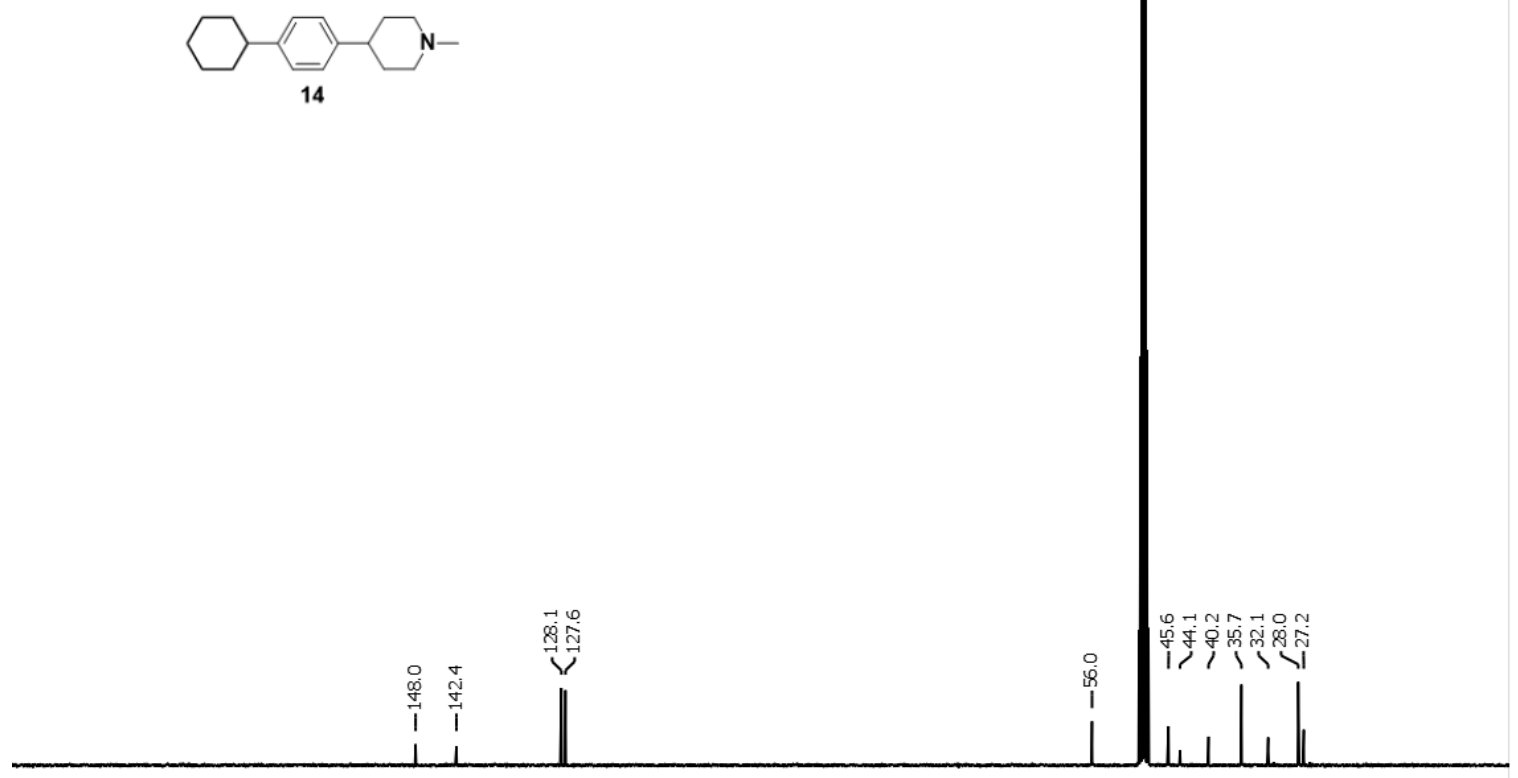

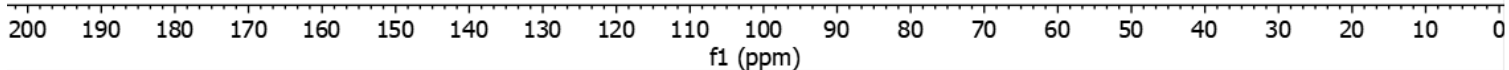


${ }^{1}$ H-NMR Spectrum of benzyl 2-(4-acetylphenyl)pyrrolidine-1-carboxylate (17).

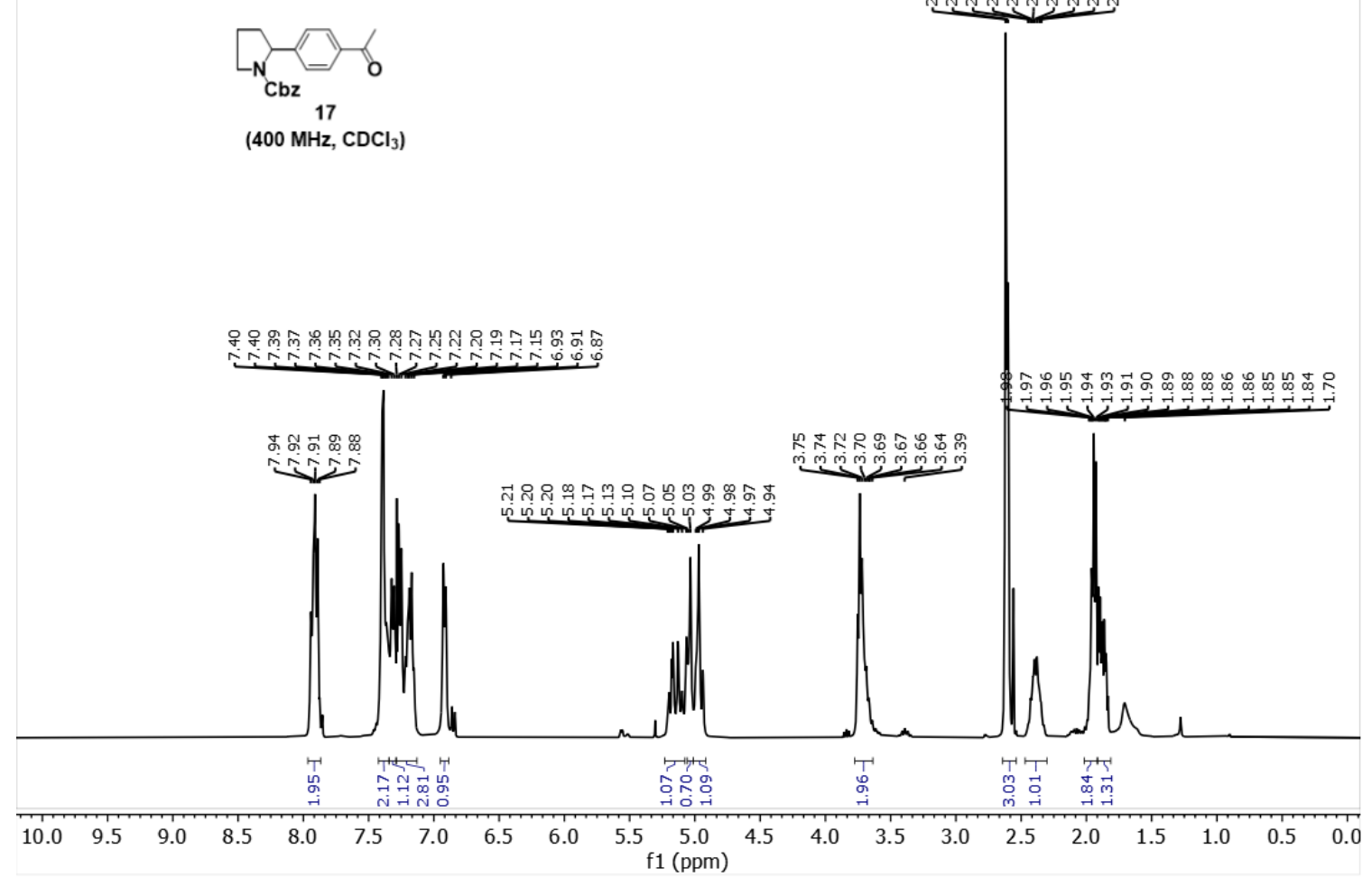

$\left(400 \mathrm{MHz}, \mathrm{CDCl}_{3}\right)$

\section{SI References}

1. Rohani, S.; Horne, S; Murthy, K. Control of Product Quality in Batch Crystallization of Pharmaceuticals and Fine Chemicals. Part 1: Design of the Crystallization Process and the Effect of Solvent. Org.Process Res.Dev. 2021, 25, 10, 2323-2330.

2. Jespersen, D.; Keen, B.; Day, J.I.; Singh, A.; Briles, J.; Mullins, D.; Weaver, J.D. III. Solubility of Iridium and Ruthenium Organometallic Photoredox Catalysts. Org. Process Res. Dev. 2019, 23, 1087-1095.

3. Goodner, K.L, Estimating turbidity (NTU) from absorption data. Synergy Inspiring Taste, Sensus Technical Note (SEN-TN-0010). 2009. 